\title{
ESTIMATIVA DE EFEITOS TÓXICOS CRÔNICOS COM DANIO RERIO (PISCES, CYPRINIDAE)
}

\section{EDUARDO BERTOLETTI}

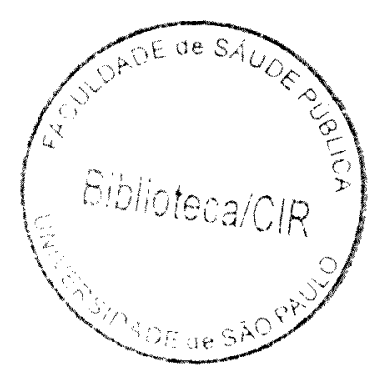

TESE APRESENTADA AO DEPARTAMENTO DE SAÚDE AMBIENTAL, DA FACULDADE DE SAÚDE PÚBLICA DA UNIVERSIDADE DE SÃO PAULO, PARA OBTENÇÃO DO GRAU DE DOUTOR EM SAÚDE PÚBLICA

ÁREA DE CONCENTRAÇÂO: SAÚDE AMBIENTAL

ORIENTADOR:

PROFESSOR DOUTOR ARISTIDES ALMEIDA ROCHA

São Paulo 
Autorizo, exclusivamente para fins acadêmicos e científicos, reprodução total ou parcial desta tese, por processos fotocopiadores.

Assinatura:

Data:

$$
40743 / 2001 \text { (doc) }
$$




\section{AGRADECIMENTOS}

Ao Professor Aristides Almeida Rocha, que sempre acreditou e incentivou o desenvolvimento deste trabalho e, no papel de orientador, conscientemente indicou o caminho a ser trilhado para a transposição deste desafio científico.

A CETESB, que desde 1978, possibilitou a aquisição de conhecimentos que culminaram na elaboração dessa tese.

Aos amigos da CETESB, Elenita G. Goldstein, Pedro A. Zagatto, Rosalina P. A. Araújo, Valéria A. Prósperi, Sandra V. Buratini e Márcia A. Aragão, que desapercebidamente, durante várias discussões técnicas, forneceram muitos subsidios para a elaboração deste trabalho.

Em especial, aos amigos Daniel F. Domingues e Lucila R. Ferrari, também da CETESB, que contribuíram sobremaneira nesta caminhada, tanto pela paciência, como pelas opiniões oportunas e execução de vários testes de toxicidade.

A minha esposa Stela, que sempre incentivou e apoiou, direta ou indiretamente, a realização deste trabalho. No contexto familiar, também agradeço minhas filhas, Juliana e Luana, por respeitarem minha ausência em momentos de necessária reflexão. 


\section{RESUMO}

Bertoletti, E. Estimativa de efeitos tóxicos crônicos com Danio rerio (Pisces:

Cyprinidae). São Paulo; 2000. [Tese de Doutorado - Faculdade de Saúde Pública da USP].

Os testes ecotoxicológicos são, hoje em dia, imprescindíveis para avaliar ou prever o impacto potencial de agentes químicos nos ecossistemas aquáticos. Assim, o presente trabalho teve como objetivo adaptar e estabelecer um novo método, com o peixe Danio rerio ("zebrafish" ou paulistinha), para estimar os efeitos tóxicos crônicos de substâncias diversas.

Para tanto, foram efetuados testes de toxicidade, com duração de 96 e 168 horas, utilizando-se as fases embriolarval, larval e juvenil de Danio rerio. Os organismos foram expostos a onze agentes químicos (cádmio, cobre, cromo, níquel, mercúrio, prata, zinco, fenol, cloreto de sódio, amônia não ionizada e dodecil sulfato de sódio), com a finalidade de avaliar os efeitos tóxicos na sobrevivência do peixe estudado.

A análise dos resultados mostrou que a fase larval de Danio rerio foi a mais sensível em relação às demais estudadas, enquanto o período mais apropriado de duração dos testes foi de 168 horas. Dentre os métodos estatísticos utilizados, o ICp (Inhibition Concentration) mostrou-se o mais adequado para calcular os resultados dos testes baseados na sobrevivência de Danio rerio. Quanto à variabilidade analítica, foi demonstrada a conveniência do uso da concentração letal [CL(I)] 25 ou $15 \%$.

Com o uso do Valor Crônico Estimado (VCest;168h), isto é, CL(I)15;168h multiplicada pelo fator 0,3 , foi possivel estimar os efeitos tóxicos subletais de substâncias para o Danio rerio. Os VCest; $168 \mathrm{~h}$ mostraram-se bastante correlacionados $\left(\mathrm{r}^{2}=0,93\right)$ com os resultados de testes com uma espécie de referência, o peixe Pimephales promelas. Concluindo, o método estabelecido para os testes de curta duração, com larvas de Danio rerio, fornece estimativas confiáveis de efeitos tóxicos a longo prazo para peixes.

Descritores: Toxicidade crônica. Peixes. Danio rerio. Ecotoxicologia. 


\section{SUMMARY}

Bertoletti, E. Estimativa de efeitos tóxicos crônicos com Danio rerio (Pisces: Cyprinidae) [Estimate of chronic toxic effects with Danio rerio (Pisces: Cyprinidae)] São Paulo (BR); 2000. [Tese de Doutorado - Faculdade de Saúde Pública da Universidade de São Paulo].

Currently, ecotoxicological tests are indispensable to evaluate or predict the potential impacts of chemicals in aquatic ecosystems. Thus, the aim of the present work was to adapt and establish a new short-term method to estimate chronic toxic effects of chemicals to the fish Danio rerio (zebrafish)

Toxicity tests were performed with early life stages of Danio rerio (embriolarval, larval and juveniles) using 96 and 168 hours exposures. Eleven chemicals (cadmium, copper, chromium, nickel, mercury, silver, zinc, phenol, sodium chloride, unionized ammonia and dodecil sodium sulphate) were used in order to evaluate their toxic effects on the fish survival.

Danio rerio larval stage was the most sensitive among those analysed, and a 168 hours exposure period was the most appropriated one. Among the statistical methods, the ICp (Inhibition concentration) was the most adequate to calculate the test results based on survival. In terms of analytical variability, it was demonstrated that lethal concentration (LC) 25 or $15 \%$ can be conveniently used.

Using the Estimated Chronic Value (168h-CVest), expressed as 168h-LC15 multiplied by a 0.3 factor, it was possible to estimate sublethal toxic effects of chemicals to Danio rerio. The $168 \mathrm{~h}-\mathrm{CV}$ est showed a high correlation $\left(\mathrm{r}^{2}=0.93\right)$ with a reference fish species Pimephales promelas tests results. In conclusion, the shortterm method proposed with Danio rerio larvae provides reliable estimates of long term toxic effects to fishes.

Descriptors: Chronic toxicity, fishes, Danio rerio, Ecotoxicology, 


\section{ÍNDICE}

1. INTRODUÇÃO 1

2. OBJETIVOS 13

2.1. Objetivo geral 13

2.2. Objetivos especificos 13

3. MATERIAIS E MÉTODOS 14

3.1. Organismos e condições de cultivo 14

3.2. Características da água utilizada $\quad 15$

3.3. Substâncias utilizadas $\quad 15$

3.4. Procedimento analítico 16

3.5. Expressão dos resultados $\quad 17$

$\begin{array}{lr}\text { 3.6. Análises estatisticas } & 18\end{array}$

4. RESULTADOS 22

4.1. Sensibilidade das diferentes fases vitais do Danio rerio 22

4.1.1. Comparações da sensibilidade através da CL(I)50 22

4.1.2. Comparações da sensibilidade nos testes crônicos de curta duração 24

4.2. Precisão analítica dos testes crônicos 29

4.3. Comparação dos resultados obtidos por diferentes métodos estatísticos 33

4.4. Correlação ecotoxicológica entre Danio rerio e Pimephales promelas 35

5. DISCUSSÃo 39

5.1. Ação tóxica dos agentes químicos estudados 39

5.2. Sensibilidade das diferentes fases do ciclo vital de Danio rerio $\quad 40$

5.2.1. Comparações da sensibilidade através da CL(I)50 41

5.2.2. Comparações da sensibilidade nos testes crônicos de curta duração 43

5.3. Precisão analítica dos testes crônicos $\quad 49$

5.4. Considerações sobre os diferentes métodos estatísticos 56

5.4.1. Uso e estimativas do teste de hipóteses 56 
5.4.2. Estimativas de efeito pelo método LRA

5.4.3. Estimativas de efeito pelos métodos ICp e Probitos 60

5.5. Correlações ecotoxicológicas entre D. rerio e P. Promelas 63

5.5.1. Relação de sensibilidade entre as duas espécies de peixe 64

5.5.2. Característica toxicológica em testes com Pimephales promelas 65

5.6. Estimativa da ecotoxicidade crônica para Danio rerio 68

6. CONCLUSÕES

7. REFERÊNCIAS BIBLIOGRÁFICAS

TABELAS 93

ANEXO

Anexo 01 - Fases de desenvolvimento, do ciclo vital de Danio rerio, utilizadas nos testes ecotoxicológicos 


\section{LISTA DE FIGURAS}

Figura

Página

01 Comparação da sensibilidade de fases distintas do ciclo vital de Danio rerio, expressa em média das CL(I)50, para diversas substâncias em diferentes períodos de exposição.

02 Comparação da sensibilidade de diferentes fases do ciclo vital de Danio rerio, expressa em ordem crescente das CL(I)50, em 168 horas de exposição

03 Comparação de resultados dos testes de toxicidade, expressa em média dos V.C., com as fases embriolarval e larval de Danio rerio, em 168 horas de exposição.

04 Comparação da sensibilidade de larvas e jovens de Danio rerio, expressa em média das PCENO em ordem crescente, para diversas substâncias em diferentes periodos de exposição.

05 Comparação de resultados dos testes de toxicidade, expressa em média das PCENO, com diferentes fases do ciclo vital de Danio rerio, em 168 horas de exposição a diversas substâncias.

06 Comparação de resultados dos testes de toxicidade, expressa em média das CL(I)5, com embriões e larvas de Danio rerio, em 168 horas de exposição a diversas substâncias.

07 Coeficientes de variação (CV), em 96 e 168 horas, dos resultados de testes com larvas de Danio rerio estimados pelo método LRA (em PCENO)

08 Coeficientes de variação (CV) de resultados dos testes ecotoxicológicos, em 168 horas, com embriões e larvas de Danio rerio, utilizando os métodos estatísticos LRA e ICp

09 Coeficientes de variação (CV) dos testes ecotoxicológicos com larvas de Danio rerio e várias substâncias, em 168 horas, para diversos níveis de efeito na sobrevivência. Estimativas pelos métodos ICp e Probitos.

10 Coeficientes de variação (CV) dos testes ecotoxicológicos com larvas de Danio rerio e diversas substâncias, em 168 horas de exposição, calculados com base nos resultados de três métodos estatisticos 
11 Comparação dos resultados dos testes ecotoxicológicos crônicos com larvas de Danio rerio, em 168 horas de exposição, calculados pelos métodos: Análise de variância, LRA, ICp e Probitos

12 Comparação dos resultados de testes ecotoxicológicos com larvas de Danio rerio e diversas substâncias, em 168 horas, calculados pelos métodos ICp e Probitos

13 Comparação dos resultados de testes ecotoxicológicos com larvas de Danio rerio e diversas substâncias, em 168 horas, calculados pelo método ICp com tratamentos em quadruplicata e duplicata...

14 Reta e equação da regressão para os resultados de testes de toxicidade aguda, em 96 horas, com jovens/adultos das duas espécies de peixe comparadas

15 Reta e equação da regressão para os resultados de testes de toxicidade aguda, em 96 horas, com larvas das espécies de peixe comparadas.

16 Reta e equação da regressão para os resultados de testes de toxicidade aguda, em 168 horas, com larvas das duas espécies comparadas.

17 Equação, reta e limites de previsão 95\%, da análise de regressão, para os resultados de testes crônicos estimados com $D$. rerio (em VCest) e determinados com $P$. promelas. 


\section{LISTA DE TABELAS}

Tabela

Página

01 Resultados dos testes ecotoxicológicos, com várias substâncias e fases distintas do ciclo de vida de Danio rerio, expressos como a média das CL(I)50 (onde apropriado) em dois períodos de exposição

02 Resultados dos testes ecotoxicológicos crônicos, de curta duração, para a sobrevivência das fases embriolarval e larval de Danio rerio frente a diversas substâncias, em 168 horas de exposição, calculados pelo teste de hipóteses.

03 Resultados dos testes ecotoxicológicos crônicos, de curta duração, com a fase embriolarval de Danio rerio e diversas substâncias, em 168 horas de exposição, calculados pelo método LRA

04 Resultados dos testes ecotoxicológicos crônicos, de curta duração, com a fase larval de Danio rerio e diversas substâncias, em diferentes períodos de exposição, calculados pelo método LRA.....

05 Resultados dos testes ecotoxicológicos com jovens de Danio rerio e diversas substâncias, em diferentes periodos de exposição, calculados pelo método LRA.

06 Resultados dos testes ecotoxicológicos crônicos, de curta duração, com a fase embriolarval de Danio rerio e diversas substâncias, em 168 horas de exposição, calculados pelo método ICp para a sobrevivência dos organismos.

07 Resultados dos testes ecotoxicológicos crônicos, de curta duração, com a fase larval de Danio rerio e diversas substâncias, em 168 horas de exposição, calculados pelo método ICp para diferentes niveis de efeito na sobrevivência

08 Resultados dos testes ecotoxicológicos crônicos, de curta duração, com a fase larval de Danio rerio e diversas substâncias, em 168 horas de exposição, calculados pelo método dos Probitos para diferentes niveis de efeito na sobrevivência 
09 Resultados dos testes ecotoxicológicos crônicos, de curta duração, com a fase larval de Danio rerio e diversas substâncias, em 168 horas de exposição, calculados pelo método ICp, para a sobrevivência dos organismos em experimentos com tratamentos em duplicata.

10 Resultados dos testes de toxicidade aguda, expressos como CL(I)50, com várias substâncias e fases distintas do ciclo vital de Pimephales promelas.

11 Resultados de testes ecotoxicológicos crônicos, de curta e longa duração, com várias substâncias e Pimephales promelas em águas com durezas semelhantes, calculados pela análise de variância.

12 Relação numérica entre diferentes critérios para avaliação de efeito tóxico em testes ecotoxicológicos com peixes.

13 Estimativas de efeitos crônicos, em testes de curta duração, calculadas pelo método ICp e associadas ao fator para previsão de efeitos a longo prazo.

14 Resultados de validação da equação estabelecida para correlacionar dados ecotoxicológicos crônicos entre Danio rerio e Pimephales promelas 


\section{INTRODUÇÃO}

Ao longo do tempo condições desejáveis de qualidade da água têm sido estabelecidas para vários usos. Dentre os usos, aquele destinado ao consumo humano é o que tem merecido maior atenção quanto à qualidade, fato natural em função da preocupação humana em preservar sua espécie.

Esta preocupação tem causado interpretações errôneas, a tal ponto de muitos considerarem que a qualidade da água apropriada para o consumo humano é, também, adequada para outro determinado uso. Mais especificamente, é comum que leigos, e até especialistas, julguem que a qualidade exigida para consumo humano seja a mesma necessária para proteção de comunidades aquáticas.

Essa tendência de julgamento pode ser considerada histórica, uma vez que há 40 séculos o homem tem tomado medidas para obter água apropriada, especialmente para o seu consumo (NAS/NAE, 1973). No entanto, somente a partir das décadas de 50 e 60 é que foram estabelecidos os critérios norte-americanos e soviéticos, ainda que rudimentares, para a proteção da vida aquática.

BERTOLETTI et al.(1989) também afirmam que, no Brasil, em 1976, quando foram estabelecidos os primeiros padrões para assegurar a qualidade das águas interiores, somente foram contemplados aqueles apropriados para o uso humano (potabilidade) e não aqueles necessários para a preservação da vida aquática. Hoje em dia, entretanto, ambos os usos são em grande parte atendidos, especialmente o de proteção de comunidades aquáticas, através de padrões unificados estabelecidos pela Resolução CONAMA n. ${ }^{\circ}$ 20/86 (BRASIL, 1986)

Ao se tratar de padrões de qualidade para agentes químicos diversos, com vistas à proteção de comunidades aquáticas, é fundamental apontar os instrumentos que são utilizados para gerá-los. A análise dos documentos que versam sobre o assunto, em especial os norte-americanos e canadenses, demonstra que algumas poucas 
informações sobre os efeitos de agentes químicos, em populações ou comunidades aquáticas, foram obtidas através de levantamentos biológicos na natureza (por exemplo, indices biológicos).

Este fato é de certa forma esperado pois, embora os organismos na natureza possam servir, com maior fidelidade, à deteç̧ão dos distúrbios que sofrem ao longo do tempo, é dificil estabelecer relações de causa-efeito em ambientes naturais que, invariavelmente, apresentam oscilações tanto qualitativas como quantitativas. Outro fator que dificulta o uso de índices biológicos, no estabelecimento de padrões de qualidade, refere-se à amostragem laboriosa e à especialização técnica necessária. Além disso, os levantamentos biológicos são, por excelência, característicos do local de estudo, sendo duvidosa a extrapolação para corpos d'água em outras localidades.

Desse modo, a maioria dos padrões de qualidade para proteção de comunidades aquáticas foram, e ainda são, estabelecidos com base em estudos de laboratório. Dentre esses estudos, pode-se destacar os experimentos de bioacumulação, de comportamento animal e, principalmente, os testes ecotoxicológicos agudos e crônicos com diversos organismos. Tais estudos têm sido utilizados pois, além de fornecerem conhecimentos básicos e apresentarem um custo reduzido, simulam o que pode ocorrer nos ecossistemas aquáticos com razoável aproximação.

Nesse contexto, os testes ecotoxicológicos ocupam lugar de destaque pois permitem, sob condições controladas, determinar as concentrações dos agentes químicos que causam efeitos inaceitáveis aos organismos aquáticos. Dentre as variáveis passiveis de serem controladas nos testes destacam-se:

- Os fatores abióticos, em combinação ou isolados, tais como o pH, oxigênio dissolvido, temperatura, dureza e salinidade da água, luminosidade, dentre outros.

- O agente químico estudado, isolado ou em misturas com outros. 
- Os critérios para caracterização do efeito adverso nos organismos, como por exemplo a redução da sobrevivência, do crescimento ou da reprodução.

- O período de exposição dos organismos.

- As concentrações de exposição.

- As espécies de organismos, incluindo a idade dos mesmos.

- As condições de cultivo e saúde dos indivíduos testados.

Em função dessas peculiaridades dos testes ecotoxicológicos, aliadas à precisão préestabelecida dos vários métodos analíticos, atribui-se uma ampla utilização dos mesmos no estabelecimento de padrões e/ou critérios de qualidade para a proteção de comunidades aquáticas.

Além dessa finalidade específica, no Brasil, embora com menor intensidade do que em outros paises, os testes ecotoxicológicos com organismos aquáticos já despontam como ferramenta de uso rotineiro para avaliação da qualidade de efluentes. GHERARDI-GOLDSTEIN et al. (1990) e BASSOI et al.(1990) indicaram tais testes para a caracterização e controle de efluentes líquidos, sendo que recentemente foram regulamentados para esse uso (SÃO PAULO, 2000). O IBAMA (BRASIL, 1996) considera-os como parte integrante do processo de registro de agrotóxicos. Outros estudos também evidenciam a importância dos testes ecotoxicológicos no monitoramento da qualidade de áquas superficiais no Estado de São Paulo (ZAGATTO et al., 1987 ; BERTOLETTI et al., 1989; ZAGATTO e GHERARDIGOLDSTEIN, 1991; ZAGATTO et al., 1999).

Apesar da crescente utilização dos testes ecotoxicológicos, no Brasil poucas espécies de organismos aquáticos são empregadas em métodos padronizados. Destacam-se 
entre as espécies os crustáceos dulciaquicolas Daphnia similis, Ceriodaphnia dubia e Hyalella sp, o crustáceo marinho Mysidopsis juniae, e o equinóide Lytechinus variegatus. Dentre os peixes, várias espécies dulciaquícolas de pequeno porte foram utilizadas, como: as indigenas Cheirodon notomelas (piquira), Hemigrammus marginatus (bandeirinha), Hyphessobrycon callistus (mato-grosso), e as exóticas Poecilia reticulata (guarú ou lebistes) e Danio rerio (paulistinha).

Com relação aos grupos taxonômicos citados, os peixes podem ser considerados aqueles que despertam maior sensibilidade aos leigos, fato decorrente da fácil visibilidade destes organismos, bem como do interesse comercial e recreacional das espécies de maior porte. Por outro lado, os peixes podem ser considerados representativos dos organismos que ocupam o topo da cadeia trófica aquática e, também, apropriados para detectar os efeitos tóxicos de determinados agentes químicos. Em decorrência desses aspectos, tais organismos são fundamentais para avaliação dos efeitos adversos de substâncias, em especial para o estabelecimento de concentrações aceitáveis destas para os ecossistemas onde vivem.

Como é possivel observar, as espécies de peixes citadas são forrageiras que, por apresentarem pequeno porte, possibilitam a execução de testes em laboratório. Além disso, segundo relatórios da CETESB $(1979,1980)$ as espécies forrageiras demonstram ser, quase sempre, mais sensíveis aos agentes químicos, o que as tornam mais apropriadas para avaliar os efeitos tóxicos desses agentes.

No entanto, é importante frisar que a disponibilidade de peixes com tais características tem uma forte dependência sazonal, o que muitas vezes impossibilita a execução rotineira dos testes ecotoxicológicos. Outro fato importante é que os espécimes adquiridos ou capturados, quando disponíveis, encontram-se na fase jovem ou adulta, sendo que sua utilização fica restrita aos testes de toxicidade aguda, os quais detectam apenas os efeitos tóxicos mais drásticos e intensos sobre as populações de peixes. 
Neste sentido, e conveniente destacar que, para uma estimativa mais adequada de concentrações de poluentes aceitáveis para a proteção da vida aquática, torna-se indispensável a execução de testes de toxicidade crônica. Através desses testes é possivel avaliar os efeitos tóxicos produzidos por baixos teores de agentes químicos sobre os estágios vitais mais sensíveis (tal como a fase embriolarval de peixes).

A essa altura é necessário enfatizar a carência de estudos fundamentais da biologia de peixes forrageiros, nativos dos ecossistemas aquáticos brasileiros. Como conseqüência, é desconhecida a possibilidade de reprodução contínua desses organismos em laboratório. Esse aspecto tem causado dificuldades na execução de testes destinados à avaliação de efeitos crônicos com peixes, pois existe a limitação de se dispor de organismos na fase embriolarval (ovos e larvas) ao longo do ano, impossibilitando assim a determinação de efeitos tóxicos mais sutis de forma rotineira e/ou a qualquer tempo.

Em função do desconhecimento da reprodução de espécies forrageiras indígenas, não há, no Brasil, metodologia estabelecida para execução de testes de toxicidade crônica com peixes autóctones. Portanto, existe uma nítida carência de métodos analíticos que possam auxiliar na caracterização e avaliação de risco, tanto de substâncias químicas como efluentes liquidos, com vistas ao estabelecimento de concentraçôes ambientalmente aceitáveis.

Alternativamente, para determinação dos efeitos crônicos em peixes, tem sido recomendada a utilização de um método para o qual são indicadas espécies exóticas (SEMA, 1988), tal como Danio rerio e Pimephales promelas, que em condições de laboratório se reproduzem continuamente. No entanto, no Brasil, a espécie Pimephales promelas está sujeita à introdução controlada pelo IBAMA, sendo que os usuários são responsáveis pelo seu confinamento. Deste modo, o uso da espécie Danio rerio é mais conveniente, pois seu cultivo e comércio ocorrem sem restrições em várias localidades do país. 
Apesar do teste crônico recomendado possuir duração de 28 dias (SEMA,1988), alguns estudos sugerem a redução do tempo para sete ou 14 dias (WARD e PARRISH, 1980; NORBERG e MOUNT, 1985; BIRGE et al., 1985; NORBERGKING, 1989), sendo que os autores postulam que os testes disponíveis, ainda, podem propiciar boas estimativas dos efeitos crônicos para a totalidade do ciclo vital. Assim, mantida a utilização de fases embriolarvais por curtos periodos, os testes sugeridos foram denominados subcrônicos ou crônicos de curta duração. Tendo em vista a representatividade dos testes de curta duração, além da significativa redução dos custos envolvidos em sua aplicação, torna-se conveniente discorrer sobre tais metodologias que podem ser usadas para as diferentes finalidades no Brasil.

Dentre as duas espécies de peixes citadas, Pimephales promelas é aquela que possui a maior base de dados ecotoxicológicos, tanto para efeitos agudos como crônicos (NORBERG e MOUNT, 1985), sendo tal peixe, há muito tempo, utilizado por pesquisadores norte-americanos. Além disso, essa espécie é considerada razoavelmente representativa, quando comparada a outras espécies de peixes (SUTER et al., 1987).

Quanto ao Danio rerio, apesar de ser utilizado há muito tempo, quase que exclusivamente por pesquisadores europeus, poucos dados ecotoxicológicos foram gerados com essa espécie e substâncias convencionais em comparação com Pimephales promelas. Recentemente, despontaram alguns estudos que preencheram tal lacuna, em especial com relação à toxicidade de metais e orgânicos a Danio rerio (DAVE e XIU, 1991; MEINELT e STAAKS, 1994).

Por tais motivos existe uma escassez de dados que permitam a comparação de sensibilidade entre as duas espécies. Em termos de toxicidade aguda, os estudos mais abrangentes da literatura que comparam a sensibilidade de várias espécies de peixes (PICKERING e HENDERSON, 1966; KENAGA, 1978; SLOOFF et al.,1983; DOHERTY, 1983; LEBLANC, 1984; PHIPPS e HOLCOMBE, 1985), incluindo Pimephales promelas, não apresentam dados relativos a Danio rerio. Da mesma 
forma VITTOZ:zl e DE ANGELIS (1991), após uma revisão da toxicidade de 200 substâncias, encontraram dados comuns somente para seis substâncias orgânicas com as duas espécies de peixe.

Quanto aos testes crônicos de curta duração, a mesma carência de dados comparativos pode ser notada. Em estudo com cobre, fenol e pentaclorofenol, MEINELT e STAAKS (1994) compararam a sensibilidade de ambas as espécies, porém algumas condições experimentais (tempos de exposição e dureza das águas) não foram equivalentes. Comparações apropriadas são registradas, quanto aos efeitos agudos ou crônicos, para as duas espécies de peixes, apenas no estudo de NAGEL et al. (1991) com 3,4-dicloroanilina e naquele efetuado por ELONEN et al. (1998) com 2,3,7,8-tetraclorodibenzo-p-dioxina.

Embora os peixes citados sejam utilizados, em vários países, para a estimativa da toxicidade crônica de substâncias, os métodos analíticos que os utilizam são um tanto diferentes. Enquanto o teste crônico de curta duração com Danio rerio, proposto por DAVE et al. (1987), não possui duração pré-definida, podendo se estender por 12 a 15 dias, no teste com Pimephales promelas (NORBERG e MOUNT, 1985) há uma duração pré-determinada, de sete dias. A princípio, esta diferença na duração dos testes pode representar diferentes respostas das espécies em questão, uma vez que a toxicidade de um agente químico é, também, função do tempo de exposição (RAND e PETROCELLI, 1985). Portanto, a comparação e a extrapolação dos resultados analíticos, entre métodos diferenciados, são questionáveis.

Outra dificuldade de comparação de dados refere-se aos diferentes estádios do ciclo vital utilizados nos testes crônicos de curta duração. Enquanto Pimephales promelas é submetido aos testes exclusivamente na fase larval, Danio rerio é exposto desde a fase embrionária até a larval. DAVE et al. (1987) verificaram que, em água limpa (controle experimental), a maior parte da mortalidade dos embriões ocorre nas primeiras 24 horas de vida e, talvez mais importante, que uma excessiva mortalidade 
nessa fase pode resultar em maior resistência dos organismos ao longo do teste. Em função dessas observaç̃̃es os autores sugerem que, acima de $33 \%$ de mortalidade dos embriões, deve-se tomar cuidados na interpretação do teste ou, ainda, encerrá-lo de imediato caso ocorra a morte de mais que $50 \%$ dos organismos.

Segundo MCKIM (1985), em testes crônicos com peixes, os efeitos tóxicos são rapidamente observados na eclosão dos ovos e/ou durante a fase larval. De acordo com esse autor, isso ocorre por dificuldades na observação dos organismos na fase embrionária ou, ainda, porque a membrana do ovo fornece alguma proteção para os embriões em desenvolvimento. LELAND e KUWABARA (1985) e NORBERGKING (1989) citam que a maior resistência dos embriões aos metais deve-se ao decréscimo da permeabilidade dos ovos após o estágio de blástula. Por tais motivos, em termos metodológicos, a equiparação dos resultados analíticos, entre Pimephales promelas e Danio rerio, pode indicar uma maior resistência deste último em função, apenas, de um aspecto experimental tal como a escolha da fase vital para início do teste.

A alimentação ou não dos organismos é outro fator que pode mascarar os dados analíticos. Nos testes com Pimephales promelas as larvas são alimentadas com náuplios de Artemia sp durante os sete dias de teste. Já no teste com Danio rerio, os organismos na fase larval não são alimentados, sendo que o teste se encerra quando $90 \%$ das larvas morrem por inanição (no período de 12 a 15 dias). A esse respeito, NAGEL et al. (1991) consideram que a ausência de alimentação de Danio rerio representa uma variável significativa no método analítico. Neste sentido, DAVE (1985), em estudo sobre a toxicidade do cádmio a essa espécie de peixe, afirma que a maior sensibilidade dos organismos pode ter sido devida à ausência de alimentação das larvas.

Considerando que as diferenças metodológicas possam ser eliminadas ou, pelo menos, minoradas, ainda assim é esperado que exista uma variação natural nos resultados dos testes ecotoxicológicos. Segundo SPRAGUE (1985), freqüentemente, 
grande parte dessa variação é inexplicável, uma vez que pode ser resultante de alterações não identificadas nos organismos (como a sensibilidade individual) ou nas condições do teste. Portanto, é necessário avaliar a variabilidade inerente de um teste ecotoxicológico, especificamente dos fatores biológicos tais como a saúde, a genética e condições gerais dos organismos utilizados (MORRISON et al. 1989).

Nesse contexto, qualquer metodologia analítica que envolva organismos vivos deve possuir avaliações de sua precisão, o que significa a medida da proximidade de concordância entre os resultados dos testes efetuados (RUE et al. 1988). Usualmente, nos estudos de precisão analítica dos testes ecotoxicológicos são utilizadas substâncias químicas de grau analítico, também chamadas de referência, as quais permitem determinar o coeficiente de variação dos resultados de uma série de experimentos

Estudos com essa característica, em testes crônicos de curta duração com Pimephales promelas, foram efetuados por BIRGE et al. (1985), NORBERG-KING (1989), PICKERING (1988) e USEPA (1991). Nesses estudos várias substâncias foram testadas, tais como: cloreto de cádmio, cromato de potássio, sulfato de zinco, selenato de sódio, nitrato de prata, carbaryl, diazinon, DSS, pentaclorofenato de sódio e diquat. Em termos gerais, foram obtidos coeficientes de variação que oscilaram entre 3 e $62 \%$, sendo possivel observar que a amplitude desses coeficientes depende do agente químico empregado.

Com relação a Danio rerio, poucos dados de precisão analítica foram gerados para os testes crônicos de curta duração. Neste sentido, DAVE et al. (1987) determinaram a variabilidade de testes com sulfato de zinco e dicromato de potássio, sendo obtidos coeficientes de variação de $<10$ e $<25 \%$, respectivamente. BERTOLETTI e FERRARI (1994), em estudo com a mesma espécie, encontraram coeficientes de variação que oscilaram entre 13 e $35 \%$ para dicromato de potássio, cloreto de sódio e DSS. 
Tendo em vista os estudos citados, é possivel verificar a necessidade de um maior número de dados sobre a precisão analítica dos testes crônicos com Danio rerio. Desse modo, à medida que se dispõe de estudos de variabilidade, com um maior número de substâncias, a metodologia analítica com essa espécie de peixe pode ser melhor avaliada quanto à sua fidedignidade.

Outro aspecto muito discutido na aplicação de testes de toxicidade de curta duração é a expressão dos seus resultados analíticos. Nesse contexto duas variáveis estão envolvidas, sendo que uma delas refere-se às técnicas estatísticas utilizadas, enquanto a outra diz respeito aos critérios biológicos (níveis de um efeito prédeterminado) empregados para o estabelecimento dos teores toleráveis das substâncias para organismos aquáticos.

Tradicionalmente, desde a década de 60, o cálculo estatístico dos testes de toxicidade crônica com peixes é efetuado através do teste de hipóteses, tal como a análise de variância seguida de múltiplas comparações, sendo que este procedimento permite detectar diferenças estatisticamente significativas entre as concentrações testadas e o controle experimental. Embora os testes de hipóteses estejam sendo utilizados há muito tempo, criticas veementes têm sido atribuídas à estes procedimentos de cálculo.

STEPHAN e ROGERS (1985) foram os primeiros a questionar o uso dos testes de hipóteses. Dentre os inconvenientes desses testes, os autores citam a dependência dos resultados em função de: a) concentração das soluções-teste escolhidas, b) modo de execução dos experimentos e do número de réplicas por tratamento, c) seleção de um $\alpha$ [nivel aceitável de erro Tipo I] arbitrário, d) escolha do método estatístico. Esses autores ressaltam que, devido à variabilidade das diferenças significativas nos testes, efeitos adversos representativos (como para 50\% da população) podem ser considerados normais. Em suma, os autores sugerem que a ausência de efeitos estatisticamente significativos não eqüivalem à ausência de efeitos biológicos limiares. 
Alternativamente, STEPHAN e ROGERS (1985) sugeriram o uso de análises de regressão para o cálculo de resultados dos testes crônicos. No entanto, os autores destacaram a necessidade de estabelecer um nível pré-determinado de efeito biológico significativo. Neste sentido, SUTER et al. (1987), analisando resultados de testes crônicos com peixes, determinaram que, com o uso de técnica de regressão, $25 \%$ de redução nos eventos biológicos usuais é um razoável previsor de efeitos crônicos. Do mesmo modo, HOEKSTRA e VAN EWIJK (1993), usando projeções estatísticas, estabeleceram que $25 \%$ de efeito adverso poderia ser utilizado para os cálculos com regressão linear.

Outros autores também sugerem o uso de regressões, tal como BIRGE et al. (1985) que, em estudo restrito ao cádmio, constataram ser $1 \%$ de mortalidade um bom estimador da toxicidade crônica para Pimephales promelas. Ainda, MAYER et al. (1994) sugerem que, com o uso de regressão, os dados de testes de toxicidade aguda poderiam prever efeitos crônicos a peixes.

Embora os estudos citados demonstrem conveniências no uso de regressões para a expressão dos resultados de testes crônicos, ainda são inexistentes estudos voltados aos cálculos estatísticos de testes de curta duração com fases embriolarvais de peixes. Por exemplo, SUTER (1990), ao fazer uma análise crítica do estudo de NORBERG-KING (1989) com larvas de Pimephales promelas, salientou que as estimativas corretas de efeito crônico nos testes de curta duração podem ter sido causadas pelas deficiências do teste de hipóteses. Desse modo, SUTER (1990) comentou que se fossem utilizados cálculos que abrangessem os princípios da análise de regressão os resultados seriam menos precisos.

Por outro lado, nos estudos referenciados, foram utilizados testes de toxicidade com substâncias predominantemente orgânicas, sendo que SUTER (1987) e MAYER et al. (1994) demonstraram que a análise de regressão é mais apropriada para estes agentes químicos. Portanto, não existem estudos que demonstrem a adequação desse 
cálculo alternativo para testes com poluentes mais comuns, como por exemplo os metais. Além disso, até o momento, os trabalhos efetuados não foram planejados de maneira a permitir a comparação de diferentes métodos estatísticos com base em testes sucessivos, impossibilitando assim verificar a influência destes cálculos na variabilidade dos resultados.

Considerando todos os aspectos citados anteriormente, é necessário gerar os conhecimentos gerados permitam avaliar a adequação da espécie Danio rerio para detectar efeitos tóxicos crônicos, sendo que para tal é conveniente utilizar, como referencial, uma espécie de reconhecida sensibilidade como Pimephales promelas. Nesse sentido, procurou-se compatibilizar dois métodos analíticos para estimar o efeito crônico de substâncias a peixes, aquele utilizado para Danio rerio e o outro para Pimephales promelas.

Tendo em vista a possibilidade de compatibilizar os métodos distintos, a hipótese de trabalho, no presente estudo, é a de que sob condições experimentais similares, em testes de toxicidade crônica de curta duração, a sensibilidade de fases embriolarvais do peixe Danio rerio é semelhante àquela de Pimephales promelas (fator $<3$ ), para diversos agentes químicos.

Em termos prospectivos, os aspectos abordados nesse trabalho permitem que os pesquisadores e técnicos brasileiros disponham de um método adequado, e também validado, para estudos que visem tanto a proteção bem como a previsão de impactos sobre as comunidades dos recursos hídricos brasileiros. 


\section{OBJETIVOS}

\subsection{Objetivo geral}

- Efetuar adaptações e estabelecer novo método para estimativa dos efeitos tóxicos crônicos de agentes químicos à espécie Danio rerio.

\subsection{Objetivos específicos}

- Efetuar testes de toxicidade de curta duração, com 11 agentes químicos distintos, utilizando fases iniciais do desenvolvimento de Danio rerio.

- Comparar a sensibilidade entre as fases iniciais e juvenil do Danio rerio em testes de curta duração.

- Determinar a precisão analítica dos testes de curta duração com Danio rerio.

- Avaliar os métodos estatísticos mais apropriados para o cálculo dos resultados de testes de curta duração com peixes.

- Comparar os resultados dos testes de toxicidade efetuados com Danio rerio e aqueles obtidos da literatura com Pimephales promelas, visando determinar a sensibilidade relativa das duas espécies.

- Estabelecer uma correlação matemática entre os resultados de testes crônicos de curta duração com Danio rerio e aqueles de prolongada duração com Pimephales promelas. 


\section{MATERIAIS E MÉTODOS}

\subsection{Organismos e condições de cultivo}

A espécie de peixe usada nessa pesquisa foi Brachydanio rerio (HamiltonBuchanan,1822), o qual teve sua denominação alterada para Danio rerio por BARMAN (1991, apud MEYER et al., 1993). Os embriões, larvas e jovens de Danio rerio, utilizados nos testes ecotoxicológicos, foram provenientes do cultivo efetuado no laboratório do Setor de Ecotoxicologia Aquática - CETESB.

Os peixes reprodutores machos e fêmeas, de cada grupo utilizado, foram mantidos em aquários separados à temperatura de $26 \pm 2{ }^{\circ} \mathrm{C}$. Para obtenção dos ovos, os peixes reprodutores foram reunidos em uma câmara de desova contida em aquário de vidro, conforme descrito por BERTOLETTI e DOMINGUES (1991), no final da tarde de dia pré-determinado. Para induzir a postura, a partir das 17:00h a câmara de desova foi coberta com um pano escuro e, após as 19:00h, as luzes do laboratório foram desligadas, sendo novamente acesas às 7:00h do dia seguinte. No dia posterior à união dos reprodutores, após a desova e fertilização, os mesmos foram recolocados nos aquários de origem.

Os ovos que ficaram no fundo do aquário foram recolhidos por aspiração, retidos em peneira, e dispostos em placas de Petri com água de manutençao até o início dos testes. A mortalidade dos ovos nunca foi superior a 33\%. Do mesmo modo, as larvas posteriormente eclodidas foram mantidas em placas de Petri, ou aquários retangulares pequenos, com água de manutenção até o início dos experimentos.

Durante o periodo de execução dos testes ecotoxicológicos, foram fornecidas diferentes rações para a alimentação diária dos peixes reprodutores. Dentre elas, ração para trutas da marca Anhanguera (com $44 \%$ de proteina bruta), ração para carpas N-1 da marca Sul-Brasil ( com $48 \%$ de proteína bruta), e ração Tetramin (com $45 \%$ de proteina bruta). Quando do uso, cada ração foi ministrada na quantidade de $4 \%$ do peso vivo dos peixes, no período matutino. A alimentação foi suplementada 
com náuplios de Artemia sp, no período vespertino, na quantidade aproximada de 3,0 $\mathrm{mL}$ de uma suspensão concentrada de náuplios vivos para cada 15 peixes/dia.

\subsection{Características da água utilizada}

A água utilizada, tanto na manutenção e cultivo dos organismos como nos testes ecotoxicológicos, foi a desclorada da rede de abastecimento. Tomando como base as determinações fisicas e químicas efetuadas nos controles experimentais, a água apresentou as seguintes características:

\begin{tabular}{|c|c|c|}
\hline Variável & Média & Amplitude \\
\hline Temperatura $\left(\mathrm{em}^{\circ} \mathrm{C}\right)$ & 24,5 & 23,0 a 27,5 \\
\hline $\mathrm{pH}(\mathrm{em}$ unidades $)$ & 7,5 & 6,3 a 8,0 \\
\hline Oxigênio dissolvido $(\mathrm{em} \mathrm{mgO} / 2)$ & 6,9 & 6,1 a 7,5 \\
\hline Dureza total $\left(\mathrm{em} \mathrm{mg} \mathrm{CaCO}_{3} / \mathrm{L}\right)$ & 45,3 & 35,0 a 62,0 \\
\hline Condutividade $\left(\mathrm{em} \mu{\mathrm{S} / \mathrm{cm}^{-1}}^{-1}\right)$ & 156,0 & 108,0 a 255,0 \\
\hline
\end{tabular}

\subsection{Substâncias utilizadas}

As substâncias utilizadas nos testes de toxicidade, aguda e crônica de curta duração com o Danio rerio, possuíam grau analítico e são abaixo descritas:

- Cloreto de cádmio $\left(\mathrm{CdCl}_{2} 21 / 2 \mathrm{H}_{2} \mathrm{O}\right)$, da Baker Analyzed.

- Sulfato de cobre $\left(\mathrm{CuSO}_{4} 5 \mathrm{H}_{2} \mathrm{O}\right)$, da Merck

- Dicromato de potássio $\left(\mathrm{K}_{2} \mathrm{Cr}_{2} \mathrm{O}_{7}\right)$, da Merck

- Sulfato de níquel $\left(\mathrm{NiSO}_{4} 6 \mathrm{H}_{2} \mathrm{O}\right)$, da CAAL

- Cloreto de mercúrio $\left(\mathrm{HgCl}_{2}\right)$, da Merck

- Nitrato de prata $\left(\mathrm{AgNO}_{3}\right)$, da Química Moderna.

- Sulfato de zinco $\left(\mathrm{ZnSO}_{4} 7 \mathrm{H}_{2} \mathrm{O}\right)$, da Carlo Erba

- Fenol, da Synth (lote 12899)

- Cloreto de sódio $(\mathrm{NaCl})$, da Merck

- Cloreto de amônio $\left(\mathrm{NH}_{4} \mathrm{Cl}\right)$, da Merck 
- Dodecil sulfato de sódio (DSS) 95\%, da J.T. Baker (lote B37707)

Ao longo do estudo, os sais metálicos foram expressos, com base no peso molecular, em massa nominal do metal estudado. Os teores de amônia não ionizada foram calculados com base na concentração nominal de nitrogênio amoniacal, segundo a fórmula abaixo estabelecida por EMERSON et al. (1975):

onde:

$$
\text { porcentagem de amônia não ionizada }=\frac{1}{\left(10^{\mathrm{pKa}-\mathrm{pH}}+1\right)}
$$

$\mathrm{pKa}=$ constante de ionização em função da temperatura da solução (tabelada)

$\mathrm{pH}=$ potencial hidrogeniônico da solução

\subsection{Procedimento analítico}

Os testes ecotoxicológicos com Danio rerio foram efetuados segundo o método descrito por BIRGE et al. (1985) para os experimentos com a fase embriolarval, e de acordo com o método preconizado por NORBERG e MOUNT (1985) nos ensaios com a fase larval, ambos estabelecidos para a utilização da espécie Pimephales promelas. A sintese do procedimento analítico segue abaixo:

- Princípio: Consistiu na exposição de embriões e larvas do peixe Danio rerio a várias concentrações dos agentes químicos, durante 168 horas. Nos testes com a fase embriolarval, os peixes foram expostos ao agente químico por 48 a 72 horas como embriões, e a partir de então como larvas. $O$ início da exposição dos embriões ocorreu em períodos superiores a 20 horas da fecundação conforme sugerido por BRESCH (1982). Nos testes com a fase larval os organismos foram expostos, exclusivamente, como larvas durante todo o período de ensaio.

- Sistema: estático com renovação (ou semi-estático).

- Renovação das soluções-teste: diariamente (a cada 24 horas), exceto aos sábados e domingos.

- Água de diluição: vide item 3.2 (pág. 15)

- Intensidade luminosa: aproximadamente 500 lux

- Fotoperíodo: 10 horas de luz e 14 horas de escuro 
- Aeração: Nenhuma

- Material dos recipientes-teste: béqueres de poliestireno ou vidro pirex

- Volume das soluções-teste: $100 \mathrm{~mL}$ nos testes com $\mathrm{K}_{2} \mathrm{Cr}_{2} \mathrm{O}_{7}$ e $250 \mathrm{~mL}$ nos demais experimentos.

- Número de concentrações-teste: cinco e um controle (água de diluição)

- Número de réplicas por concentração: Três nos testes com $\mathrm{K}_{2} \mathrm{Cr}_{2} \mathrm{O}_{7}$, DSS e $\mathrm{NaCl}$, e quatro nos testes com os demais agentes químicos.

- Número de organismos por réplica: dez

- Idade dos organismos no início do teste: menos que 36 horas nos testes embriolarvais, e entre 96 e 120 horas nos testes larvais (ver anexo 01).

- Alimentação dos organismos: Nenhuma

- Efeito observado: letalidade ou sobrevivência (dependente do método estatístico utilizado na expressão dos resultados).

- Validade do teste: mínimo de $80 \%$ de sobrevivência dos organismos no controle

Os testes ecotoxicológicos com jovens de Danio rerio, os quais possuíam massa média de 0,11 gramas (amplitude de 0,07 a 0,20 gramas) foram efetuados segundo a método descrito pela ABNT (1993). Resumidamente, o método consistiu da exposição de dez jovens, em cada uma das cinco ou seis concentrações-teste (sem réplicatas) além do controle, por um período de 96 e 168 horas, sendo a letalidade o efeito observado.

\subsection{Expressão dos resultados}

Os resultados dos testes ecotoxicológicos crônicos, de curta duração, foram expressos de acordo com o critério para avaliação do efeito tóxico e, também, em função do método estatístico utilizado. As seguintes expressões foram usadas:

- $\quad$ L(I) 50;96h e 168h (concentração letal mediana) = concentração nominal do agente quimico que causa letalidade a 50\% dos embriões e larvas, em 96 e 168 horas de exposição 
- $\mathrm{CL}(\mathrm{I}) 25,15,5$ e $1 ; 168 \mathrm{~h}$ (concentração letal para o nível especificado) = concentração nominal do agente químico que causa letalidade (ou redução da sobrevivência) a $25,15,5$ e 1\% dos embriões e larvas, em 168 horas de exposição.

- $\mathrm{CEO} ; 168 \mathrm{~h}$ (concentração de efeito observado) = menor concentração nominal do agente químico que causa efeito, estatisticamente significativo, na sobrevivência de embriões e larvas, em 168 horas de exposição.

- $\mathrm{CENO} ; 168 \mathrm{~h}$ (concentração de efeito não observado) = maior concentração nominal do agente químico que não causa efeito, estatisticamente significativo, na sobrevivência de embriões e larvas, em 168 horas de exposição.

- PCENO; 96 e 168h (previsão da concentração de efeito não observado) = concentração nominal do agente químico prevista para não causar efeito letal a embriões e larvas, em 96 e 168 horas de exposição.

- V.C. (valor crônico) = média geométrica entre os valores de CEO e CENO.

- VCest;168h (valor crônico estimado) = concentração nominal do agente químico que não causa efeito expressivo na sobrevivência e crescimento de larvas, em 168 horas de exposição, calculada multiplicando-se o fator 0,3 pela $\mathrm{CL}(\mathrm{I}) 15 ; 168 \mathrm{~h}$.

\subsection{Análises estatísticas}

As CL(1)50;96h e $168 \mathrm{~h}$ foram calculadas pelo método computadorizado Trimmed Spearman-Karber (HAMILTON et al., 1977 e 1978) modificado para a USEPA/EMSL-Cincinnati (WEBER, 1993). As CL(I)15, 5 e 1;168h foram calculadas pelo método computadorizado dos Probitos (versão 1.4) elaborado para a USEPA/EMSL-Cincinnati (WEBER, 1993). 
$\mathrm{O}$ cálculo da $\mathrm{CEO} ; 168 \mathrm{~h}$ e CENO;168h foi efetuado através do programa computadorizado Toxstat 3.3 (GULLEY et al., 1991). Na maioria dos testes ecotoxicológicos, o programa computadorizado calculou a CEO e CENO através da análise de variância (ANOVA) seguida do teste de Dunnett, utilizando os dados de sobrevivência transformados em arco-seno. Para os testes em que os dados não demonstraram homocedasticidade, isto é, quando ao menos uma das concentrações estudadas possuía número de sobreviventes idêntico para todas as réplicas, foi adotado o seguinte procedimento seqüencial para o cálculo da CEO e CENO:

a) Repetição do teste de homocedasticidade, excluindo as concentrações que possuiam o mesmo número de sobreviventes em todas as réplicas.

b) Constatada a homocedasticidade dos dados, executou-se a análise de variância.

c) Cálculo manual do teste de Dunnett, conforme a fórmula que se segue:

$$
\mathrm{DMS}=\mathrm{d} \sqrt{\frac{2 \mathrm{QMR}}{\mathrm{R}}} \quad \text { onde : }
$$

$\mathrm{DMS}=$ diferença mínima significativa

QMR = quadrado médio do resíduo

$\mathrm{R}$ = número de réplicas por concentração

$\mathrm{d}=$ valor tabelado $\mathrm{d}(\alpha=0,05)$, na tabela de valores " $\mathrm{t}$ " de Dunnett, onde $\mathrm{v}=\mathrm{n}$. de graus de liberdade do residuo, e $\mathrm{K}=\mathrm{n}^{\circ}{ }^{\circ}$ de concentrações utilizadas nos cálculos (exceto o controle).

d) Cálculo da diferença entre a média de organismos sobreviventes no controle e as demais concentrações utilizadas na estatística.

e) Comparação das diferenças calculadas com a DMS, onde:

- média do controle - média da concentração $X>D M S=$ existência de diferença significativa da concentração $X$ em relação ao controle.

- média do controle - média da concentração X $<$ DMS = inexistência de diferença significativa da concentração $\mathrm{X}$ em relação ao controle.

Para o cálculo da PCENO; 96 e 168h, foi utilizado o programa computadorizado Acute to Chronic Estimation (ACE, versãol) elaborado por MAYER et al. (1996). 
Nesse programa, um dos métodos consiste de análise de regressão linear (denominado LRA) em dois momentos.

O primeiro momento consiste na estimativa da $\mathrm{CL}(\mathrm{I}) z e r o$ (igual a $0,01 \%$ de efeito) para cada periodo de observação, isto é, 24;48;72;96 e 168h, sendo que os dados de letalidade são transformados em Probitos e os das concentrações testadas em logaritmos. Deste modo, a seguinte equação foi utilizada:

\section{$1,281=a+b \bullet$ concentração em log}

onde:

$1,281=$ valor do probito para $0,01 \%$ de letalidade

$a=$ intercepção no eixo $y$

$\mathrm{b}=$ coeficiente angular

Quando a equação acima não produziu resultados coerentes com os dados brutos foram utilizados o cálculo manual ou a análise de Probitos computada no programa ACE.

O segundo momento refere-se à análise de regressão entre as $\mathrm{CL}$ (I)zero e a recíproca dos periodos de observação correspondentes ( $1 / t)$, sendo que a intercepção (a) dessa regressão determina o valor de PCENO. Tendo em vista que o método LRA fornece seis modelos de ajuste dos dados para obtenção do PCENO, selecionou-se aquele mais apropriado à maioria dos testes efetuados. Deste modo, a seguinte equação foi utilizada: $\log$ CL(I)zero $=a+b(1 / t)$

Para o cálculo da $\mathrm{CL}(\mathrm{I})$ foi utilizado, também, o método computadorizado Inhibition Concentration (ICp, versão 2.0) editado por NORBERG-KING (1993). Esse método baseia-se na regressão não-paramétrica monotônica dos dados de reprodução ou crescimento dos organismos, sendo que no presente estudo foi utilizada a sobrevivência de Danio rerio. Nos casos em que não é observada a monotonicidade dos dados, o método citado efetua ajustes que permitem a uniformização dos mesmos. Na simulação dos experimentos com tratamentos em duplicata, foram 
sorteadas duas réplicas de cada concentração-teste e destas calculadas as $\mathrm{CE}(\mathrm{I}) 15 ; 168 \mathrm{~h}$.

A precisão analítica dos resultados dos testes ecotoxicológicos foi avaliada pelo cálculo do coeficiente de variação (C.V.), de acordo com a fórmula abaixo:

$$
\text { C.V. }=\frac{\mathbf{s}}{\mathrm{x}} \bullet 100
$$

onde:

$\mathrm{s}=$ desvio padrão

$\mathrm{x}=$ média aritmética dos resultados de testes efetuados.

As análises de regressão, usadas para correlacionar os resultados dos testes com Danio rerio e Pimephales promelas, foram efetuadas pelo método dos mínimos quadrados utilizando-se o programa computadorizado Microcal Origin (versão 4.1, 16 bit). De acordo com os diagramas de dispersão, foi utilizada a função não-linear redutível à forma linear, como segue:

$$
\log y=a+b \log x
$$

onde:

$\mathrm{y}=$ resultado de teste de toxicidade com Danio rerio (D.r.)

$\mathrm{x}=$ resultado de teste de toxicidade com Pimephales promelas (P.p.)

$\mathrm{a}=$ intersecção com o eixo y

$b=$ coeficiente angular da regressão

O erro padrão corrigido, denominado limite de previsão (LP) $95 \%$, para as equações de regressão, foi calculado como segue:

$$
L P=10^{t \cdot s}[1+1 / N]^{1} 2
$$

onde:

$\mathrm{t}=0,975$ da distribuição de Student. com $\mathrm{n}-2$ graus de liberdade

$\mathrm{s}=$ desvio padrão da estimativa

$\mathrm{N}$ = número de pares de dados 


\section{RESULTADOS}

\subsection{Sensibilidade das diferentes fases vitais de Danio rerio}

\subsubsection{Comparações da sensibilidade através da CL(I)50}

$\mathrm{Na}$ Figura 01A, com dados originários da Tabela 01, verifica-se que o cobre, o níquel e o cloreto de sódio $(\mathrm{NaCl})$ foram mais tóxicos aos embriões de Danio rerio após o período de 168 horas quando as respectivas CL(I)50 são comparadas com aquelas de 96 horas.

Quanto às larvas, conforme demonstrado na Figura 01B e Tabela 01, diferenças expressivas na sensibilidade de Danio rerio ocorreram no período de 168 horas com o níquel, DSS, fenol e $\mathrm{NaCl}$, sendo que para as demais substâncias as diferenças foram menores do que o fator 2 .

Com exceção do níquel, os demais agentes químicos demonstraram a mesma intensidade no efeito tóxico aos jovens de Danio rerio (Figura 01C) nos dois periodos de exposição.

Por outro lado, a análise das CL(I)50 das fases distintas do ciclo vital de Danio rerio, em 168 horas (Tabela 01 e Figura 02), revelou que as larvas foram expressivamente mais sensiveis do que os embriões para o cobre (2,5 vezes), cádmio ( 7,4 vezes), niquel ( 3,0 vezes) e fenol ( 3,7 vezes $)$.

Em relação aos jovens, as larvas foram mais sensíveis ao mercúrio $(8,7$ vezes), cobre (2,9 vezes), cádmio ( 21 vezes) e, também, discretamente mais sensíveis ao $\mathrm{NaCl}(2,1$ vezes), conforme demonstrado na Tabela 01 e Figura 02. 


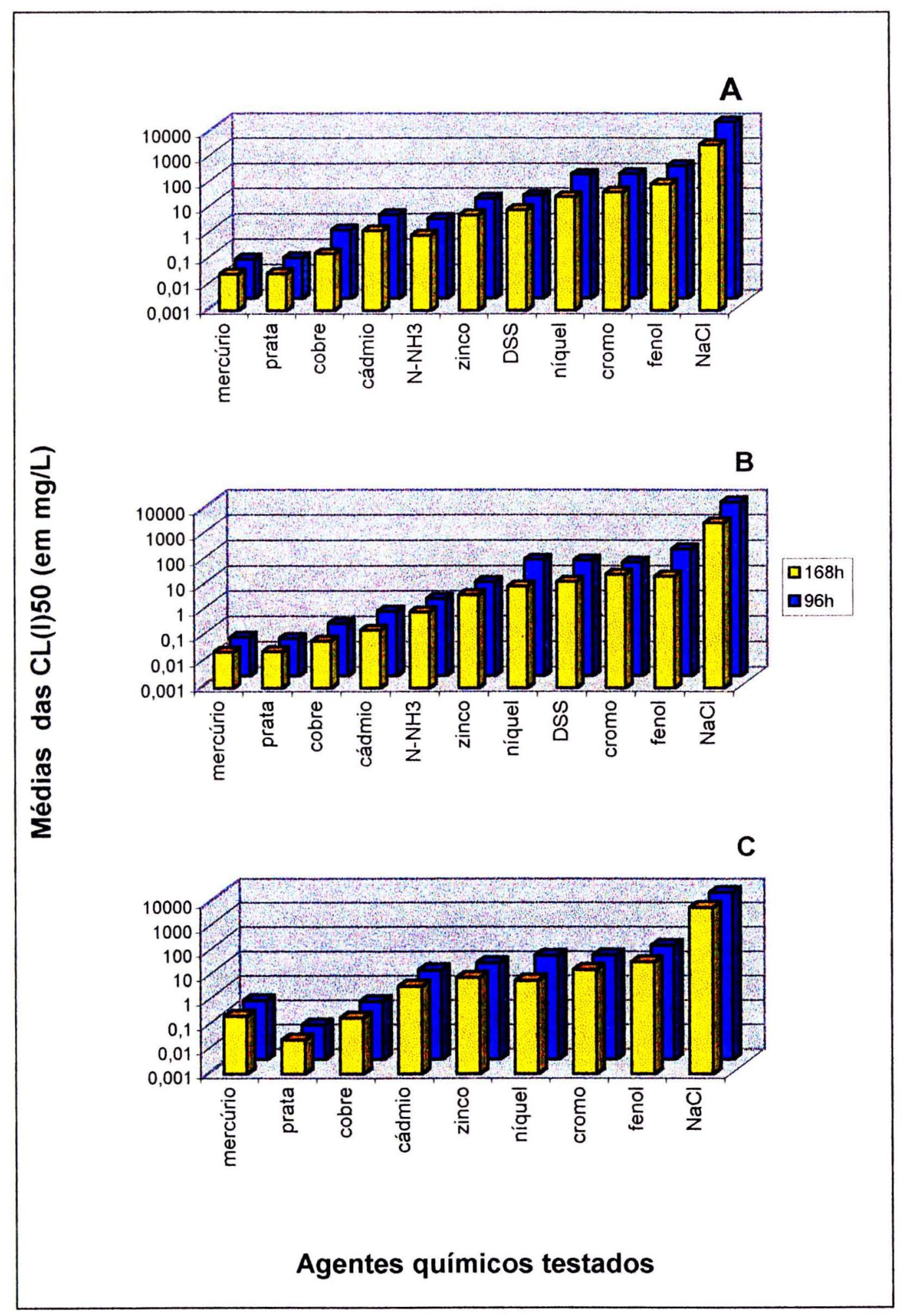

Figura 01 - Comparação da sensibilidade de fases distintas do ciclo vital de Danio rerio, expressa em média das $\mathrm{CL}(\mathrm{I}) 50$, para diversas substâncias em diferentes períodos de exposição.

(A) embriões; (B) larvas; (C) jovens. 


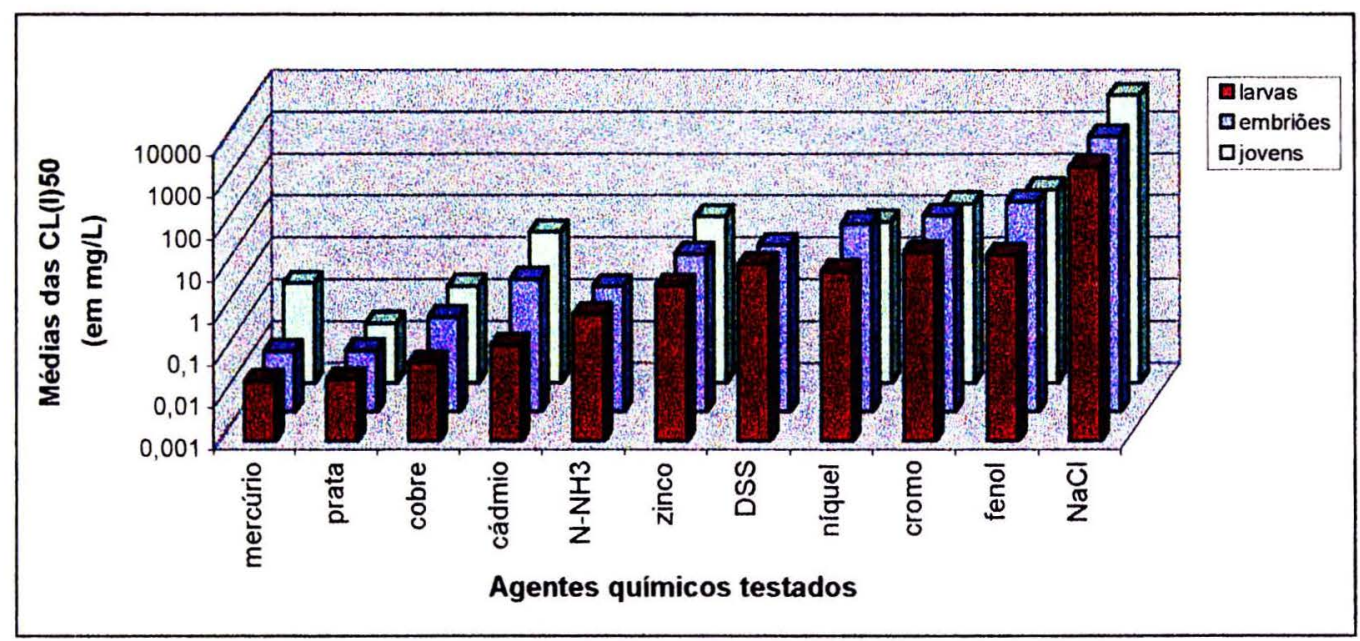

Figura 02 - Comparação da sensibilidade de diferentes fases do ciclo vital de Danio rerio, expressa em média das $\mathrm{CL}(\mathrm{I}) 50$, em 168 horas de exposição a diferentes agentes quimicos.

Outros agentes químicos tais como a prata, zinco, $\mathrm{N}_{-} \mathrm{NH}_{3}$ e DSS foram tóxicos com a mesma intensidade, tanto para larvas quanto para embriões ou jovens, sendo que o níquel e o cromo apresentaram-se mais tóxicos para jovens do que para os embriões (Figura 02).

\subsubsection{Comparações da sensibilidade em testes crônicos de curta duração}

Na figura 03 estão representadas as comparações com base nos cálculos pelo teste de hipóteses. Nesta figura, observa-se que na fase larval os organismos foram mais sensíveis do que na fase embriolarval. As diferenças de sensibilidade foram significativas (Teste $t, \alpha=0,05)$ para o cádmio (5,0 vezes), cromo (2,6 vezes) e níquel (2,4 vezes). Quanto ao cobre, a maior sensibilidade das larvas (2,9 vezes) também foi significativa, porém, ao nível de $\alpha=0,19$. Do mesmo modo, as larvas foram significativamente mais sensíveis do que os embriões $(4,7$ vezes) quando expostas ao fenol, sendo que o nível de significância (teste t) foi igual a $11 \%$. 


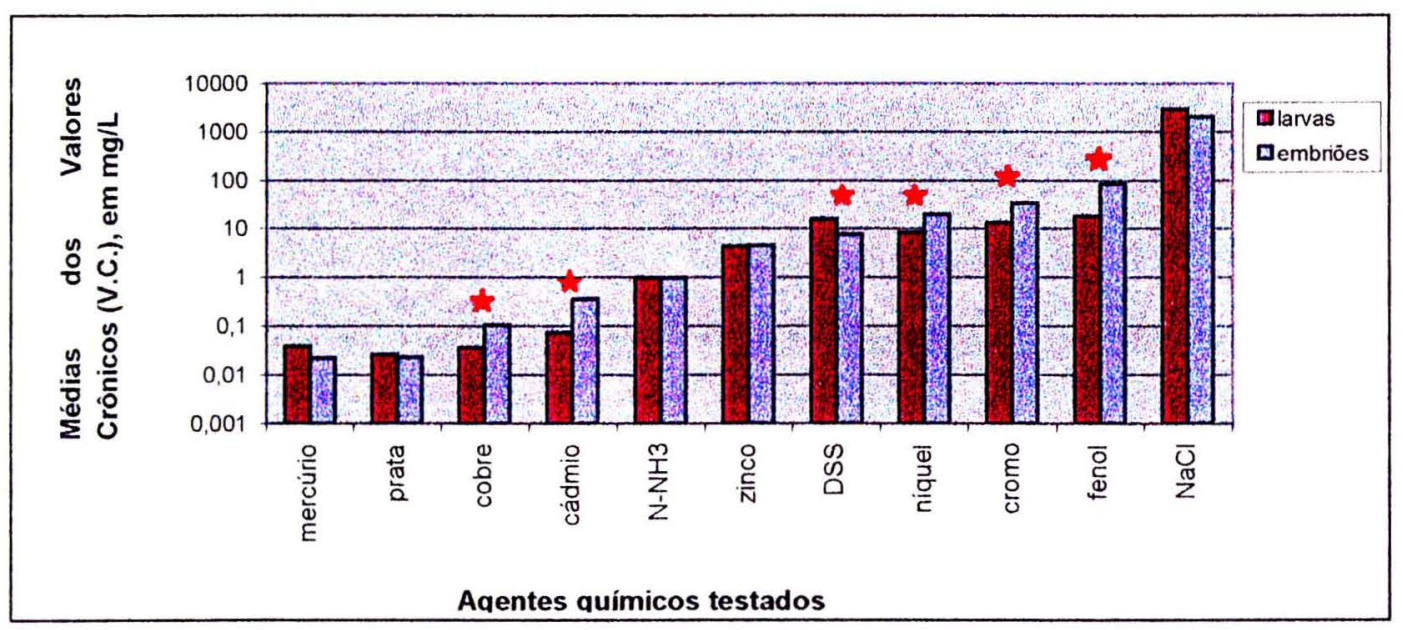

Figura 03 - Comparação da sensibilidade das fases embriolarval e larval de Danio rerio, expressa em média dos V.C., em 168 horas de exposição a diversas substâncias Representa diferença significativa entre os resultados.

Com exceção do DSS, o qual foi significativamente mais tóxico para os embriões (fator 2,1), os demais agentes químicos (mercúrio, prata, zinco, $\mathrm{NaCl}$ e $\mathrm{N}-\mathrm{NH}_{3}$ ) apresentaram a mesma intensidade de efeito, tanto na fase de desenvolvimento embriolarval como na larval (Figura 03).

Uma comparação adicional da sensibilidade de Danio rerio consistiu no uso do método estatístico de regressão linear (LRA), conforme apresentado nas Figuras $04 \mathrm{e}$ 05. Nesse sentido, foi utilizado o cálculo analítico de vários testes com Danio rerio para as três fases estudadas, ou seja, a embriolarval (Tabela 03), a larval (Tabela 04) e juvenil (Tabela 05). Tendo em vista a ausência de registro de dados em vários testes embriolarvais, em especial nos períodos de 48 e 72 horas (devido aos finais de semana), optou-se por não calcular o PCENO;96h para os embriões, com a finalidade de evitar estimativas duvidosas.

$\mathrm{Na}$ Figura 04 constam, resumidamente, as comparações efetuadas com larvas e jovens, considerando os períodos de 96 e 168 horas de exposição. Nessa Figura (04 A), é possível notar que as larvas foram significativamente mais sensíveis após 168 horas para o níquel (2,6 vezes) de acordo com o teste-t $(\alpha=0,05)$. Nesse período, também foram observados efeitos tóxicos mais pronunciados para as larvas (Figura 
04A) frente ao cádmio (5,7 vezes) e fenol (2,2 vezes), com níveis de significância iguais a $31 \%$ e $35 \%$ respectivamente. Os níveis de significância elevados estão associados à elevada variabilidade das PCENO;96h, conforme pode ser constatado, indiretamente, pelos coeficientes de variação dos respectivos testes (Tabela 04). Quanto aos jovens (Figura 04B), somente o níquel apresentou maior efeito tóxico em 168 horas de exposição (3 vezes).

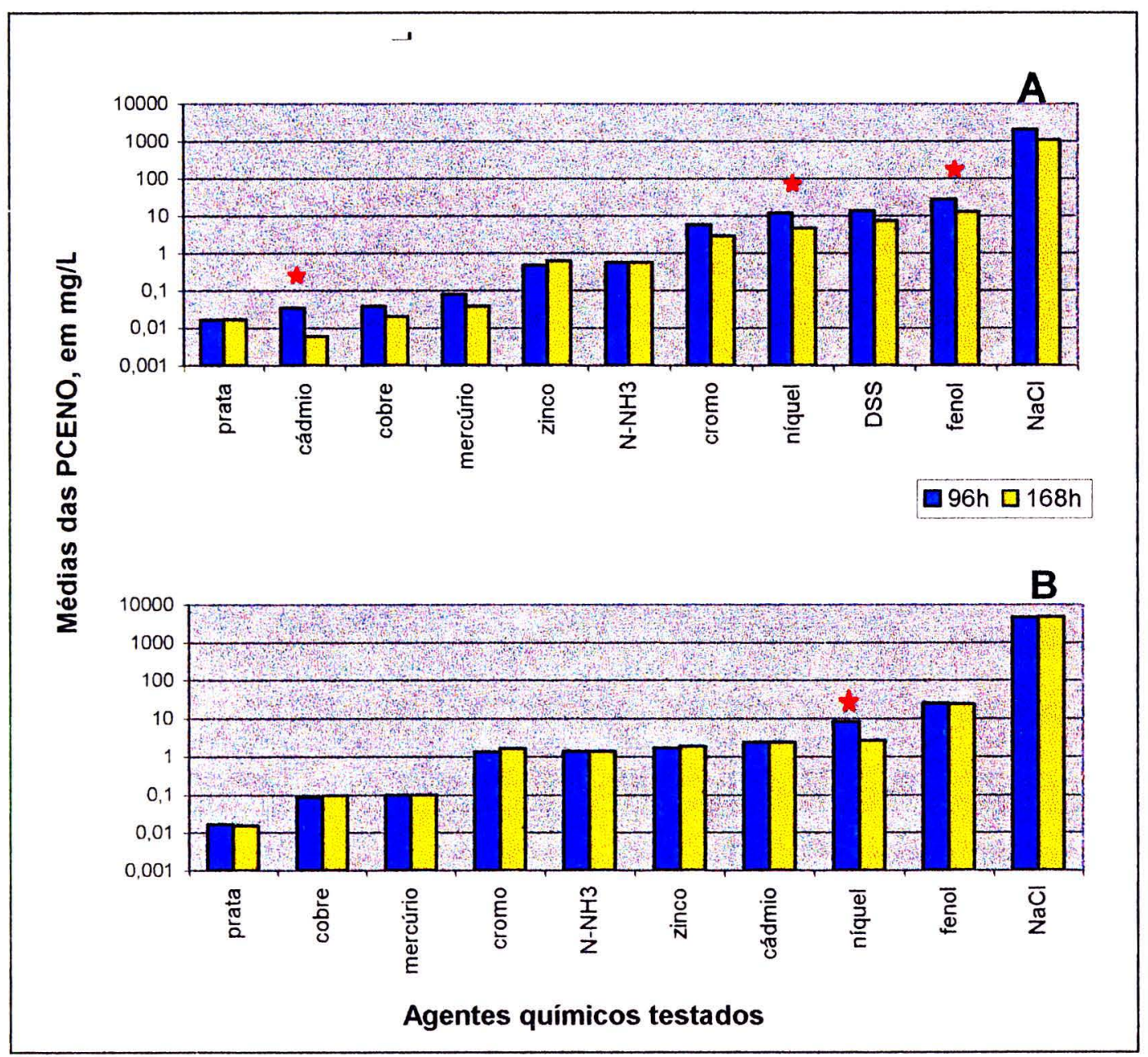

Figura 04 - Comparação da sensibilidade de larvas $(A)$ e jovens $(B)$ de Danio rerio, expressa em média das PCENO em ordem crescente, para diversas substâncias em diferentes períodos de exposição. $\star$ Representa diferença significativa entre os resultados. 
Os cálculos da PCENO possibilitaram, também, a comparação da sensibilidade do peixe estudado nas três fases do ciclo vital. Na Figura 05 observa-se, de maneira geral, que as larvas foram mais sensíveis para seis dos agentes químicos analisados. Em comparação com as larvas, os embriões foram mais resistentes para o cobre $(2,3$ vezes, $\alpha=0,27)$, cádmio (22,7 vezes, $\alpha=0,25)$, zinco (3,2 vezes, $\alpha=0,23)$, cromo (3,0 vezes, $\alpha=0,26)$, níquel (3,0 vezes, $\alpha=0,20)$ e fenol $(2,4$ vezes, $\alpha=0,16)$, sendo os níveis de significância elevados devido às grandes variações dos resultados dos testes com embriões, fato que se pode observar pelos coeficientes de variação da Tabela 03. Somente nos testes com DSS os embriões foram mais sensíveis do que as larvas, ao redor de 2,4 vezes com $\alpha=0,05$.

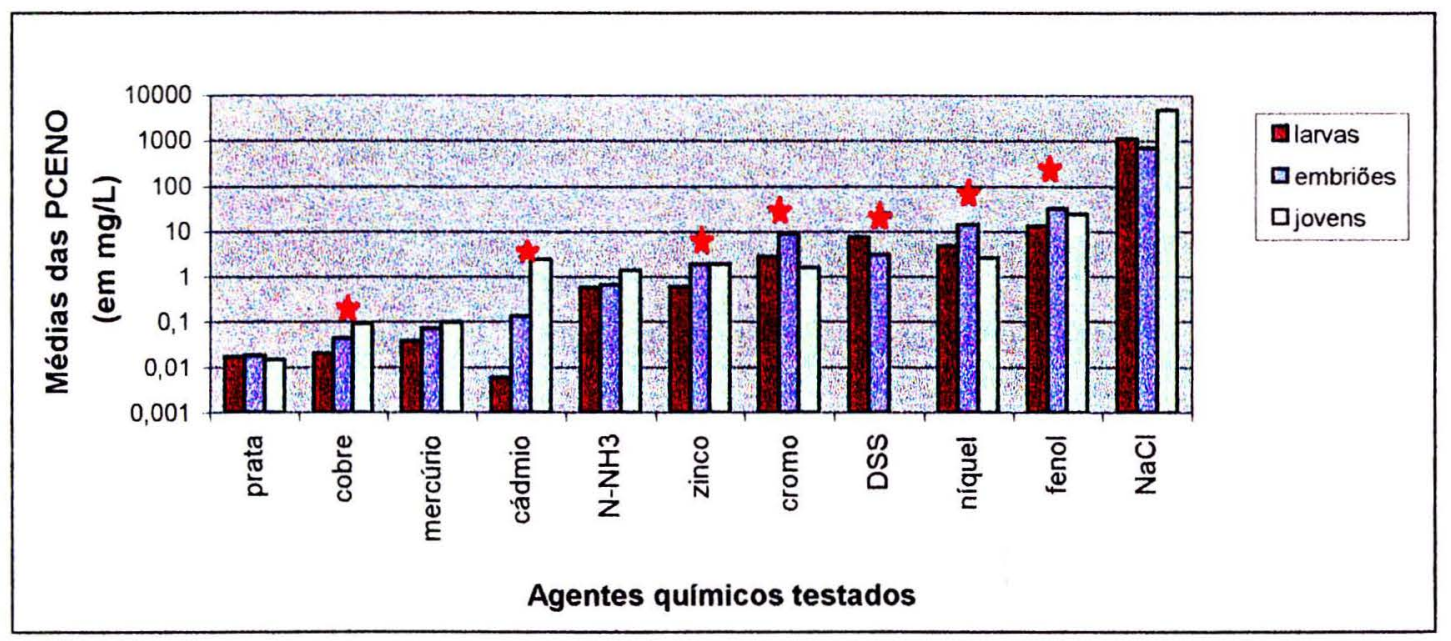

Figura 05 - Comparação da sensibilibade de diferentes fases do ciclo vital de Danio rerio, expressa em média das PCENO, em 168 horas de exposição a diversas substâncias. $\quad \star$ Representa diferença significativa entre os resultados para embriões e larvas.

Ainda na Figura 05, a mesma tendência pode ser notada para os jovens, os quais foram, expressivamente, mais resistentes do que as larvas com o cobre (4,6 vezes), mercúrio (2,5 vezes), cádmio (400 vezes), $\mathrm{N}-\mathrm{NH}_{3}$ (2,5 vezes), zinco (3,2 vezes) e $\mathrm{NaCl}$ (4,3 vezes). Quanto aos jovens, verificou-se que foram mais resistentes do que 
os embriões para o cádmio e $\mathrm{NaCl}$ (18 e 7 vezes, respectivamente) e, ainda, ao redor de 5,5 vezes mais sensíveis do que os embriões tanto para o cromo como para o níquel. Essa maior resistência dos embriões também foi observada nas comparações das CL(I)50; 168h dessas fases do ciclo vital.

Da mesma forma que para os outros métodos estatísticos, foi comparada a sensibilidade de embriões e larvas de Danio rerio, com base no método de cálculo ICp, utilizando-se os dados provenientes das Tabelas 06 e 07 respectivamente. A síntese desses dados, em termos das médias das CL(I)5; 168h, é apresentada na Figura 06.

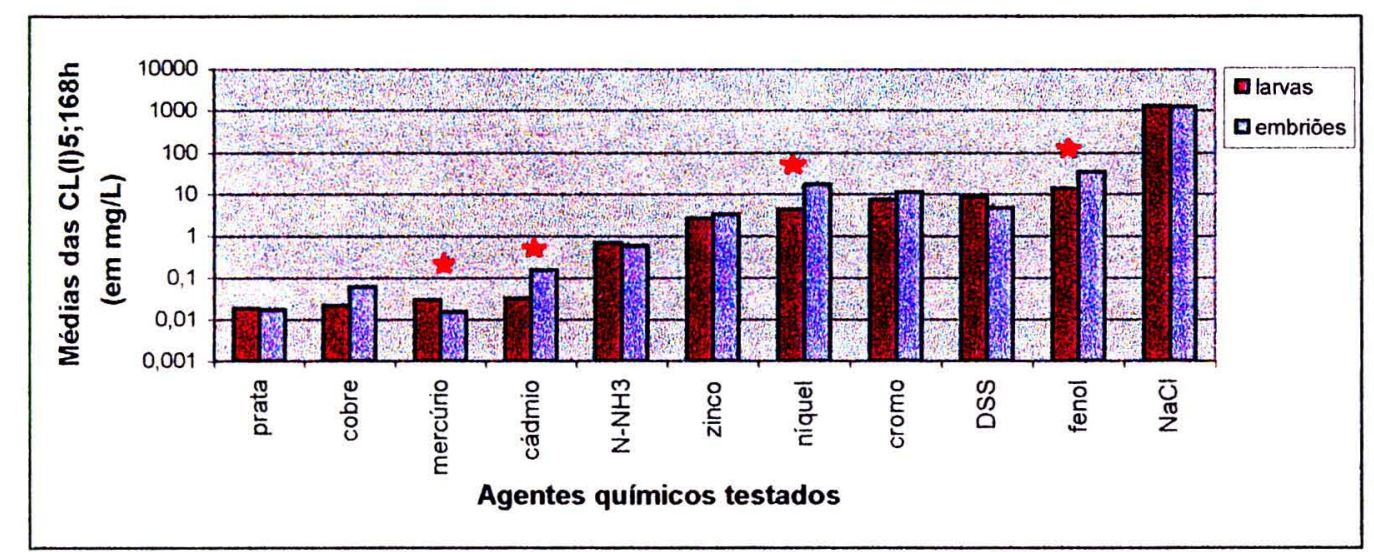

Figura 06 - Comparação da sensibilidade de embriões e larvas de Danio rerio, expressa em média das $\mathrm{CL}(\mathrm{I}) 5$, em 168 horas de exposição a diversas substâncias. $\star$ Representa diferença significativa entre os resultados.

Nessa figura, observa-se que as larvas foram mais sensíveis $(\alpha=0,05$, Teste $t)$ do que os embriões para o cádmio (4,8 vezes), níquel (4 vezes) e fenol (2,5 vezes). Para o cobre, as larvas também foram mais sensíveis (2,9 vezes), porém o nível de significância apresentou-se mais elevado $(\alpha=0,20)$ devido à alta variabilidade nos testes com embriões (Tabela 06). 


\subsection{Precisão analítica dos testes crônicos}

A precisão analítica dos testes de toxicidade crônica, de curta duração, foi determinada para os diferentes estádios do desenvolvimento de Danio rerio, com diferentes métodos estatísticos e, onde aplicável, com períodos de exposição diferenciados.

Na tabela 04 são apresentados os dados de variabilidade dos resultados dos testes, expressos em PCENO, com a fase larval de Danio rerio e os 11 agentes químicos, considerando os períodos de 96 e 168 horas de exposição. Na figura 07, é possível observar que os coeficientes de variação foram mais elevados em 96 horas de exposição, para a maioria das substâncias, exceto para o cobre, cromo e $\mathrm{N}_{-} \mathrm{NH}_{3}$. Por outro lado, nos testes com níquel e DSS a variabilidade foi maior em 168 horas de exposição.

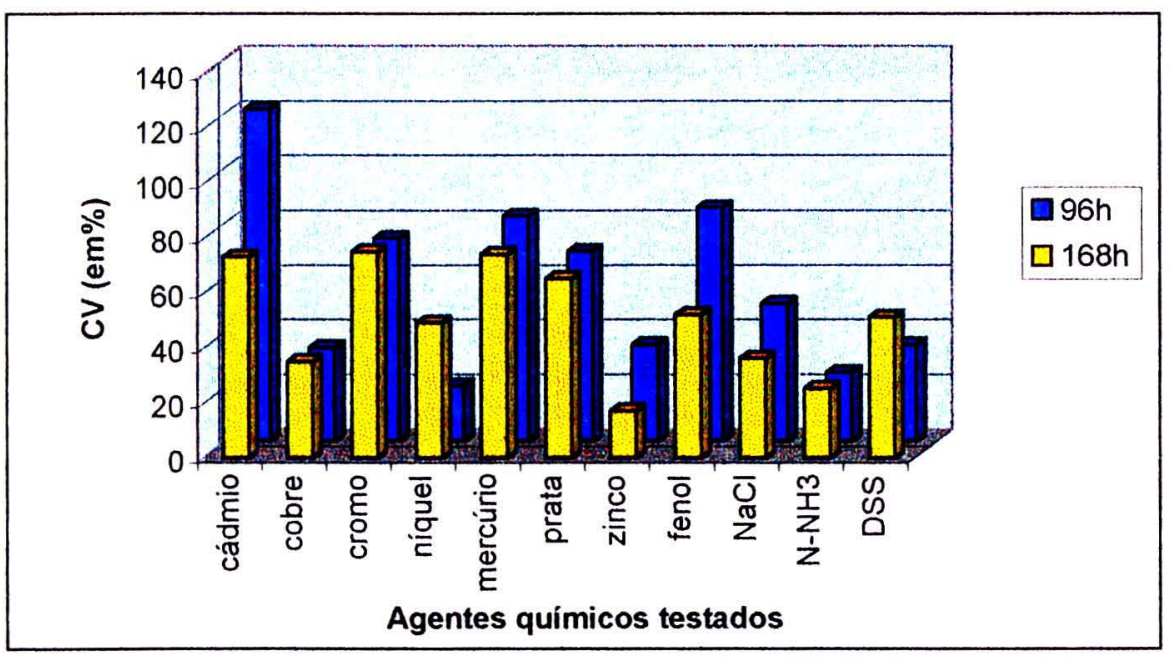

Figura 07 - Coeficientes de variação (CV), em 96 e 168 horas, dos resultados de testes com larvas de Danio rerio estimados pelo método LRA (em PCENO).

A Figura 08A mostra que, nos testes com embriões (Tabela3), em 168 horas, houve um aumento expressivo na variação dos resultados estimados pelo método LRA (como PCENO) quando comparados com aqueles estimados pelo método ICp 
(Tabela 06) através da CL(I)5. A variabilidade nos resultados analíticos foi elevada especialmente para o cádmio, cobre, cromo, zinco e $\mathrm{NaCl}$, para os quais os coeficientes de variação situaram-se acima de $84 \%$ pelo método LRA. Na Figura $8 \mathrm{~B}$ essa mesma tendência, embora com menor intensidade, pode ser notada nos resultados dos testes com larvas (Tabelas 04 e 07), sendo que para o cobre, níquel zinco houve um aumento da variabilidade analítica com o uso do método ICp.

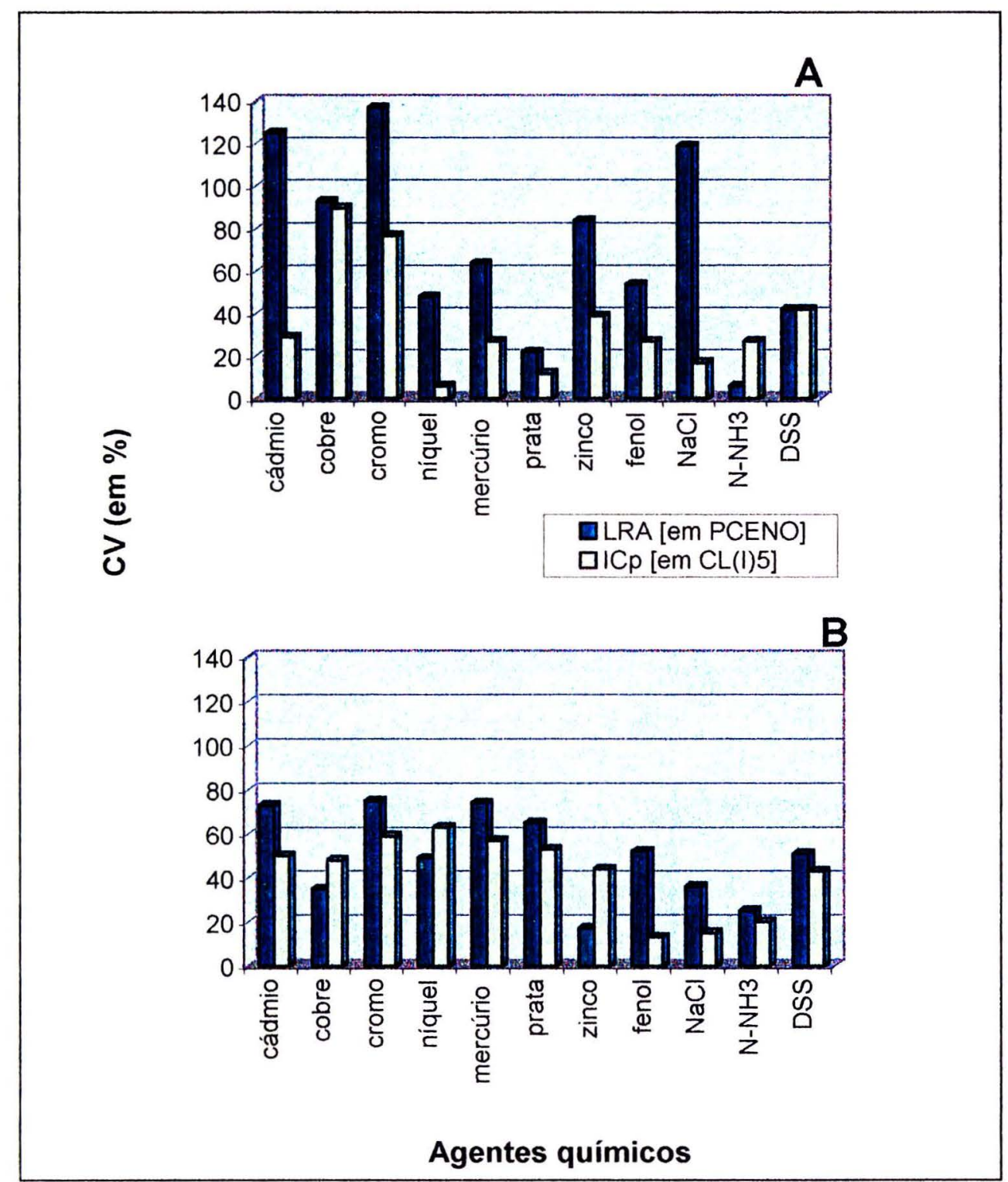

Figura 08 - Coeficientes de variação (CV) de resultados dos testes ecotoxicológicos, em 168 horas, com embriões $(A)$ e larvas (B) de Danio rerio, utilizando os métodos estatísticos LRA e ICp. 
Na Figura 09 está representada a variação analítica dos resultados de testes ecotoxicológicos com larvas, calculados pelo método não paramétrico ICp (Tabela 07) e pelo método paramétrico dos Probitos ('Tabela 08), para diversos níveis de efeito. A comparação entre os dois métodos permite verificar que, de modo geral, a variabilidade analítica dos testes foi menor utilizando-se o método dos Probitos.

No nível de $1 \%$ de efeito, ambos os métodos apresentaram os maiores coeficientes de variação. No nível de $5 \%$ de efeito não foi verificada uma tendência definida para a variabilidade dos resultados pelo método ICp (Figura 09A), enquanto que para o método dos Probitos observou-se coeficientes de variação similares e um pouco mais elevados do que o nível de efeito igual a 15\% (Figura09B).

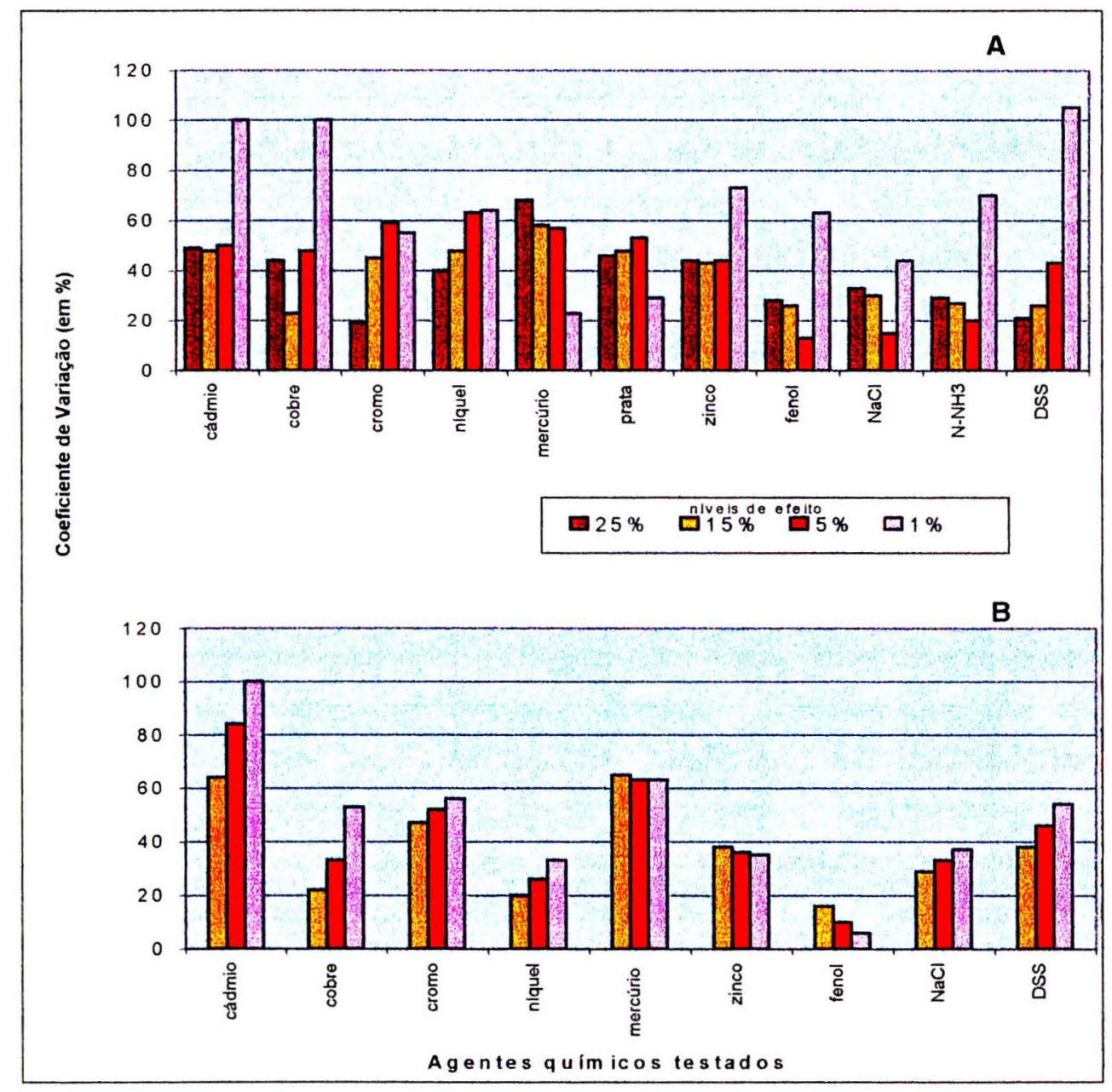

Figura 09 - Coeficientes de variação (CV) dos testes ecotoxicológicos com larvas de Danio rerio e várias substáncias, em 168 horas, para diversos niveis de efeito na sobrevivência. Estimativas pelos métodos ICP(A) e Probitos(B). 
A Figura 09A mostra, também, que para o nível de $15 \%$ e $25 \%$ de efeito os coeficientes de variação foram semelhantes, exceto para os resultados dos testes com cobre e cromo, quando do uso do método ICp. Quanto ao método dos Probitos, o nível de $15 \%$ de efeito foi menos variável que os demais níveis, sendo que devido às limitações estatísticas desse método não foi possível calcular a variação analítica para os testes com prata e $\mathrm{N}-\mathrm{NH}_{3}$ (Figura 09B).

A comparação entre os coeficientes de variação, utilizando-se três métodos estatísticos distintos, revelou que, nos testes com a fase larval em 168 horas de exposição, os resultados com o método ICp e Probitos foram menos variáveis para a maioria dos agentes químicos (Figura 10). Nessa figura nota-se que o método ICp produziu resultados com menor variabilidade para o cobre, fenol, $\mathrm{NaCl}, \mathrm{N}_{-} \mathrm{NH}_{3}$ e DSS, enquanto o método dos Probitos foi mais preciso para o cobre, níquel, fenol e $\mathrm{NaCl}$. Deve-se ressaltar que, devido à restrição inerente do método dos Probitos, não foi possível calcular tanto os resultados analíticos para os testes com prata e $\mathrm{N}_{-} \mathrm{NH}_{3}$, assim como os coeficientes de variação correspondentes.

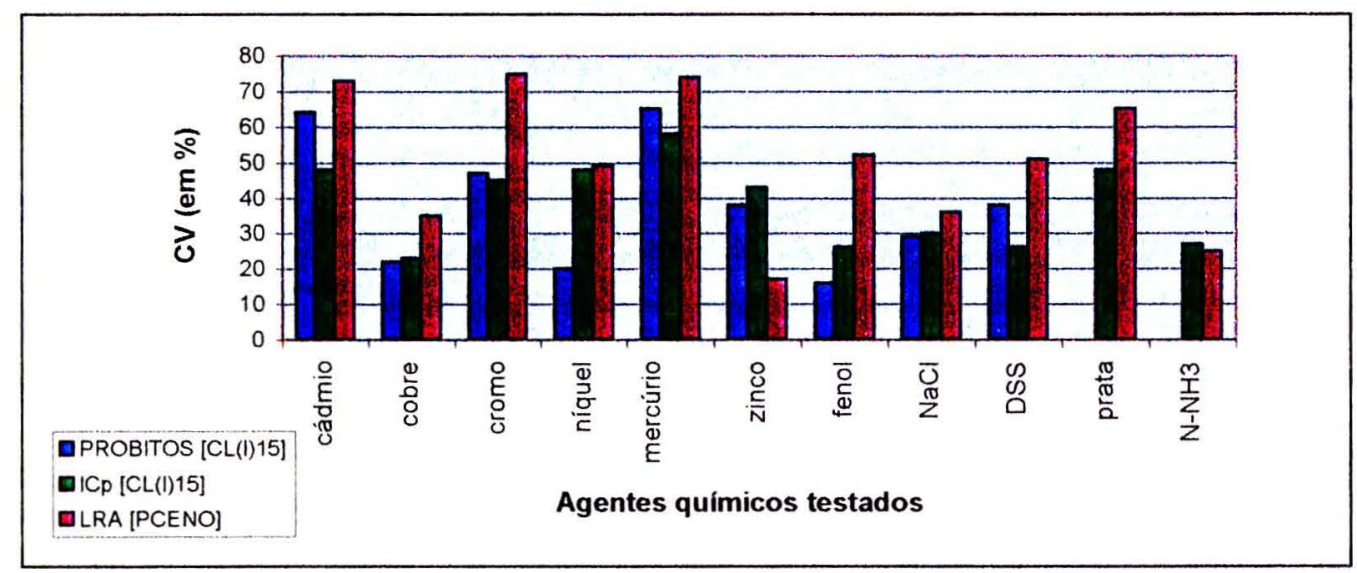

Figura 10 - Coeficientes de variação (CV) dos testes ecotoxicológicos com larvas de Danio rerio e diversas substâncias, em 168 horas de exposição, calculados com base nos resultados de três métodos estatísticos. 


\subsection{Comparação dos resultados obtidos por diferentes métodos estatísticos}

Na Figura 11 é possível observar que, para as onze substâncias testadas, os Valores Crônicos; $168 \mathrm{~h}$ (Tabela 02) foram praticamente iguais às CL(I) $15 ; 168 \mathrm{~h}$ determinadas pelos método ICp e Probitos (Tabela 07 e 08). Do mesmo modo, as PCENO;168h (Tabela 04) estiveram muito próximas aos resultados calculados pelos outros métodos, exceto para o cádmio, zinco e cromo, que apresentaram valores significativamente menores.

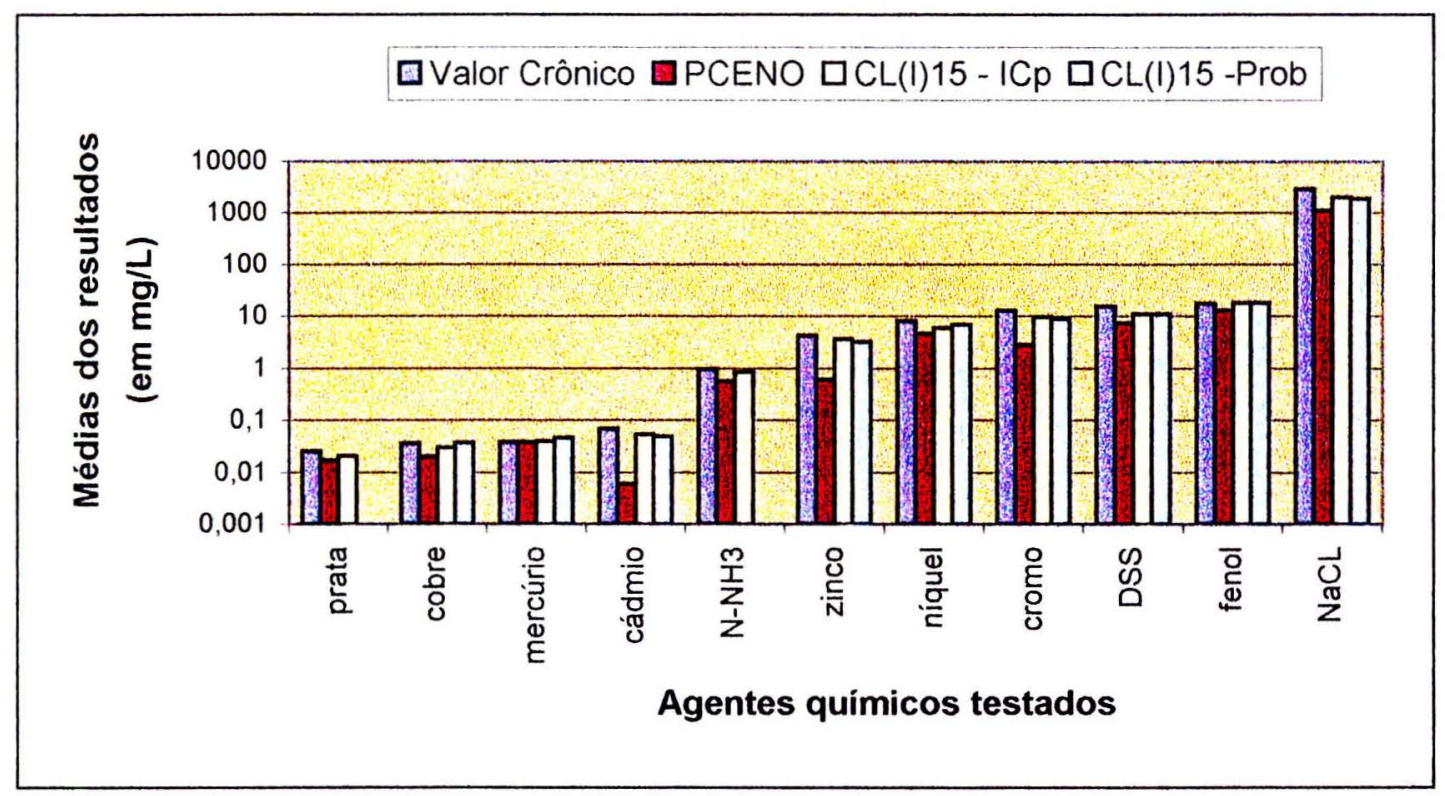

Figura 11 - Comparação dos resultados dos testes ecotoxicológicos crônicos com larvas de Danio rerio, em 168 horas de exposição, calculados pelos métodos: Análise de Variância, LRA, ICp e Probitos.

Em termos dos resultados analíticos, a Figura 12 mostra que o método não paramétrico ICp (Tabela 07) produz valores similares àqueles calculados pelo método paramétrico Probitos (Tabela 08), sendo que não há diferença significativa (Teste $t, \alpha=0,05$ ) entre as médias das CL(I)15:168h nos testes com larvas e os nove agentes químicos comparados. Na Figura 12, nota-se que, utilizando-se o método dos Probitos os intervalos de confiança foram mais amplos para algumas das substâncias testadas. 

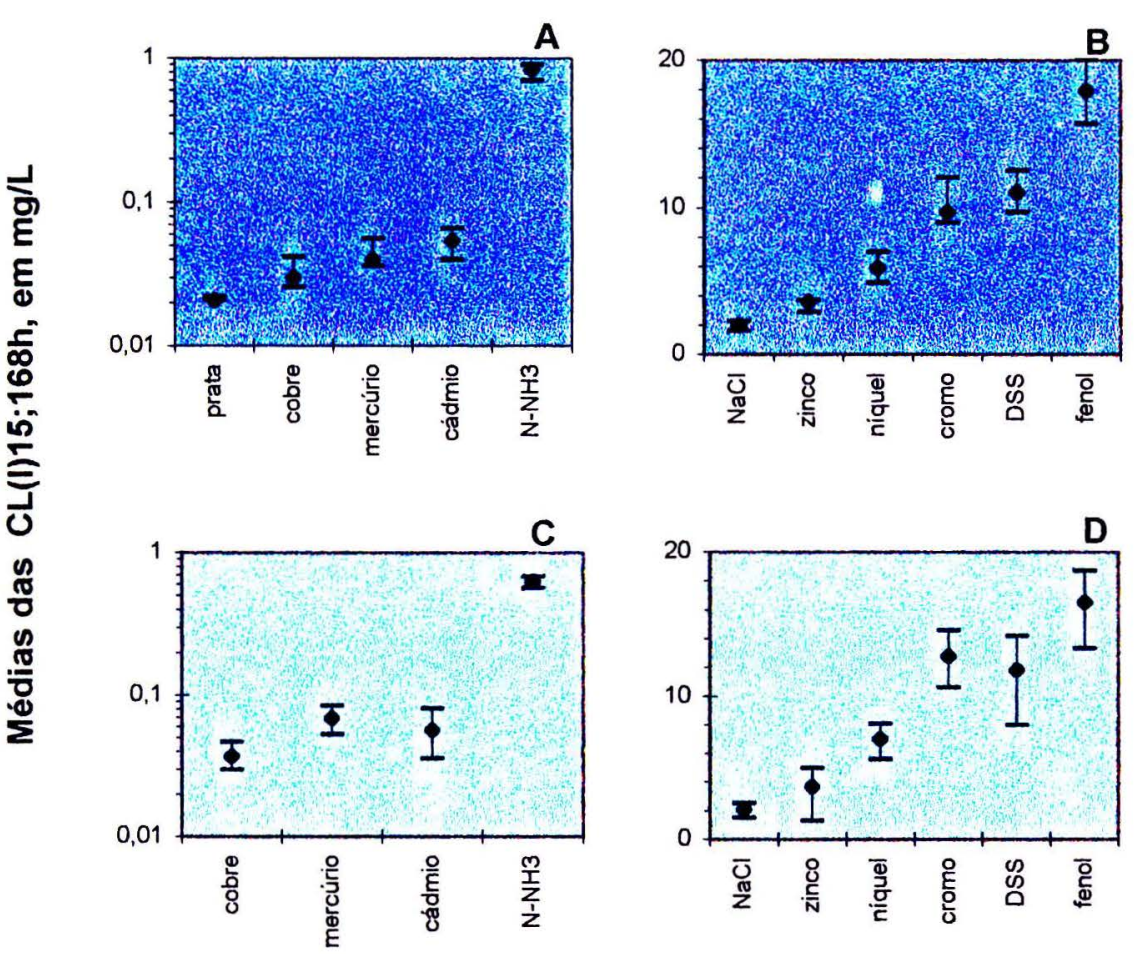

Agentes químicos testados

Figura 12 - Comparação dos resultados de testes ecotoxicológicos com larvas deDanio rerio e diversas substâncias, em 168 horas, calculados pelo métodos ICp (A e B) e Probitos (C e D). Barras de erros representam os intervalos de confiança $(P=0,05)$.

Do mesmo modo, os valores médios de $\mathrm{CL}(\mathrm{I}) 15 ; 168 \mathrm{~h}$ não apresentaram diferenças significativas (Teste $\mathrm{t}, \alpha=0,05$ ), nos testes com as diversas substâncias e larvas de Danio rerio (Figura 13), quando os cálculos foram efetuados usando dados dos experimentos com tratamentos em quadruplicata (Tabela 07) e em duplicata (Tabela 09), em ambos utilizando-se o método ICp. Na Figura 13 observa-se que os intervalos de confiança foram semelhantes entre os resultados calculados para os experimentos com tratamentos em número diferenciado de réplicas. 


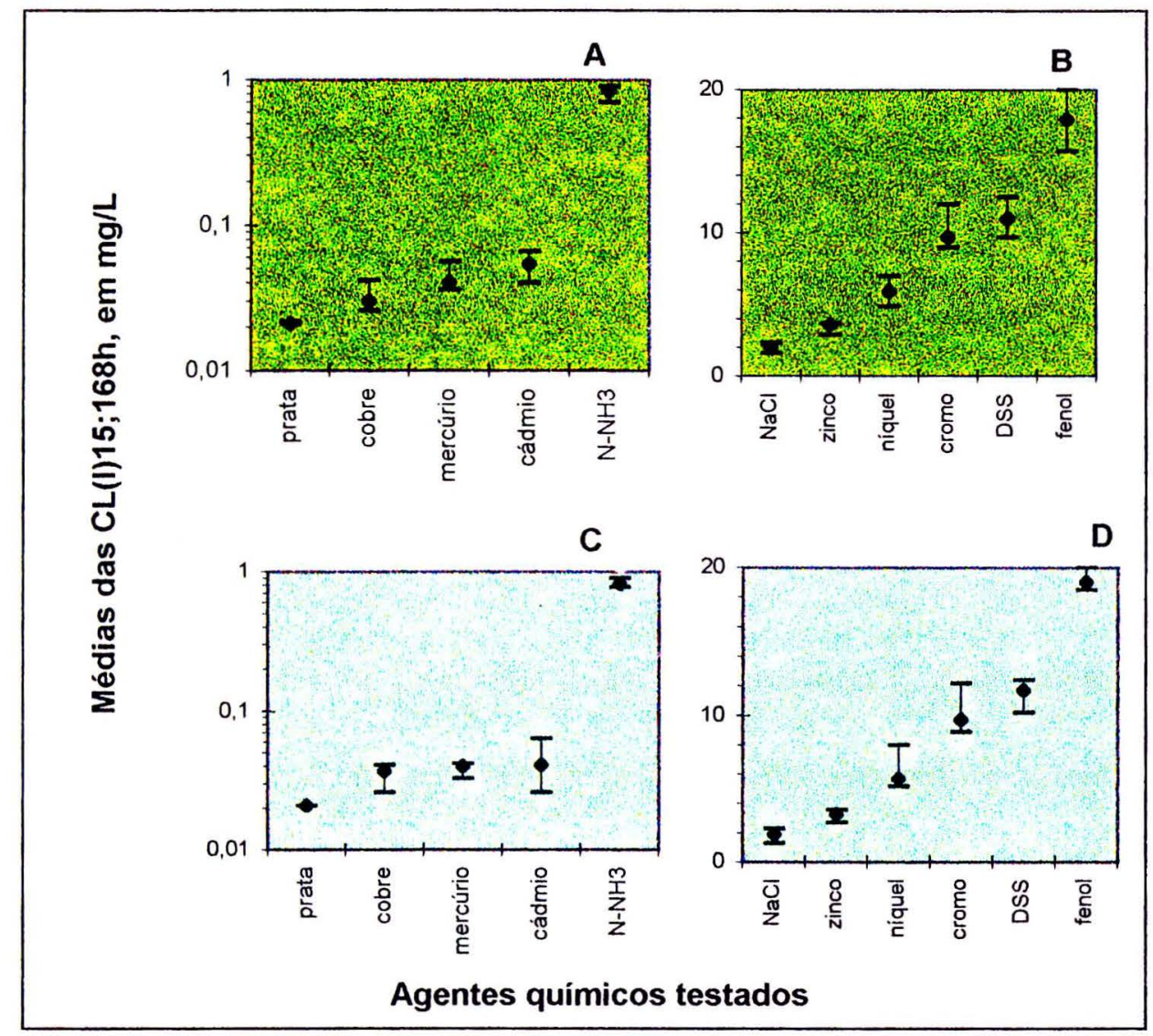

Figura 13 - Comparação dos resultados de testes ecotoxicológicos com larvas de Danio rerio e diversas substâncias, em 168 horas, calculados pelo método ICp com tratamentos em quadruplicata $(A$ e $B)$ e em duplicata ( $C$ e D). Barras de erros representam os intervalos de confiança $(P=0,05)$.

\subsection{Correlação ecotoxicológica entre Danio rerio e Pimephales promelas}

$\mathrm{Na}$ figura 14 constata-se a excelente correlação, expressa pelo coeficiente de determinação $\left(\mathrm{r}^{2}\right)$, entre os dados de toxicidade aguda com adultos e jovens de Danio rerio (tabela 01) e Pimephales promelas (tabela 10) em 96 horas de exposição. A figura 15 mostra que, embora o coeficiente de determinação tenha sido menor, ainda existe uma boa correlação entre os dados de toxicidade aguda (tabelas 01 e 10) para as larvas das espécies de peixe comparadas. 


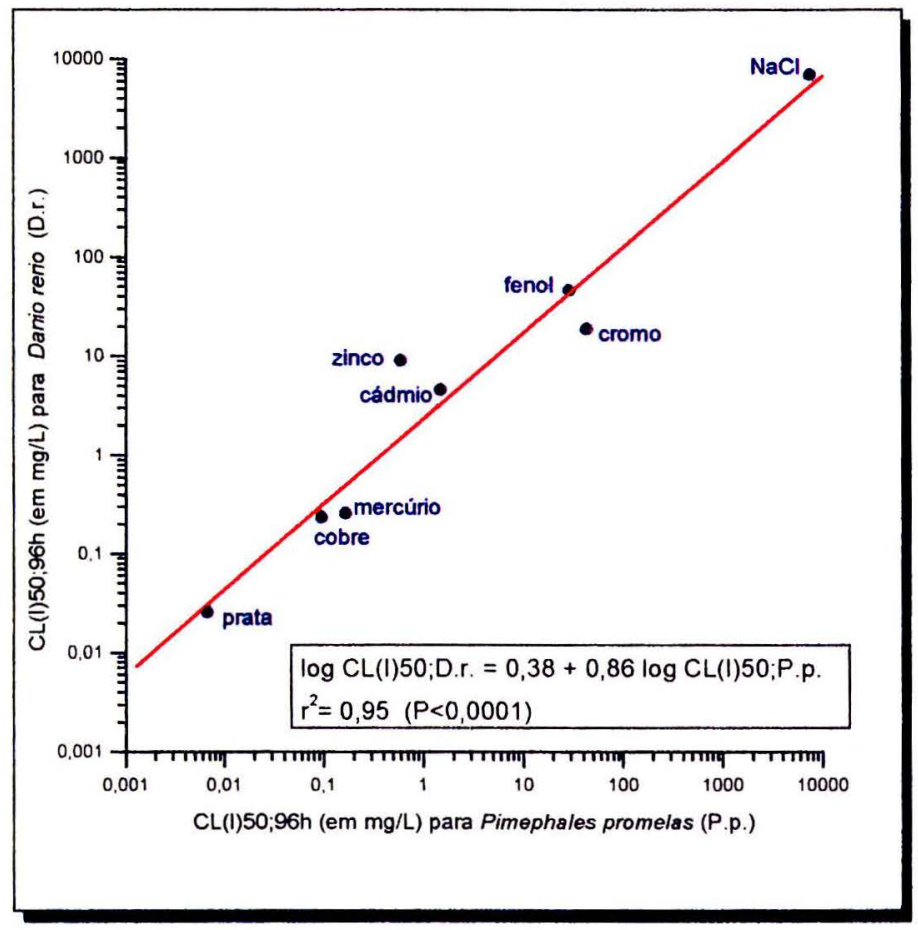

Figura 14 - Reta e equação da regressão para os resultados de testes de toxicidade aguda, em 96 horas, com jovens/adultos das duas espécies de peixe comparadas.

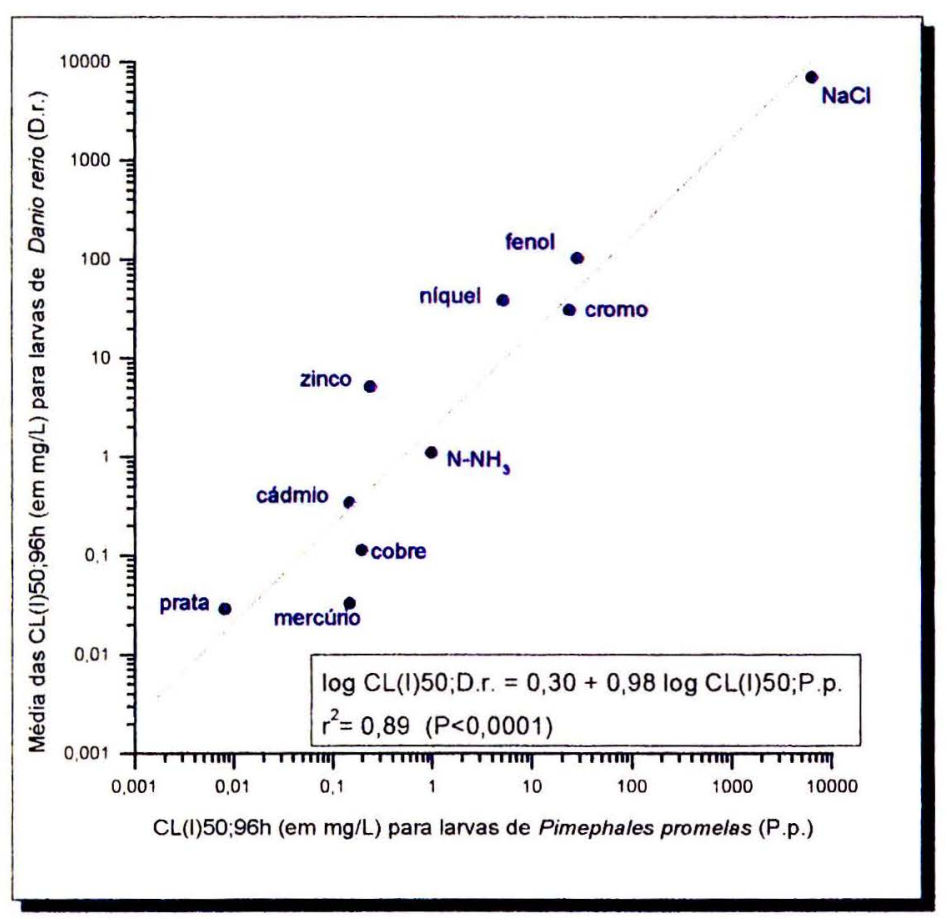

Figura 15 - Reta e equação da regressão para os resultados de testes de toxicidade aguda, em 96 horas, com larvas das espécies de peixe comparadas. 
Na figura 16 observa-se que persiste a elevada correlação na toxicidade aguda para larvas das duas espécies, durante o período de 168 horas, apesar do número reduzido de pares de dados que constam nas Tabelas 01 e 10.

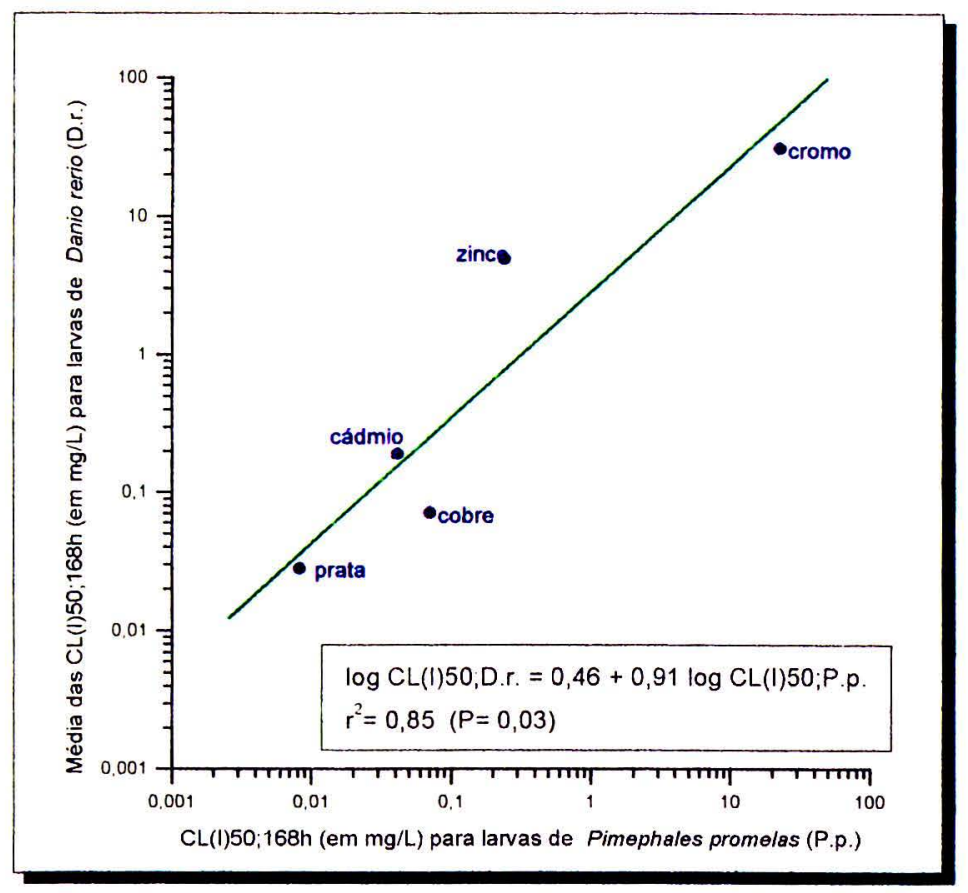

Figura 16 - Reta e equação da regressão para os resultados de testes de toxicidade aguda, em 168 horas, com larvas das duas espécies comparadas.

$\mathrm{Na}$ figura 17 está representado o modelo matemático para a estimativa da toxicidade crônica ao Danio rerio a partir dos dados de testes com Pimephales promelas(Tabela 11). O coeficiente de determinação $\left(\mathrm{r}^{2}\right)$ indica, também, a adequação das estimativas do Valor Crônico (VC) com base na CL(I) 15;168h (tabela 07) e no fator de aplicação igual a 0,3 (tabela 12). Os limites de previsão ( $\pm 11,5$ vezes) demonstram a baixa variação do modelo determinado. 




Figura 17 - Equação, reta $\longrightarrow$ e limites de previsão 95\%(-) da análise de regressão, para os resultados de testes crônicos estimados com $D$. rerio (em VCest.) e determinados com $P$. promelas.

A validação da equação apresentada na Figura 17, para estimativa do VCest; $168 \mathrm{~h}$, consta da tabela 13 . 


\section{DISCUSSÃO}

\subsection{Ação tóxica dos agentes químicos estudados}

Com a finalidade de estabelecer qualquer método ecotoxicológico, é imprescindivel o uso de agentes químicos diferenciados. Idealmente, tais agentes devem ter sido testados em métodos desenvolvidos com outras espécies de organismos e, além disso, possuírem características toxicológicas particulares. Assim, com uma maior diversidade de substâncias, é possível efetuar comparações que validem tanto o método como a sensibilidade do organismo estudado.

No presente estudo, dos onze agentes químicos testados, a maioria pertence ao grupo dos metais. Apesar de enquadradas na mesma categoria, algumas dessas substâncias possuem modo de ação um tanto distinto. WOOD et al. (1997) afirmaram que o efeito tóxico inicial dos metais ocorre, em geral, pelo bloqueio no transporte branquial de sódio ou cálcio. Esses autores confirmaram o bloqueio na tomada do sódio com o cobre e a prata, enquanto que com o cádmio e o zinco o bloqueio se dá para os íons cálcio.

Dentre os outros agentes químicos, a amônia não ionizada $\left(\mathrm{N}-\mathrm{NH}_{3}\right)$ afeta o sistema nervoso central, causando aumento na ventilação branquial, hiperexcitabilidade e convulsão (RUSSO, 1985). O fenol, segundo ALABASTER e LLOYD (1980), causa paralisia do sistema nervoso. Já o DSS (dodecil sulfato de sódio), um detergente aniônico, produz inchaço e necrose nas brânquias (LELAND e KUWABARA, 1985). Quanto ao cloreto de sódio $(\mathrm{NaCl})$, é esperado efeito tóxico causado por falha osmoregulatória.

Portanto, no presente estudo, a diversidade de substâncias testadas permite que as conclusões sejam razoavelmente fundamentadas. 


\subsection{Sensibilidade das diferentes fases do ciclo vital de Danio rerio}

A definição de um método ecotoxicológico requer o conhecimento de variáveis que podem modificar os resultados analíticos. No presente estudo, tanto a duração dos experimentos quanto a idade dos organismos-teste são variáveis básicas que necessitam de uma definição prévia.

Embora alguns trabalhos de revisão indiquem as fases iniciais do ciclo vital de peixes como as mais sensiveis (MCKIM, 1985; CHAPMAN, G.A. et al., 1996), outros recomendam também o uso de peixes jovens (SUTER et al., 1987; MAYER et al., 1994) na execução de testes ecotoxicológicos para prever efeitos crônicos. Considerando que tais trabalhos referem-se a experimentos com espécies de peixes (principalmente salmonídeos) que não incluem o Danio rerio, torna-se conveniente o conhecimento da sensibilidade de fases vitais distintas dessa espécie.

Antes de proceder à análise da sensibilidade das fases vitais de Danio rerio, é importante que se estabeleça a base para as comparações efetuadas. Tendo em vista a impossibilidade de se efetuar uma análise estatística apropriada (por exemplo, análise de variância) para o conjunto de dados, utilizou-se uma análise descritiva que fixa o fator $>2$ (isto é, o quociente entre a maior e menor concentração de um efeito pré-determinado) como diferença expressiva na comparação de resultados de testes com uma determinada espécie. Este fator é sugerido em vários estudos (McKIM, 1977; ADAMS et al., 1983; CHAPMAN, 1983; SLOOF et al., 1983; SPRAGUE, 1985), sendo que diferenças de resultados acima do fator mencionado podem ser usadas como uma medida de significância das variáveis analisadas, no presente caso o periodo de exposição e a fase do ciclo vital utilizada. 


\subsubsection{Comparações da sensibilidade através da CL(I)50}

A primeira comparação dos resultados analíticos foi efetuada com base na letalidade dos agentes químicos a $50 \%$ dos organismos (expressa como a concentração letal mediana, ou $\mathrm{CL}(1) 50$ ), uma vez que para esse nível de efeito as estimativas possuem menor variância amostral do que outros quartis e, consequentemente, são mais reprodutiveis (GELBER et al. 1985).

Embora seja esperado que as substâncias tornem-se mais tóxicas à medida que se prolonga o período de exposição, os vários métodos padronizados adotam o período de 96 horas como sendo suficiente para caracterizar os efeitos letais para peixes (SPRAGUE, 1969; BUIKEMA et al., 1982). No entanto, ao se analisar as comparações da Figura 01, observa-se que as CL(I)50 para embriões e larvas são consideravelmente menores, para algumas substâncias, com o prolongamento do periodo de exposição para 168 horas. Dentre as substâncias estão o cobre, níquel, $\mathrm{NaCl}$, fenol e DSS.

Os resultados obtidos para as fases iniciais de vida de Danio rerio, considerando o prolongamento do periodo de exposição, são semelhantes aos determinados por NORBERG e MOUNT (1985) e NORBERG-KING (1989) para larvas do Pimephales promelas. Enquanto os primeiros autores demonstraram que a razão entre as $\mathrm{CL}(\mathrm{I}) 50 ; 96 \mathrm{~h}$ e $168 \mathrm{~h}$ foi maior do que o fator 2 com um efluente de refinaria de petróleo, a segunda autora constatou o mesmo para um dos testes com selênio.

Outros resultados dos autores mencionados também são concordantes com os do presente estudo, no que se refere às substâncias que não apresentam diferenças expressivas (fator $<2$ ) após o prolongamento do período de exposição. Dentre os resultados concordantes, pode-se citar os dos testes de toxicidade aguda com cobre, prata e zinco. 
Quanto à intensidade semelhante de efeitos tóxicos para os jovens do Danio rerio em ambos períodos de exposição (Figura 01C), com exceção do níquel, constata-se a veracidade da afirmação de SPRAGUE (1969), que apontou os testes ecotoxicológicos de 96 horas como estimadores razoáveis dos efeitos agudos (tal como a letalidade) em peixes jovens ou adultos. Com relação à extensão de testes com adultos de Danio rerio, somente foi encontrado o estudo de DAVE et al. (1981), no qual se constatou que a toxicidade de quatro substâncias para extração solvente, além do cádmio, também manteve-se praticamente inalterada por periodos de exposição prolongados de 96 para 144 horas.

No que se refere à comparação entre as fases de vida, a maior sensibilidade das larvas do Danio rerio (Figura 02) em relação aos embriões e jovens também foi evidenciada por outros autores. VanLEEUWEN et al. (1985) obtiveram menores valores de $\mathrm{CL}(\mathrm{I}) 50 ; 96 \mathrm{~h}$ para larvas de trutas, expostas a seis agentes químicos, quando comparados com os embriões dessa espécie de peixe. Do mesmo modo, NORBERG-KING (1989) relatou outros estudos em que se verificou a maior resistência de embriões, em relação às larvas de Pimephales promelas, para o tolueno, cádmio, selênio e triclorofenol.

Resultados semelhantes foram obtidos por MARKLE et al. (2000), os quais demonstraram maior resistência dos jovens em relação às larvas de Pimephales promelas em testes de 96 horas com o cobre e amônia não ionizada $\left(\mathrm{N}-\mathrm{NH}_{3}\right)$, assim como para Danio rerio na presente pesquisa. Devido à impossibilidade de calcular as $\mathrm{CL}(\mathrm{I}) 50$ para $\mathrm{N}-\mathrm{NH}_{3}$ e jovens de Danio rerio (Tabela 01), causada por interferências do $\mathrm{pH}$ das soluções-teste, efetuou-se as comparações com base no sal utilizado $\left(\mathrm{NH}_{4} \mathrm{Cl}\right)$. Deste modo, a média das $\mathrm{CL}(\mathrm{I}) 50 ; 168 \mathrm{~h}$ para larvas foi de $286,4 \mathrm{mg}$ $\mathrm{NH}_{4} \mathrm{Cl} / \mathrm{L}$, enquanto no teste com jovens a $\mathrm{CL}(\mathrm{I}) 50 ; 168 \mathrm{~h}$ foi de $1.320,0 \mathrm{mg} \mathrm{NH} \mathrm{NH}_{4} \mathrm{Cl}$, resultando em uma maior sensibilidade das larvas, ao redor de 4,6 vezes.

Embora NORBERG-KING (1989) tenha observado que, para o zinco, as larvas de Pimephales promelas foram três vezes mais sensiveis do que os jovens, tal fato foi 
constatado para Danio rerio somente com o cobre e, com maior intensidade, o mercúrio (Figura 02). Além disso, essa pesquisadora detectou maior sensibilidade das larvas para o cádmio (fator de 29 vezes) em relação aos jovens, sendo que para esse metal a mesma intensidade foi encontrada (Tabela 01) na comparação entre as referidas fases vitais de Danio rerio, ou seja, um fator de 21 vezes.

Outro fato a ser destacado refere-se à maior resistência dos embriões, em relação aos jovens, tanto para o níquel quanto para o cromo (Figura 2). Apesar de parecer contraditório, essa maior resistência dos embriões pode ser devida a uma proteção do córion durante o desenvolvimento dos organismos nesta fase do ciclo vital (McKIM, 1985; vanLEEUWEN et al., 1985). Essa suposição parece razoável, uma vez que os jovens demonstraram sensibilidade similar à das larvas para estes dois metais.

Considerando o nivel de letalidade a $50 \%$ dos organismos, pode-se constatar que as larvas de Danio rerio são indicadas para execução de testes ecotoxicológicos que têm a finalidade de estimar efeitos crônicos à espécie estudada. Esta constatação se justifica pela maior sensibilidade das larvas, em relação aos embriões ou jovens, quando expostas a seis dos onze agentes químicos estudados. Além disso, os resultados evidenciam que a larvas são sensiveis para detectar efeitos adversos significativos, na sobrevivência, por periodos maiores do que 96 horas.

\subsubsection{Comparações da sensibilidade nos testes crônicos de curta duração.}

Outra forma de avaliação dos aspectos relacionados à sensibilidade de Danio rerio consistiu da comparação dos dados relativos aos níveis apropriados para estimar efeitos crônicos, isto é, niveis que expressam efeitos biológicos mínimos sobre uma população, conforme citado por BRUCE e VERSTEEG (1992). Nesse sentido, três métodos estatísticos, diferenciados, foram utilizados para estimar os níveis de efeito citados, bem como para comparar a sensibilidade do peixe estudado. 
$\mathrm{Na}$ análise dos dados, através do cálculo da análise de variância (ANOVA), foram utilizadas as médias dos Valores Crônicos (V.C.) para cada substância. O motivo para o uso de tais valores refere-se ao aproveitamento integral das estimativas geradas nos testes, isto é, CEO e CENO, além de que os valores crônicos são numericamente semelhantes aos resultados calculados pelos outros métodos estatísticos utilizados nas comparações.

Devido ao desenho experimental dos testes crônicos de curta duração (isto é, número pré-determinado de tratamentos para periodo de tempo específico) e, também, em função da exigência intrínseca da análise de variância e do método ICp (ou seja, ao menos duas a quatro réplicas por tratamento), as comparações dos respectivos resultados ficaram restritas aos períodos de 168 horas, conforme apresentado nas Tabelas 02, 06 e 07. Desta forma, não foi possível determinar os Valores Crônicos (V.C.) e CL(I) para as fases embriolarval e larval em 96 horas. Também, não foi possível, ainda que tentativamente, expressar resultados analíticos para os jovens de Danio rerio nos dois períodos de exposição, com ambos os métodos, uma vez que a norma técnica utilizada ( $\mathrm{ABNT}, 1993)$ não prevê tratamentos com replicatas.

Embora o método ICp permita calcular a CL(I) para qualquer nível de efeito entre 0 e 100\%, optou-se pela comparação da CL(I) $5 ; 168 \mathrm{~h}$ pois, segundo DENTON e NORBERG-KING (1996), o nível de 5\% é o mínimo para ser usado em tal método nos cálculos de efeitos crônicos.

No que se refere às comparações de sensibilidade pela análise de variância e método ICp (Figuras 03 e 06), verifica-se que tais estimativas apresentam a mesma tendência demonstrada na análise das CL(I) 50\% (Figura 02). Deste modo, as larvas mostraram-se mais sensiveis do que embriões para o cádmio, cobre, níquel e fenol. Além dessas substâncias, as larvas foram também mais sensiveis ao cromo, exclusivamente na comparação efetuada pela análise de variância. 
Essas constatações mostram que a maior sensibilidade das larvas, no que se refere à sobrevivência, é praticamente a mesma, tanto em testes ecotoxicológicos agudos como em crônicos de curta duração. Tal fato é de certa forma esperado pois, embora os níveis de efeito sejam diferenciados, o tempo de exposição nos testes de toxicidade aguda (96 horas) é muito próximo daquele dos testes de toxicidade crônica (168 horas).

Além das comparações de sensibilidade de Danio rerio, os dados da Tabela 02 permitem comparar os resultados obtidos nos testes de 168 horas com outros testes efetuados em períodos de exposição diferentes. Tendo em vista que os resultados de outros pesquisadores são originários de experimentos que consistiram da exposição de embriões e larvas simultaneamente, a comparação a seguir refere-se aos dados com a fase embriolarval da presente pesquisa (Tabela 02).

DAVE (1985), em experimentos com duração de seis a 13 dias, verificou que a concentração de $1,0 \mu \mathrm{g} / \mathrm{L}$ de cádmio causava efeitos na sobrevivência de Danio rerio, portanto, em nível muito mais tóxico do que o obtido no presente estudo (Tabela 02). No entanto, o referido autor sugeriu que tal nível de toxicidade poderia estar mais relacionado à ausência de alimentação dos organismos do que à sensibilidade dos mesmos ao cádmio.

DAVE e XIU (1991), analisando a sobrevivência de Danio rerio, em experimentos com duração superior a 13 dias, obtiveram Valores Crônicos iguais a $0,0014 \mathrm{mg} / \mathrm{L}$ para o cobre, $0,36 \mathrm{mg} / \mathrm{L}$ para o niquel, e $0,002 \mathrm{mg} / \mathrm{L}$ para o mercúrio. Tais dados são de uma até duas ordens de magnitude menores do que aqueles da Tabela 02, onde as médias dos Valores Crônicos foram de $0,103 \mathrm{mg} / \mathrm{L}$ para o cobre, $19,8 \mathrm{mg} / \mathrm{L}$ para o niquel e $0,022 \mathrm{mg} / \mathrm{L}$ para o mercúrio.

Analisando a publicação de DAVE e XIU (1991), foi possível verificar que no periodo de sete dias de exposição, adotado na presente pesquisa, o Valor Crônico para o cobre seria semelhante àqueles com a fase larval (Tabela 02). Do mesmo 
modo, o Valor Crônico para o mercúrio estaria muito próximo ao determinado tanto para a fase embriolarval como para a larval, considerando o período de sete dias. Por extrapolação, o mesmo poderia ser dito quanto ao níquel, uma vez que os dados apresentados pelos autores não possibilitaram a verificação no periodo de sete dias. Além disso, talvez o mais importante a ser notado foi que a mortalidade dos peixes, em concentrações intermediárias de efeito, ocorreu de forma abrupta após o $10^{\circ} \mathrm{e}$ $11^{\circ}$ dia de exposição dos organismos.

Diante dessas evidências, supõe-se que os testes efetuados por DAVE e XIU (1991) foram fortemente influenciados pela inanição das larvas de Danio rerio, fato observado pelos autores nos testes com o mercúrio. Desse modo, o exacerbado efeito tóxico dos metais, reconhecido pelos próprios autores, pode ter sido potencializado pela debilidade dos organismos-teste. Em estudo publicado por MEINELT e STAAKS (1994), com Danio rerio, confirmaram-se os dados de toxicidade para o cobre descritos na Tabela 02 , uma vez que esses autores obtiveram valores de $\mathrm{CEO}=$ $0,050 \mathrm{mg} / \mathrm{L}$ e CENO $<0,050 \mathrm{mg} / \mathrm{L}$ em testes com 144 horas de duração.

Outros estudos também demonstram concordância com os resultados descritos na Tabela 02. DAVE et al. (1987) encontraram valores de $15,0 \mathrm{mg} / \mathrm{L}$ para o cromo e de $8,0 \mathrm{mg} / \mathrm{L}$ para o zinco, em testes com duração superior a 14 dias para estágios iniciais de vida de Danio rerio. Em experimentos com 144 horas de duração, MEINELT e STAAKS (1994) obtiveram valores de $\mathrm{CEO}=80,0 \mathrm{mg} / \mathrm{L}$ e $\mathrm{CENO}=$ $40,0 \mathrm{mg} / \mathrm{L}$ para o fenol, portanto, similares aos da Tabela 02.

Outra forma de expressão dos dados ecotoxicológicos refere-se à estimativa da PCENO, isto é, a concentração prevista de efeito não observado conforme proposto por MAYER et. al. (1994). Segundo esses autores, o método para o cálculo da PCENO, denominado LRA (análise de regressão linear), tem como vantagem a possibilidade da utilização de dados ecotoxicológicos agudos, provenientes de testes com 96 horas de duração, para a estimativa de efeitos crônicos com peixes. Também 
está previsto o uso de dados com peixes de idades variadas, desde estágios iniciais do ciclo vital até a fase juvenil.

Partindo desses fundamentos, efetuou-se o cálculo da PCENंO de vários testes com Danio rerio para as três fases estudadas, ou seja, a embriolarval (Tabela 03), a larval (Tabela 04) e juvenil (Tabela 05).

As comparações efetuadas pelo método LRA demonstram a necessidade do prolongamento dos testes com larvas, visto que em 168 horas de exposição houve uma progressão dos efeitos letais aos organismos para o níquel, cádmio e fenol (Figura 04A). Para os jovens de Danio rerio, a maioria das substâncias produziu efeito letal até no período de 96 horas (Figura 04B), da mesma forma como verificado com os resultados analíticos calculados pela CL(I) 50 (Figura 01).

As PCENO calculadas nos testes com Danio rerio demonstram que tais estimativas de efeito crônico estão sujeitas a reduções numéricas significativas que dependem do estádio vital utilizado. Nesse sentido, o uso de organismos jovens, além do período de exposição de 96 horas, pode subestimar os efeitos crônicos a peixes.

Analisando o estudo de MAYER et al. (1994), verifica-se que com o uso da PCENO foi obtido $84 \%$ de concordância com resultados de testes crônicos prévios, isto é, variação entre resultados menores que o fator 2 , para 18 substâncias orgânicas sintéticas, principalmente agroquímicos, com sete espécies de peixes. Os referidos autores verificaram que, para os restantes $16 \%$ das estimativas, equivalentes a seis substâncias, as diferenças nas previsões variaram por fatores de 3 a 6 delimitando, assim, a imprecisão das estimativas.

Através da análise de dados mais detalhada do referido estudo (MAYER et al., 1992), verificou-se que dois dos valores imprecisos, os quais subestimaram os efeitos crônicos, foram baseados em testes ecotoxicológicos com trutas jovens ou adultas. 
Tal fato sugere que as imprecisões observadas podem estar associadas à idade dos peixes, aspecto este não analisado no estudo citado.

$\mathrm{Na}$ presente pesquisa, onde foram utilizadas substâncias com características diferenciadas, principalmente metais, verifica-se que as diferenças entre as PCENO podem variar do fator $>2$ até 400 vezes, dependendo da fase mais sensível do ciclo vital, no caso quase que invariavelmente a fase larval. Desse modo, considerando somente os resultados obtidos para larvas e jovens de Danio rerio, as variações das PCENO foram maiores que o fator dois para $54 \%$ das substâncias, isto é, para seis dos onze agentes químicos analisados.

Diante dessas constatações, a estimativa da PCENO parece apropriada para estimar efeitos crônicos, com base em testes de curta duração. No entanto, para evitar imprecisões nas estimativas, que são concernentes à escolha da idade dos peixes e ao tempo de exposição utilizado, é recomendável o uso de larvas em experimentos de 168 horas para a geração de dados analíticos.

Os resultados analíticos dos testes crônicos de curta duração demonstram que, independentemente dos métodos estatísticos utilizados, o estádio larval de Danio rerio apresenta-se mais sensivel para estimar efeitos crônicos, particularmente para o cobre, cádmio, cromo, níquel e fenol. Essa evidência, comprovada por experimentos independentes quanto à idade dos organismos, confirma aquelas levantadas nos estudos clássicos de MCKIM (1977) e SUTER et al. (1987), os quais chegaram a conclusões semelhantes em experimentos com sucessão de fases do ciclo de vida de outras espécies de peixes. Outro aspecto que merece destaque é a conveniência de executar o teste crônico em periodo de exposição de 168 horas. 


\subsection{Precisão analítica dos testes crônicos}

Os testes ecotoxicológicos crônicos de curta duração têm demonstrado, em vários países, grande utilidade tanto em ações de controle de fontes pontuais de poluição, tal como os efluentes líquidos, e também no processo de registro de produtos agroquímicos. Tendo em vista tais finalidades, é necessário que se disponha de testes ecotoxicológicos que possuam a precisão analítica conhecida, sendo que desse modo estará disponível uma das informações sobre o grau de incerteza no estabelecimento de padrões de qualidade ambiental.

Usualmente, a precisão analítica de testes ecotoxicológicos é calculada levando-se em consideração o critério de avaliação e o nível do efeito pré-determinado, por exemplo a concentração letal mediana $50 \%$ (CL50). Na presente pesquisa, com a finalidade de calcular os coeficientes de variação (C.V.), os resultados dos testes crônicos foram expressos de acordo com os níveis de efeito apropriados a cada método de cálculo.

Particularmente com o método ICp que, embora permita calcular a CL(I) para qualquer nível de efeito entre 0 e $100 \%$, optou-se pelo cálculo da CL(I) $5 ; 168 \mathrm{~h}$ pois, segundo DENTON e NORBERG-KING (1996), o nível de 5\% é o mínimo para ser usado em tal método. Dessa forma, tornam-se razoavelmente comparáveis os coeficientes de variação calculados com os resultados dos diferentes métodos estatísticos utilizados.

Tendo em vista a sugestão de MAYER et al. (1994) quanto à utilização de testes ecotoxicológicos com peixes em períodos de 96 horas de duração, torna-se oportuno conhecer a variabilidade analítica do teste crônico efetuado em períodos de exposição diferentes.

Utilizando o método LRA, verificou-se que os valores da PCENO para larvas foram, em geral, mais variáveis no período de 96 horas de exposição (Figura 07), 
particularmente nos testes com o cádmio, zinco, fenol e $\mathrm{NaCl}$. Quanto ao período de 168 horas, ocorreu um expressivo aumento do coeficiente de variação somente para o níquel (Figura 07). Resultados semelhantes foram obtidos por ADELMAN e SMITH (1976), em experimentos de toxicidade aguda com os peixes Pimephales promelas e Carassius auratus, nos quais, para a maioria das substâncias, os coeficientes de variação foram mais elevados no menor período de exposição.

Em termos práticos, a diferença numérica dos coeficientes de variação (C.V.) pode indicar que os organismos não respondem uniformemente aos efeitos tóxicos no período de tempo em que foram detectados os maiores coeficientes. Por outro lado, as diferenças na variabilidade dos resultados, nos diferentes períodos de exposição, podem ter sido ocasionadas por uma tendência estatística do método LRA. Tal possibilidade refere-se ao modo como são calculadas as PCENO, ou seja, através de extrapolação da concentração que causa $0,01 \%$ de efeito, ao invés de se restringir somente ao intervalo de concentrações onde se observa efeitos tóxicos mensuráveis. Sob o ponto de vista dos períodos de tempo estudados, independentemente dos fatores que justificam a variabilidade observada, os testes com Danio rerio em períodos de exposição de 168 horas demonstram ser os mais indicados, pois apresentam coeficientes de variação mais reduzidos.

Outro aspecto analisado, quanto aos testes crônicos com Danio rerio, refere-se à precisão analítica dos resultados utilizando-se embriões e larvas, no período de exposição apropriado, no caso 168 horas, conforme já discutido anteriormente. Além disso, é necessário avaliar a precisão analítica dos resultados gerados com os diferentes métodos estatísticos utilizados, uma vez que os mesmos expressam em um valor único os dados brutos do teste de toxicidade.

Os resultados apresentados na Figura 08A mostram que, tanto com o método LRA como com o ICp, os coeficientes de variação foram elevados nos testes com embriões. A elevada variabilidade nos testes embriolarvais com o cromo ( $\mathrm{CV}=77 \mathrm{e}$ $137 \%$ ), conforme consta nas Tabelas 03 e 06 , pode ser notada pela comparação com 
os estudos de DAVE et al. (1987) em testes embriolarvais com Danio rerio. Os referidos autores obtiveram $\mathrm{C} . \mathrm{V} .=26 \%$ em testes com o cromo, embora o tempo de exposição dos organismos (13 dias) certamente tenha contribuído para uma uniformização do efeito tóxico e, conseqüentemente, para o baixo coeficiente de variação. Em relação ao trabalho de DAVE et al. (1987), os coeficientes de variação dos testes com zinco também foram elevados, de 84 e $39 \%$ (Tabelas 03 e 06), sendo que os referidos autores determinaram C.V. $=23 \%$ em experimentos de 14 dias.

A comparação dos coeficientes de variação dos testes embriolarvais com pesquisas efetuadas com Pimephales promelas, nos mesmos períodos de exposição e estádio larval, demonstram resultados mais concordantes. Através de estimativas do trabalho de BIRGE et al. (1985), foi obtido coeficiente de variação de $62 \%$ para as CL1\% com o cádmio, valor este bem menor que o de $125 \%$ determinado com o método LRA (Tabela 03), porém, acima do C.V. $=29 \%$ calculado pelo método ICp (Tabela 06). PICKERING (1988) obteve C.V. $=36 \%$ em testes embriolarvais de oito dias com DSS, portanto muito próximo aos coeficientes de variação do presente estudo $(42 \%)$ com resultados calculados por ambos os métodos estatísticos.

Em termos ecotoxicológicos, os coeficientes de variação elevados nos testes embriolarvais, especialmente para o cobre e cromo, estão relacionados com a oscilação natural no tempo de eclosão das larvas durante a fase embriolarval, conforme observado durante os experimentos. Desse modo, em testes distintos, os organismos podem ter sofrido efeitos tóxicos diretos em diferentes intervalos de tempo, efeitos estes que variaram em função da proteção temporária do córion durante parte desta fase do ciclo vital. Aparentemente, comparando com os estudos de DAVE et al. (1987), o tempo de exposição dos testes embriolarvais no presente estudo com Danio rerio, de sete dias, é insuficiente para a obtenção de uma variabilidade aceitável.

Quanto à variabilidade analítica nos testes com larvas, a Figura 08B demonstra que os coeficientes de variação foram mais uniformes, embora relativamente altos para 
algumas substâncias. Em testes crônicos com larvas de Pimephales promelas, NORBERG-KING (1989) encontrou coeficientes de variação de 3,5 e 49\% para cromo e zinco, respectivamente. Os coeficientes dos testes larvais com Danio rerio são bem mais elevados para o cromo, sendo de $75 \%$ para os resultados dos cálculos com o método LRA (Tabela 04) e de 59\% para os resultados do ICp (Tabela 07). Para os testes com zinco, o C.V. $=17 \%$, oriundo do método LRA, foi bem mais baixo do que o esperado, enquanto que com o método ICp o coeficiente de variação de $44 \%$ foi similar àquele descrito para Pimephales promelas.

Com relação ao DSS, PICKERING (1988) obteve coeficientes de variação de $23 \%$ em testes crônicos larvais com Pimephales promelas, enquanto na presente pesquisa os coeficientes foram de 51 e $43 \%$ para os cálculos por LRA e ICp respectivamente, portanto razoavelmente mais elevados. Quanto ao cobre, MORRISON et al. (1989) encontraram, para as CL50 determinadas em testes larvais com os peixes marinhos Cyprinodon variegatus e Menidia beryllina, coeficientes de variação iguais a 21,7 e $33,2 \%$ respectivamente, sendo estes próximos aos C.V. $=35 \%($ Tabela 04$)$ e C.V. $=$ $48 \%$ (Tabela 07) nos testes com Danio rerio.

No que se refere aos métodos utilizados para expressar os resultados dos testes crônicos de curta duração, e consequentemente para o cálculo dos coeficientes de variação, são necessárias algumas considerações. Como pode ser observado na Figura 08, os resultados calculados pelo método LRA apresentaram, na maioria dos casos, coeficientes maiores do que os calculados pelo método ICp. Com base nos aspectos já discutidos, é suposto que os elevados coeficientes de variação obtidos com o método LRA, bem como aqueles mais reduzidos, estejam influenciados por tendências analíticas inerentes a esse método.

Mais especificamente, conforme já mencionado, notou-se que o fato do método LRA se basear em extrapolações dos dados, ao invés de interpolações, pode ter super ou subestimado os valores de PCENO em certos casos. Deste modo, é razoável supor 
que parte da variabilidade encontrada nos resultados dos testes com Danio rerio seja devida, exclusivamente, ao método de cálculo LRA.

Embora os coeficientes de variação nos testes crônicos com larvas de Danio rerio tenham se apresentado, em termos gerais, mais elevados do que aqueles para Pimephales promelas, é importante notar que tais coeficientes foram calculados com os dados de CL(I)5. Tendo em vista que, estatisticamente, as respostas dos organismos abaixo do nivel de efeito de $16 \%$ são mais variáveis (correspondentes à menos 1 desvio-padrão da mediana), é de se esperar que os coeficientes de variação das CL(I)5 sejam mais elevados do que aqueles de estudos que utilizaram a CL50 ou Valor Crônico. Esta expectativa é comprovada quando se compara os dados de variabilidade dos testes agudos (Tabela 01) e dos crônicos (Tabela 07) com larvas, sendo possivel observar que os coeficientes de variação da CL(I)50 são sempre iguais ou bem menores do que os coeficientes das CL(I)5.

Considerando que as larvas de Danio rerio apresentam maior sensibilidade que os embriões e jovens e, ainda, que a variabilidade dos resultados analíticos com larvas demonstra uma maior uniformidade, torna-se pertinente aprofundar a análise da precisão dos testes crônicos de curta duração com esta fase do ciclo vital. Nesse sentido, CHAPMAN, G.A. et al. (1996) enfatizaram a necessidade de examinar os coeficientes de variação para os níveis de efeito de interesse.

Com a finalidade de escolher os coeficientes de variação adequados, a seleção dos níveis de efeito na sobrevivência das larvas de Danio rerio foi baseada nos rotineiramente utilizados ( 25 e $1 \%$ ), bem como naqueles de uso eventual (15 e 5\%). Para aferir os coeficientes de variação dos resultados calculados pelo método nãoparamétrico ICp, foi utilizado o método paramétrico dos Probitos que, segundo BAIRD et al. (1996), pode ser descrito por uma função matemática relacionada com a curva normal. O método LRA não pôde ser utilizado nessa análise pois o mesmo é restrito ao cálculo da CL(I) $0,01 \%$. 
Na Figura 09 foi demonstrado que o nível de efeito $1 \%$ é o mais variável quanto à precisão dos resultados dos testes de toxicidade, tanto pelo método ICp quanto dos Probitos, sendo por este motivo não recomendável para o uso. Os demais níveis de efeito foram relativamente menos variáveis, porém as diferenças da variação entre eles foram dependentes do agente químico empregado.

Para uma análise mais objetiva, com a finalidade de reduzir a relatividade dos dados, foi adotado o coeficiente $<40 \%$ como critério para definição do nivel mais apropriado para os testes crônicos com o Danio rerio. Tal critério foi baseado em estudos de precisão analítica (ENVIRONMENT CANADA, 1990; PARKHURST et al., 1992; BAIRD et al., 1996; MOORE et al., 2000) que indicam coeficientes de variação menores do que 30 ou $40 \%$ como aqueles normalmente obtidos em testes ecotoxicológicos.

Analisando os dados da Figura 09A, verifica-se a freqüência de coeficientes de variação $<40 \%$ em $54 \%$ dos casos para o nível de efeito $25 \%$, enquanto para o nível de efeito $15 \%$ e $5 \%$ a frequêencia foi de 45 e $27 \%$ respectivamente. Do mesmo modo, para os dados do método Probitos (Figura 09B), a maior freqüência de $\mathrm{CV}<40 \%$ ocorreu no nivel de efeito $15 \%$ (67\% dos casos), ao passo que para o nivel de efeito $5 \%$ a ocorrência foi um pouco mais baixa ( $55 \%$ dos casos). Para os coeficiente de variação calculados com o método dos Probitos é importante notar, também, que o nível de efeito $15 \%$ sempre foi, relativamente, mais baixo que o nível $5 \%$, com exceção para os testes com fenol.

Outro aspecto que merece considerações refere-se à comparação dos coeficientes de variação, entre os diferentes métodos estatísticos, dentro do nível de efeito apropriado para os testes com Danio rerio. Assim, a Figura 10 mostra que, além da elevada variabilidade dos resultados calculados pelo método LRA, no nível de $15 \%$ de efeito na sobrevivência tanto o método ICp como o Probitos apresentaram coeficientes de variação menores e similares de acordo com os agentes químicos analisados. 
Com relação ao conjunto de dados, na Figura 10 constata-se que os menores coeficientes de variação foram coincidentes para várias das substâncias, dentre elas o cobre, fenol e $\mathrm{NaCl}$. Esses agentes químicos demonstraram ser as substâncias de referência para futuros testes de toxicidade crônica com Danio rerio, do mesmo modo que tais substâncias são sugeridas pelo ENVIRONMENT CANADA (1990). Este documento também sugere que para o cádmio, cromo e prata é esperada uma maior variabilidade dos dados analíticos, em função do comportamento instável desses metais em soluções aquosas, fato que justifica os elevados C.V. com esses metais (Figura 10).

Ainda, de forma geral, verificou-se que a média dos coeficientes de variação para todos os agentes químicos analisados foi de $50 \%$ com os resultados calculados pelo método LRA (Tabela 04). No entanto, com base no nível de efeito $15 \%$, foi possível constatar que a média dos coeficientes de variação de todas as substâncias testadas, com larvas (Tabelas 07 e 08 ), foi de $38 \%$ tanto com os resultados do método ICp como para os do Probitos. Esse resultado é semelhante ao encontrado por BAIRD et al. (1996), os quais determinaram o coeficiente de variação igual a 35\% para o nível de efeito igual a $20 \%$ na sobrevivência de larvas de Pimephales promelas com várias substâncias.

Diante dessas evidências, utilizando tanto o método ICp como o dos Probitos, os niveis de efeito 25 ou $15 \%$ demonstram ser os mais apropriados para caracterizar a variabilidade de resultados dos testes crônicos com a sobrevivência de larvas de Danio rerio. 


\subsection{Considerações sobre os diferentes métodos estatísticos}

Atualmente, existe o consenso de que a análise estatística dos dados de testes ecotoxicológicos crônicos deve ser efetuada por métodos que evitem a ocorrência de falsos positivos ou negativos. Em outras palavras, o que se pretende evitar é a aceitação de que existe um efeito tóxico estatisticamente significativo enquanto biologicamente tal efeito pode não estar ocorrendo, e vice-versa, devido ao desenho experimental dos testes. As características mencionadas são aquelas pertinentes ao teste de hipóteses, no qual está inclusa a análise de variância, procedimento este que tem sido, quase que exclusivamente, utilizado na interpretação de testes ecotoxicológicos crônicos.

Embora STEPHAN e ROGERS (1985) tenham alertado quanto às inconveniências do teste de hipóteses, somente na década de 90 , devido ao uso crescente das análises ecotoxicológicas, intensificaram-se suas criticas (CHAPMAN, P.M. et al. 1996; BAIlER e ORIS, 1999), os estudos para aprimorá-lo (ORIS e BAIlER, 1993; ERICKSON e McDONALD, 1995; CHAPMAN, G.A. et al., 1996; THURSBY et al., 1997) e, ainda, sugestões para substituí-lo (BRUCE e VERSTEEG, 1992; HOEKSTRA e VanEWIJK, 1993; MOORE e CAUX, 1997; BAILER e ORIS, 1997).

\subsubsection{Uso e estimativas do teste de hipóteses}

A principal dificuldade em substituir o teste de hipóteses, utilizados em testes ecotoxicológicos, reside no desconhecimento do nível de efeito adverso, em uma população, que seja ecologicamente significativo. Devido à inexistência de estudos com esse objetivo, dada a complexidade envolvida, DENTON e NORBERG-KING (1996) sugeriram o uso da diferença mínima significativa (DMS, em \%), proveniente de teste de hipóteses, para o estabelecimento do nivel de efeito tóxico com significância biológica, mais propriamente "significância prática", segundo esses autores. 
Nesse sentido, CHAPMAN, G.A. et al. (1996) recomendaram a utilização de valores críticos da DMS (diferença mínima significativa, em \%), com base no $75^{\circ}$ percentil de série de testes (isto é, $75 \%$ das DMS menores que um determinado valor), para os métodos ecotoxicológicos já estabelecidos. Segundo esses autores, e também DENTON e NORBERG-KING (1996), o valor crítico da DMS pode ser usado tanto no teste de hipóteses como para a estimativa do nível de efeito em regressões e, ainda, no teste de bioequivalência descrito por ERICKSON e McDONALD (1995).

Seguindo essas recomendações, o valor crítico da DMS nos testes de hipóteses (Tabela 02), para $075^{\circ}$ percentil, foi igual a $17 \%$ para 41 dos testes com a fase embriolarval, e de $15 \%$ para 43 dos testes crônicos com a fase larval de Danio rerio. Tendo em vista a conveniência demonstrada quanto ao uso dos testes com larvas (itens 5.2 e 5.3), verifica-se que o nivel de efeito tóxico igual a $15 \%$ é o mais apropriado para expressar os resultados de testes, para esse estádio vital, calculados por modelos de regressão (no caso a CL(I)15) ou testes de hipóteses modificados.

Torna-se importante ressaltar que o valor crítico da DMS determinado, no presente estudo, é bastante expressivo, visto que o mesmo foi originário de testes crônicos com onze substâncias diferentes. Na pesquisa desenvolvida por DENTON e NORBERG-KING (1996), resultado semelhante foi obtido (DMS=16\%) para testes crônicos baseados na sobrevivência de Pimephales promelas; no entanto, foi utilizado, exclusivamente, o cloreto de sódio.

Apesar das críticas essencialmente teóricas aos testes de hipóteses, na Figura 11 nota-se que, considerando a sobrevivência das larvas de Danio rerio, os resultados obtidos pelo referido método (Valor Crônico) foram praticamente os mesmos em relação aos calculados pelos outros métodos estatísticos. Deve ser ressaltado que os Valores Crônicos (média geométrica entre a CEO e a CENO) foram próximos aos da CENO (concentração de efeito não observado), a qual é o alvo das criticas de vários pesquisadores. Deste modo, as comparações entre os Valores Crônicos e as CL(I)15 
e PCENO ainda são válidas, indicando de forma geral que, mesmo com onze substâncias diferentes, os resultados dos testes ecotoxicológicos são semelhantes.

Quanto ao teste de hipóteses, vale mencionar que alguns ensaios poderiam ser desconsiderados em função da DMS crítica. Assim, onze experimentos constantes na Tabela 02 , os quais apresentaram DMS $>15 \%$, apesar de não expressarem valores discrepantes dos outros resultados, deveriam ser retestados devido somente a essa exigência estatística. Tal fato torna-se indesejável quando se pretende utilizar, rotineiramente, testes de toxicidade crônica com amostras que apresentam tempo de validade restrito, além de dificuldades em recoletas.

\subsubsection{Estimativas de efeito pelo método LRA}

Na Figura 11 verificou-se que as PCENO com o cádmio, zinco e cromo foram entre 5 a 12 vezes mais baixas em relação aos outros métodos de cálculo. Embora as PCENO, para esses metais, tenham sido mais precisas na previsão dos Valores Crônicos para o ciclo de vida parcial de peixes (Tabela 11), as mesmas não demonstraram o mesmo padrão para as demais substâncias. Desse modo, o método LRA parece restrito para a estimativa de efeitos tóxicos de determinados metais, sendo que para os demais agentes químicos tal método produz os mesmos resultados do teste de hipóteses (Análise de variância), do ICp e dos Probitos.

Tendo em vista sua especificidade, o método LRA demonstra ser limitado quanto ao uso rotineiro pois, dependendo do agente químico, está sujeito a tendências que podem distorcer os resultados analíticos de testes de toxicidade crônica de curta duração com peixes, especialmente com misturas de substâncias, tal como efluentes líquidos. Um outro exemplo de distorção, detectada no método LRA, foi observada nas Tabelas 04 e 05, onde as PCENO de alguns testes foram menores em 96 horas do que em 168 horas. Essas distorções, embora pouco significativas, demonstram que a 
extrapolação dos dados podem produzir resultados ilógicos, os quais são dependentes do modelo de regressão utilizado no método LRA.

Os dados apresentados sugerem que o método LRA é apropriado, quase que exclusivamente, para expressar e prever os resultados de testes crônicos com substâncias orgânicas sintéticas, conforme demonstrado por MAYER et al. (1994). Esses autores verificaram que $84 \%$ das estimativas de PCENO foram semelhantes (menor que o fator dois) aos valores de toxicidade crônica compreendidos entre a CEO e a CENO para várias espécies de peixes. No presente estudo, comparando-se os dados das Tabelas 04 e 11, e adotando-se o mesmo critério de MAYER et al. (1994), a concordância entre os resultados foi de apenas $40 \%$.

Outro aspecto que merece considerações refere-se aos intervalos de confiança dos testes efetuados. Em termos ecotoxicológicos, tais intervalos indicam, com probabilidade de $95 \%$, a faixa onde pode ser encontrada a estimativa resultante dos dados experimentais. Como conseqüência desse conceito, CHAPMAN, G.A. et al (1996) admitem o uso do intervalo de confiança como medida de dispersão aceitável em estimativas de impacto de efluentes líquidos. Desse modo, para modelos de regressão, espera-se que a amplitude do intervalo de confiança seja limitada a valores próximos da estimativa pontual (por exemplo, CL(I)15), fato que indica a adequação do método estatístico utilizado.

Nesse sentido, foi possivel observar que, com o método LRA, os intervalos de confiança das PCENO foram muito amplos, tanto nos testes com embriões (Tabela 03 ) como naqueles com larvas (Tabela 04). Tomando como base o limite superior dos intervalos nos testes com larvas (Tabela 04), verifica-se que, em média, estes foram $745 \%$ maiores do que as PCENO. Deve-se notar que, no cálculo dessa média, não foram inclusos os limites dos intervalos de confiança dos testes $n^{\circ} 1$ com cádmio e n. $^{\circ} 3 \mathrm{com}$ niquel ( $259 \times 10^{3}$ e $17,5 \times 10^{3} \%$ maiores, respectivamente), os quais se evidenciaram irreais. 
Utilizando o mesmo procedimento para o cálculo da média dos intervalos nos métodos ICp (Tabela 07) e Probitos (Tabela 08), 26 e 24\% respectivamente, é possivel notar a discrepância dos intervalos de confiança produzidos pelo método LRA.

Ao que parece, os amplos intervalos de confiança do método LRA são causados pelo baixo nível de efeito medido na sobrevivência $(0,01 \%)$ e, ainda, pela extrapolação dos valores de PCENO além da faixa de concentrações experimentais. Essa afirmação é plausível pois, segundo MOORE e CAUX (1997), modelos de regressão produzem intervalos de confiança excessivamente grandes para níveis de efeitos menores do que $5 \%$ e, também, quando o nível de efeito é resultante de extrapolações de dados.

\subsubsection{Estimativas de efeitos pelos métodos ICp e Probitos}

O método não paramétrico $\mathrm{ICp}$, embora elaborado para respostas baseadas em contagens (por exemplo, número total de jovens produzidos) ou contínuas (crescimento), mostrou-se apropriado para respostas dicotômicas tal como a sobrevivência do Danio rerio. Na Figura 11, verifica-se que as CL(I) $15 ; 168 \mathrm{~h}$ foram praticamente idênticas quando se comparou os resultados dos testes calculados pelo método ICp (Tabela 07) e dos Probitos (Tabela 08).

No presente estudo, o método dos Probitos foi utilizado como referencial na comparação, uma vez que é baseado em uma função matemática relacionada com a curva normal (BAIRD et al. 1996). Apesar de possuir essa característica, o método dos Probitos não permitiu o cálculo de resultados de quatro testes com prata e de alguns testes com $\mathrm{N}-\mathrm{NH}_{3}, \mathrm{NaCl}$ e DSS (Tabela 08), fato não ocorrido com o método ICp (Tabela 07). Essa eventual limitação do método dos Probitos é bem conhecida no campo da Ecotoxicologia, em especial para testes que não possuem ao menos 
dois níveis de efeito intermediários, sendo que tal acontecimento é bastante freqüente em testes de toxicidade.

Além das CL(I) $15 ; 168 \mathrm{~h}$, os intervalos de confiança dos dois métodos foram bastante semelhantes, quando foram comparados os testes que possibilitaram o cálculo em ambos (Figura 12). Tomando como base o limite superior dos intervalos de confiança nos testes com larvas verificou-se que, em média, tais intervalos foram $26 \%$ maiores do que as CL(I) $15 ; 168 \mathrm{~h}$ nos cálculos com o ICp, e $24 \%$ maiores nos cálculos com o método dos Probitos. Embora, estatisticamente, não seja possível estabelecer um tamanho ideal para o intervalo de confiança, essa variação determinada é semelhante àquela normalmente encontrada em testes de toxicidade com organismos aquáticos.

Outro aspecto analisado refere-se ao uso de réplicas nos testes de toxicidade crônica, de curta duração, com Danio rerio. Para o aproveitamento dos dados em testes crônicos com peixes, independentemente da análise estatistica utilizada, é recomendado o uso de, no mínimo, quatro réplicas por tratamento experimental (WEBER et al., 1988). Tal requisito é pertinente quando se emprega o teste de hipóteses para a análise dos dados, sendo que para os modelos de regressão o número de réplicas não é tão crítico.

Considerando que para o método ICp são necessárias ao menos duas réplicas por tratamento, no presente estudo foi sorteada essa quantidade de réplicas, dentre as quatro utilizadas em todos os testes com larvas. Desse modo, utilizando somente duas réplicas, foram recalculadas as CL(I)15 com o método ICp (Tabela 09). A comparação das $\mathrm{CL}(\mathrm{I}) 15$, na Figura 13, mostra que os resultados dos testes com quatro e duas réplicas não apresentaram diferenças significativas (Teste $t, \alpha=0,05$ ). $\mathrm{Na}$ Figura 13, é possivel observar que os intervalos de confiança também foram muito semelhantes. 
Como conseqüência da semelhança dos resultados, os coeficientes de variação das CL(I) 15 nos testes larvais com tratamentos em duplicata (Tabela 09) foram bastante próximos aos experimentos com quadruplicatas (Tabela 07). Em termos práticos, essas constatações indicam que, mesmo que haja perda de réplicas devido a problemas operacionais durante os testes, os resultados analíticos com a sobrevivência de Danio rerio são confiáveis, mesmo com apenas duas réplicas por tratamento

Algumas das críticas ao método ICp têm sido sua dependência de dados monotônicos decrescentes e da linearidade das concentrações adjacentes (CHAPMAN G.A. et al., 1996 e BAILER et al., 2000). Na prática, violações a essas exigências estatísticas podem produzir estimativas tendenciosas das CL(I), particularmente quando ocorre "hormesis" (estimulação na resposta dos organismos, que ocorre em baixas concentrações de exposição). Usualmente, a "hormesis" é freqüente em testes crônicos com a reprodução do cladócero Ceriodaphnia dubia (BAILER e ORIS, 1999).

Nos experimentos com Danio rerio não foi verificada qualquer ocorrência de "hormesis", fato de certa forma esperado para respostas dicotômicas que, por sua natureza, são menos variáveis e raramente não monotônicas. Desse modo, o método ICp parece compativel para expressar efeitos na sobrevivência em testes crônicos com peixes.

As comparações entres os métodos ICp e dos Probitos concordam com a suposição de CHAPMAN G.A. et al. (1996), os quais afirmaram que as estimativas de efeito provavelmente são similares entre uma série de modelos adequados, especialmente se o nivel de efeito é maior do que $15 \%$.

Em testes ecotoxicológicos, com o uso de modelos paramétricos, MOORE e CAUX (1997) demonstraram que as estimativas pontuais de efeito tóxico podem se tornar dependentes dos modelos utilizados somente quando o nivel de efeito for menor que 
$10 \%$. Esses autores também argumentaram que, independentemente do tipo de resposta dos organismos (dicotômica ou contínua), os modelos genéricos de regressão fornecem estimativas razoáveis de efeitos tóxicos, particularmente quando essas estimativas são resultantes de interpolações, como no caso das CL(I) 15 calculadas pelo método ICp.

Com base nos resultados obtidos, dentre os modelos de regressão estudados, o método ICp é o mais apropriado para o cálculo da CL(I) em testes ecotoxicológicos, de curta duração, com a sobrevivência de larvas de Danio rerio.

\subsection{Correlações ecotoxicológicas entre $D$. rerio e $P$. promelas}

Como pôde ser observado nos itens anteriores, a CL(I) 15 demonstrou ser a melhor forma de expressão dos resultados de testes crônicos de curta duração, com larvas de Danio rerio, tanto estatisticamente como quanto à precisão analítica.

No entanto, as médias das CL(I) $15 ; 168 \mathrm{~h}$ em testes com Danio rerio (Tabela 07) apresentaram-se duas a 56 vezes mais elevadas em relação aos Valores Crônicos (VC) dos testes de duração prolongada ( $\geq 28$ dias) com Pimephales promelas (Tabela 11). Em termos ecotoxicológicos, isso significa que, tomando Pimephales promelas como espécie de referência, os testes com Danio rerio não seriam apropriados para estimar efeitos crônicos a peixes. Na prática, seria de se esperar que, para vários agentes químicos, concentrações abaixo das CL(I)15 para Danio rerio ainda causassem efeitos tóxicos significativos para outras espécies de peixes.

Teoricamente, a menor sensibilidade de Danio rerio estaria associada ao reduzido período de exposição (sete dias) nos testes de toxicidade efetuados ou, ainda, à uma caracteristica fisiológica de Pimephales promelas. Desse modo, torna-se conveniente abordar ambos os aspectos separadamente. 


\subsubsection{Relação de sensibilidade entre as duas espécies de peixe}

Quanto à diferença de sensibilidade entre as duas espécies, em relação à sobrevivência, nas Figuras 14 a 16 é possivel notar que Pimephales promelas mostrase ligeiramente mais sensivel do que Danio rerio. Através dessas figuras observa-se que, para as substâncias mais tóxicas à Pimephales promelas, em média a diferença de sensibilidade foi ao redor de 2,5 vezes, independentemente da fase do ciclo vital e do tempo de exposição. Nesse sentido, deve ser mencionado que ocorreram exceções na sensibilidade de Pimephales promelas com o zinco ( $>15$ vezes), tanto para adultos como para larvas, e com o niquel para larvas em 96 horas (sete vezes).

Nas Figuras 14 a 16, também é demonstrada a excelente correlação entre as CL(I)50 com as duas espécies de peixes, em experimentos de curta duração. Os coeficientes de determinação evidenciam que as equações estabelecidas podem fornecer boas estimativas de efeitos, na sobrevivência de Danio rerio, em função dos resultados de testes com Pimephales promelas.

Deve-se ressaltar que as expressivas correlações obtidas foram influenciadas pelas condições experimentais semelhantes. A esse respeito, embora a dureza das águas tenha sido diferenciada nos testes com Pimephales promelas frente ao cádmio, cobre, cromo e $\mathrm{N}^{-\mathrm{NH}_{3}}$ (Tabelas 10 e 11), essa variável pouco influenciou nas comparações. A suposta baixa interferência da dureza da água, nos resultados analíticos, é devida às propriedades do agente químico (cromo e $\mathrm{N}_{-} \mathrm{NH}_{3}$ ) ou, ainda, às irrelevantes diferenças esperadas (para o cádmio e cobre) com a água utilizada nos testes com Danio rerio.

A semelhança na sensibilidade dessas duas espécies de peixe, ambas da família Cyprinidae, é um fato esperado no que se refere aos efeitos tóxicos na sobrevivência. STEPHAN et al. (1983), quando estabeleceram critérios numéricos de qualidade de águas para proteção da vida aquática, afirmaram que, em média, espécies de 
organismos dentro de famílias são toxicologicamente muito mais semelhantes do que entre familias diferentes.

Em outros estudos LEBLANC (1984) e SUTER et al. (1985) demonstraram que, com ampla base de dados de toxicidade aguda, as correlações entre as espécies declinam com o aumento da distância taxonômica. Esses últimos autores também evidenciaram que o coeficiente de determinação para gêneros dentro de famílias $\left(r^{2}=0,89\right)$ foi similar àquele para espécies dentro de gêneros $\left(r^{2}=0,90\right)$.

Apesar da sensibilidade comparável quanto à sobrevivência, tal critério de avaliação de efeito crônico com larvas de Danio rerio, expresso em CL(I)15 em testes de curta duração, ainda permanece insuficiente para estimar efeitos crônicos de longa duração para Pimephales promelas. Do mesmo modo, as $\mathrm{CL}(\mathrm{I}) 15 ; 168 \mathrm{~h}$ com larvas de Danio rerio (Tabela 07) mostram-se insuficientes para expressar os efeitos crônicos, com base no crescimento de Pimephales promelas, em curtos períodos de exposição como 168 horas (Tabela 11).

\subsubsection{Característica toxicológica em testes com Pimephales promelas}

A essa altura, convém destacar a relação existente entre os resultados dos testes crônicos de longa e curta duração com o Pimephales promelas (Tabela 11), sendo que tal relação justifica o uso de testes de curta duração, segundo NORBERG e MOUNT (1985) e NORBERG-KING (1989). Assim, com a referida espécie, nos testes com 168 horas de exposição o crescimento larval foi o critério mais sensivel para avaliar os efeitos do cádmio, cobre, cromo e prata. Por outro lado, nos testes com duração maior ou igual a 28 dias, para as mesmas substâncias, o critério mais sensivel foi a sobrevivência de jovens. Desse modo, embora o efeito tóxico tenha se manifestado com diferentes respostas dos organismos, sua intensidade permaneceu a mesma, independentemente do período de exposição. Essa característica nos testes 
com Pimephales promelas foi também observada no estudo de NORBERG-KING (1989) com as substâncias orgânicas diazinon e carbaryl.

Aparentemente, diante dessa evidência, o crescimento larval (medido através da massa) sofre efeitos adversos momentâneos durante as fases iniciais do ciclo vital, caso contrário continuaria a ser o critério mais sensível após 28 dias. Alguns estudos indicam a ocorrência de efeitos temporários de agentes químicos no crescimento de peixes.

BARRON e ADELMAN (1985) demonstraram que o cianeto retardou, temporariamente, o crescimento de larvas de Pimephales promelas até 48 horas de exposição. Em outro estudo, os mesmos autores observaram que em 96 horas de exposição a concentração de $19,0 \mu \mathrm{g} \mathrm{HCN} / \mathrm{L}$ reduziu o crescimento, enquanto que após 30 dias o crescimento foi reduzido apenas em $47,0 \mu \mathrm{g} \mathrm{HCN} / \mathrm{L}$.

PICKERING (1980) verificou que o crescimento de jovens de Pimephales promelas, expresso em massa dos organismos, foi significativamente reduzido em algumas concentrações de cromo durante nove semanas de exposição, sendo que após esse período os peixes apresentaram massa corpórea semelhante àqueles do controle experimental. O mesmo autor citou ocorrência similar em testes com trutas. Nesse sentido, LELAND e KUWABARA (1985) atribuiram a redução temporária no crescimento de trutas ao efeito inicial do cobre e zinco sobre o apetite desses peixes.

BURTON et al. (1996) alertaram para o fato de que o alimento pode agir como substrato para absorção de agentes químicos, alterando deste modo a exposição dos organismos àqueles agentes. BENOIT et al. (1982) enfatizaram que a existência de métodos padronizados de alimentação dos peixes poderia assegurar que a diferença na massa dos organismos, entre o controle experimental e as concentrações-teste, não fosse causada pela técnica de alimentação. 
Embora tenham controlado a quantidade de alimento fornecido, ARTHUR e DIXON (1994), em estudo com pentaclorofenol e 2,4,5-triclorofenol, evidenciaram que o crescimento de Pimephales promelas é influenciado pela densidade de peixes em testes com 28 dias de exposição. Esses autores observaram que, quanto menor a densidade maior é a redução na massa corpórea dos peixes, sendo que não foi possivel ser demonstrada a interrelação entre a absorção dos agentes químicos e a densidade. Além disso, a alta variabilidade da massa individual dos peixes, em testes com densidade elevada, foi suspeita de reduzir a capacidade da análise estatística em detectar efeitos significativos no crescimento.

As pesquisas mencionadas sugerem que o crescimento, nas fases iniciais do ciclo de vida de Pimephales promelas, está sujeito a interferentes analíticos, sendo que tal fato poderia justificar a coincidência de resultados com a sobrevivência dos peixes em períodos superiores a 28 dias de exposição (Tabela 11). No entanto, embora possam ocorrer interferências, os dados da Tabela 11 demonstram que o crescimento de larvas é, ao menos, um excelente estimador de efeitos tóxicos para períodos de exposição prolongados.

Outros estudos efetuados confirmam que o crescimento larval de Pimephales promelas é bastante afetado em testes crônicos de curta duração. NORBERG-KING (1989) constatou que em $59 \%$ dos testes o crescimento foi o critério de avaliação mais sensivel, enquanto o mesmo ocorreu para a sobrevivência em apenas $11 \%$ dos ensaios

Em testes com efluentes líquidos, PICKERING (1988) observou que o crescimento larval foi a resposta mais sensivel em $60 \%$ dos experimentos efetuados. HUGHES et al. (1989). em testes de sete dias, verificaram que o crescimento de Cyprinodon variegatus foi mais sensivel para detectar efeitos crônicos em $52 \%$ dos efluentes liquidos testados, enquanto a sobrevivência foi mais afetada somente em $7 \%$ dos testes. 
Estas pesquisas indicam resultados diferentes daqueles obtidos em experimentos com duração maior do que 28 dias. Por exemplo, MAYER et al. (1986) notaram que o crescimento, de sete espécies de peixe, foi a resposta mais sensível em $36 \%$ dos 42 testes crônicos analisados, enquanto a sobrevivência foi igualmente ou mais afetada para o restante dos casos. WARD e PARRISH (1980), em experimentos de 28 dias com Cyprinodon variegatus, relataram que a sobrevivência foi mais sensível do que o crescimento em $94 \%$ dos testes. Em levantamento bibliográfico efetuado na CETESB (1986) foi verificado que a sobrevivência apresentou-se mais sensível em $46 \%$ dos 56 ensaios pesquisados, sendo que o crescimento foi mais afetado em apenas $23 \%$.

As pesquisas mencionadas permitem afirmar que os dados de ciclo de vida (Tabela 11) são coerentes quanto aos efeitos tóxicos mais pronunciados na sobrevivência de Pimephales promelas, em periodos de exposição maiores que 28 dias. Do mesmo modo, está evidenciado que o crescimento é, expressivamente, mais afetado durante as fases iniciais do ciclo vital de peixes.

\subsection{Estimativa da ecotoxicidade crônica para Danio rerio}

Considerando os efeitos tóxicos no crescimento de Pimephales promelas, em testes de curta duração, parece razoável utilizar esse critério nos experimentos com Danio rerio. Embora no presente estudo não tenha sido estimado o efeito das substâncias no crescimento de Danio rerio, especialmente devido à ausência de alimento apropriado (DAVE e XIU, 1991), é pertinente fazer extrapolações entre a sobrevivência e o crescimento com base nas características de outro ciprinídeo, tal como Pimephales promelas.

Estas extrapolações se justificam pois, além de apresentar expressivas correlações ecotoxicológicas (conforme discutido na secção 5.5.1), ambas as espécies apresentam semelhanças quanto à evolução no ciclo vital. Dentre os aspectos 
similares conhecidos pode-se citar: o tempo de desenvolvimento da fase embrionária (entre três a seis dias), o tempo para atingir a maturidade sexual (ao redor de três a quatro meses), além da capacidade de produção contínua de gametas em condições controladas de luminosidade e temperatura.

Tendo em vista a possibilidade de efetuar extrapolações de efeitos com base no crescimento, foram levantados dados bibliográficos sobre a relação numérica entre a sobrevivência e o crescimento de Pimephales promelas e, também, de Danio rerio (Tabela 12). Tais dados consistiram de 36 experimentos, com diferentes períodos de exposição, onde exclusivamente a CENO (concentração de efeito não observado) para o crescimento foi menor para aquela da sobrevivência. Portanto, os dados obtidos referem-se às concentrações de agentes químicos que não causaram efeito tóxico estatisticamente significativo.

$\mathrm{Na}$ Tabela 12 nota-se que as concentrações que não causam efeito no crescimento foram, em média, três vezes menores do que aquelas que não afetaram a sobrevivência. Da mesma forma que ocorreu para a totalidade dos dados, os testes com Pimephales promelas, em sete dias de exposição, mostram um fator igual a quatro, indicando assim o mesmo padrão dos períodos mais prolongados.

Outro aspecto que merece destaque, na Tabela 12 , refere-se ao fator 2,8 obtido nos testes com Danio rerio. Essa constatação indica a similaridade de respostas com o Pimephales promelas, embora os dados se baseiem em um número reduzido de substâncias orgânicas.

Portanto, levando-se em conta que, em testes crônicos de curta duração com ciprinideos, os efeitos no crescimento podem prever efeitos a longo prazo, o fator três ou sua reciproca $(0,3)$ parece apropriado para o uso em testes com a sobrevivência de larvas do Danio rerio. Resultado idêntico (fator 0,3 ) foi obtido por MAYER et al. (1986), em estudo com sete espécies de peixes e 28 agentes químicos diferentes daqueles que constam na Tabela 12. Esses autores concluíram, ainda, que 
o fator 0,2 pode ser aplicado a resultados de sobrevivência, em testes crônicos, com a finalidade de evitar outros efeitos tóxicos biologicamente significativos.

Aplicando o fator 0,3 às CL(I) $15 ; 168 \mathrm{~h}$ para larvas de Danio rerio (Tabela13), verifica-se que os Valores Crônicos estimados (VCest;168h) foram muito próximos aos V.C. $\geq 28$ dias para Pimephales promelas. Para a maioria dos agentes químicos a diferença entre os Valores Crônicos foi menor que o fator dois, exceto para o níquel (fator 8,1), mercúrio (fator 17), prata (fator 12) e zinco (fator 5,3). A maior resistência de Danio rerio a esses metais pode ser natural dessa espécie, visto que nos testes de toxicidade aguda (Figuras 14 e 15) a mesma tendência foi observada para o níquel, prata e zinco. Quanto ao mercúrio, é suposto que a maior sensibilidade de Pimephales promelas esteja associada ao maior período de exposição dessa espécie, de 41 semanas, no estudo de SNARKI e OLSON (1982).

VanLEEWEN et al. (1990) verificaram que, para substâncias com modo de ação específico, isto é, agentes químicos que exercem efeitos tóxicos após ativação metabólica, tal como as cloraminas, os resultados dos testes de curta duração são inadequados para prever efeitos tóxicos de longa duração, devido ao fato de apresentarem-se ao redor de uma ordem de magnitude menos tóxicos. No entanto, aplicando-se o fator 0,3 aos resultados dos testes embriolarvais em sete dias efetuados por VanLEEWEN et al. (1990), com Danio rerio e seis substâncias com modo de ação específico (anilina e cloroanilinas), verificou-se que a diferença na previsão do efeito crônico em 28 dias foi de, apenas, três vezes para cinco dos referidos agentes químicos.

Essa diferença pode ser considerada pouco expressiva, visto que a mesma encontrase próxima daquela considerada comum em testes ecotoxicológicos (fator 2). Por outro lado, deve-se considerar, também, que os experimentos de VanLEEWEN et al. (1990) foram efetuados com a fase embriolarval de Danio rerio, fato que pode ter contribuido para a diferença remanescente quando da aplicação do fator 0,3 . Nesse sentido, vale ressaltar que no presente estudo (Figuras 03 e 05 ) foi demonstrado que, 
para várias substâncias, a fase embriolarval é ao redor de três vezes mais resistente do que a larval. Portanto, esses dados também confirmam a adequação do uso do fator 0,3 na previsão dos efeitos a longo prazo com base nos resultados de testes de curta duração com Danio rerio.

Outra forma de avaliar a adequação dos Valores Crônicos estimados (VCest;168h), nos testes com Danio rerio (Tabela 13), consistiu da análise de regressão com os Valores Crônicos (V.C. $\geq 28$ dias) de testes com Pimephales promelas. A Figura 17 demonstra que, mesmo com as diferenças de sensibilidade para o níquel, mercúrio, prata e zinco, foi obtido um excelente coeficiente de determinação $\left(r^{2}=0,93\right)$. Devese notar que os dados de $\mathrm{NaCl}$ com larvas de Pimephales promelas foram incluídos na análise, uma vez que há ausência de estudos de longa duração, sendo que sua exclusão reduziria o referido coeficiente $\left(r^{2}=0,86\right)$.

Consultas na literatura indicaram que para poucos dados, somente de toxicidade aguda, foram obtidos coeficientes de determinação similares aos do presente estudo, em regressões entre outras espécies de peixes e Pimephales promelas. KENAGA (1978) e DOHERTY (1983) encontraram $r^{2}=0,92$ e $r^{2}=0,95$, respectivamente, com o Lepomis macrochirus ("bluegill") em testes com nove substâncias. Dados recalculados do estudo de MAYER e ELLERSIECK (1986) mostram correlações expressivas entre Pimephales promelas com os ciprinídeos Carassius auratus $\left(r^{2}=0,94\right)$ e Cyprinus carpio $\left(r^{2}=0,92\right)$, além de Perca flavescens $\left(r^{2}=0,98\right)$, em testes com sete a 19 agentes químicos.

Torna-se importante destacar que existe uma maior probabilidade de boas correlações com resultados de testes de toxicidade aguda, uma vez que nas regressões são utilizadas as CL50. Deste modo, os coeficientes são calculados com dados mais precisos, tanto biológica como estatisticamente, fato pouco controlável em correlações que envolvem baixos níveis de efeito na sobrevivência e no crescimento. Por tal motivo, as correlações obtidas, no presente estudo, se mostram bastante significativas. 
Tão importante quanto os coeficientes de determinação e as equações determinadas são os limites de previsão a 95\%. Alguns pesquisadores (KENAGA, 1978; DOHERTY, 1983; e SLOOF et al., 1986) utilizaram esses limites para a seleção de organismos aquáticos que representassem outros em testes de toxicidade aguda.

Estatisticamente, os limites de previsão são análogos aos de confiança. Enquanto os limites de confiança são restritos ao conjunto de dados utilizados na equação, os limites de previsão são aqueles dentro dos quais se espera que $95 \%$ das observações futuras se localizem (DRAPER e SMITH, 1981).

Na Figura 17 está representado o limite de previsão 95\% entre os resultados do VCest; $168 \mathrm{~h}$ com Danio rerio e do VC $\geq 28$ dias com Pimephales promelas. Numericamente, esses limites foram de $\pm 11,5$ vezes, o que representa $\pm 1,15$ ordem de magnitude. Deste modo, com uma probabilidade de $95 \%$, os valores estimados de toxicidade crônica para Danio rerio correspondem até 11,5 vezes os valores determinados, analiticamente, para Pimephales promelas.

Os limites de previsão representados na Figura 17 são muito semelhantes aos obtidos, por outros autores, em testes de toxicidade aguda. Em estudo que revelou correlações expressivas entre as espécies Salmo gairdneri, Lepomis macrochirus e Pimephales promelas, KENAGA (1978) obteve limites de previsão de $\pm 0,91 ; 1,22$ e 1,42 ordens de magnitude das CL50. Da pesquisa desenvolvida por DOHERTY (1983), foi estimado um limite de previsão de $\pm 1,6$ ordem de magnitude para a equação de regressão com as espécies de peixe Salmo gairdneri e Lepomis macrochirus, consideradas pelo autor como as únicas de sensibilidade equivalente em termos de toxicidade aguda.

Para a validação da equação determinada (Figura 17), foram utilizados quatro agentes químicos, para os quais estavam disponíveis dados de toxicidade crônica equivalentes tanto para Danio rerio como para Pimephales promelas (Tabela 14). As 
substâncias usadas pertencem a grupos químicos diferentes daqueles que deram origem à equação de regressão, sendo eles: metabólito de herbicidas $(3,4$ dicloroanilina), organoclorado (lindano), herbicida (atrazina) e organofosforado (diazinon).

Como resultado, na Tabela 14, verifica-se que as estimativas de efeito crônico não observado (CENO) para Danio rerio foram muito próximas àquelas determinadas experimentalmente. À exceção da 3,4 dicloroanilina, a diferença entre os valores de CENO determinados e estimados foi menor que o fator 2 , indicando assim a adequação da equação estabelecida. Embora VanLEEUWEN et al. (1990) tenham encontrado diferença próxima ao fator 10, entre testes de sete e 28 dias com Danio rerio e outras cloroanilinas, a diferença na estimativa obtida no presente estudo foi de apenas 2,6 vezes em relação ao resultado experimental (Tabela 14).

Com base na correlação obtida (Figura 17), confirma-se que o nivel de efeito (letalidade) igual a 15\% é apropriado para estimar efeitos crônicos em testes de curta duração com Danio rerio, conforme já demonstrado estatisticamente nos itens $5.3 \mathrm{e}$ 5.4. Assim, tal nível de efeito pode ser utilizado, também, em teste de hipóteses com bioequivalência, o qual é uma alternativa recomendada para o cálculo de resultados de testes crônicos.

No entanto, o nivel de $15 \%$ de efeito em testes com bioequivalência é factivel apenas para experimentos que envolvam dois tratamentos (controle e amostra de água superficial). Essa recomendação se justifica pois, em estudos comparativos entre resultados de laboratório e campo, os experimentos com a sobrevivência de larvas de peixes têm se correlacionado melhor com os efeitos adversos em comunidades naturais (ADAMS et al., 1983; WALLER et al.,1996; e BIRGE et al., 1989).

Com relação ao cálculo dos resultados de testes crônicos utilizando-se o teste de hipóteses, apesar das criticas quanto ao seu uso, a equação de regressão obtida foi 
excelente. Neste sentido, aplicando-se o fator 0,3 aos V.C.; $168 \mathrm{~h}$ calculados para a sobrevivência de larvas, foi determinada a seguinte equação:

$\log$ V.C.; $168 \mathrm{~h}$ Danio rerio $=0,40+0,85 \log$ V.C. Pimephales promelas

Esse modelo apresentou $r^{2}=0,93$ e limite de previsão igual a $\pm 11,3$ vezes. Deste modo, tal equação pode ser utilizada como alternativa na impossibilidade de cálculos da CL(I) $15 ; 168$ h para Danio rerio.

Tomando como base os resultados do presente estudo, os modelos de regressão apresentados podem fornecer estimativas fidedignas de efeito tóxico crônico para Danio rerio a partir de resultados de testes de toxicidade com Pimephales promelas. Além disso, e certamente mais relevante, foi demonstrado que, nas condições experimentais propostas, Danio rerio é uma espécie de peixe adequada para estimar efeitos tóxicos de longa duração. 


\section{CONCLUSÕES}

Os testes de toxicidade de curta duração e renovação das soluções-teste a cada 24 horas, executados com Danio rerio e onze agentes químicos, permitiram concluir que:

- A fase larval é significativamente mais sensivel do que as fases embriolarval e juvenil de Danio rerio, em experimentos com 96 e 168 horas de exposição. Esta constatação foi evidente tanto nos testes com efeito a $50 \%$ dos organismos, bem como para níveis mais baixos de efeito na sobrevivência da espécie estudada. Portanto, a fase larval é indicada para avaliar efeitos tóxicos crônicos de agentes quimicos.

- Em geral, a variabilidade analítica é menor nos testes com 168 horas do que nos experimentos com 96 horas de duração. Coeficientes de variação aceitáveis $(<40 \%)$ são obtidos com os níveis 25 ou $15 \%$ de efeito na sobrevivência larval. O método estatístico ICp (Inhibition Concentration), assim como o dos Probitos, mostram-se apropriados para avaliar a precisão analítica dos testes crônicos com larvas de Danio rerio.

- Dentre os agentes químicos testados o cobre, o fenol e o cloreto de sódio são os mais indicados para avaliar a precisão analítica do teste ecotoxicológico com Danio rerio.

- O método estatístico ICp é apropriado para o cálculo dos resultados de testes de toxicidade crònica de curta duração. As CL(I) determinadas, bem como os respectivos intervalos de confiança, são similares àquelas calculadas pelo método paramétrico de referência (Probitos). Em função do uso de resposta dicotômica (sobrevivência), praticamente não existem limitações experimentais que inviabilizem o uso do metodo ICp. 
- Pela semelhança dos resultados, o teste de hipóteses pode ser utilizado como alternativa aos modelos de regressão (ICp e Probitos) no cálculo de resultados dos testes crônicos, desde que a análise de variância apresente diferença mínima significativa (DMS) menor do que $15 \%$.

- Para a maioria dos agentes químicos estudados, o método estatístico LRA (Análise de Regressão Linear) é impróprio para prever efeitos crônicos a Danio rerio. Embora forneça resultados semelhantes aos demais métodos estatísticos utilizados, tanto os intervalos de confiança como a variabilidade analítica são elevados.

- O efeito tóxico crônico de agentes químicos a peixes, em testes de curta duração com Danio rerio, pode ser estimado através do cálculo da VCest;168h, isto é, o valor da CL(I) $15 ; 168 \mathrm{~h}$ multiplicado pelo fator 0,3 . Desse modo, além da sobrevivência, são também estimados os efeitos sobre o crescimento de fases iniciais do ciclo vital de peixes.

- Sob condições experimentais similares, a correlação dos resultados de testes crônicos entre Pimephales promelas e Danio rerio é bastante significativa $\left(r^{2}=0,93\right)$, sendo expressa pela seguinte equação:

$\log$ VCest; $168 \mathrm{~h}$, Danio rerio $=0,30+0,84 \log$ V.C., Pimephales promelas

- O método do teste de curta duração com Danio rerio, conforme descrito no presente trabalho, fornece estimativas confiáveis de efeitos tóxicos a longo prazo. Assim sendo, pesquisadores, de universidades e órgãos ambientais, podem dispor de método suplementar para a previsão e detecção de efeitos adversos de agentes químicos em ecossistemas aquáticos. 


\section{REFERÊNCIAS BIBLIOGRÁFICAS}

ABNT (Associação Brasileira de Normas Técnicas). Água - Ensaio de toxicidade aguda com peixes- Parte $\Pi$ - sistema semi-estático. NBR 12715. 15 p., Março 1993.

Adams W.J.; Kimerle, R.A.; Heidolph, B.B. e Michael, P.R. Field comparison of laboratory-derived acute and chronic toxicity data. In: Bishop, W.E.; Cardwell, R.D.; Heidolph, B.B. (Eds). Aquatic Toxicology and Hazard Assessment: Sixth Symposium. STP 802 Philadelphia. ASTM. p. 367-385, 1983.

Adelman, I.R. e Smith Jr, L.L. Fathead minnows (Pimephales promelas) and goldfish (Carassius auratus) as standard fish in bioassays and their reaction to potential reference toxicants. J.Fish.Res.Board.Can. 33: 209-214, 1976.

Alabaster, J.S. e Lloyd, R. Water quality criteria for freshwater fish. London. Butterworths. FAO. 296 p., 1980.

Arthur, A.D. e Dixon, D.G. Effects of rearing density on the growth response of juvenile fathead minnow ( Pimephales promelas) under toxicant-induced stress. Can.J.Fish.Aquat.Sci. $51:$ 365-371,1994.

Bailer, A.J. e Oris, J.T.. Estimating inhibition concentrations for different response scales using generalized linear models. Environ.Toxicol.Chem. 16 (7):1554$1559,1997$.

Bailer, A.J. e Oris, J.T.. What is an NOEC? Non-monotonic concentration-response patterns want to know. SETAC News. March, p. 22-24, 1999. 
Bailer, A.J.; Hughes, M.R.; Denton, D.L. e Oris, J.T. An empirical comparison of effective concentration estimators for evaluating aquatic toxicity test responses. Environ.Toxicol.Chem. 19 (1) : 151-157, 2000.

Baird, R.B.; Berger, R. e Gully, J.. Improvements in point estimation methods and application to controlling aquatic toxicity test reliability. In: Grothe,D.R.; Dickson, K.L; Reed-Judkins, D.K.(eds). Whole effluent toxicity testing: An evaluation of methods and prediction of receiving system impacts. Pensacola (FL). SETAC Press. p. 103-130, 1996.

Barron, M.G. e Adelman, I.R. Temporal characterization of growth of fathead minnow (Pimephales promelas) larvae during sublethal hydrogen cyanide exposure. Comp.Biochem.Physiol. 81C (2): 341-344, 1985.

Bassoi, L.J.; Nieto, R. e Tremaroli, D.. Implementação de testes de toxicidade no controle de efluentes líquidos. São Paulo. CETESB/PROCOP. Série Manuais/SMA. 7 p., 1990.

Benoit, D.A. e Holcombe, G.W. Toxic effects of zinc on fathead minnows Pimephales promelas in soft water. J.Fish.Biol. 13: 701-708, 1978.

Benoit, D.A.; Puglisi, F.A. \& Olson, D.L. A fathead minnow, Pimephales promelas, early life stage toxicity test method evaluation and exposure to four organic chemicals. Environ.Pollut. (Series A) 28 : 189-197, 1982.

Bertoletti, E. e Domingues, D.F. Desenvolvimento e implantação de testes de toxicidade com organismos aquáticos. Volume II - Testes crônicos com peixes. São Paulo, CETESB. Relatório Técnico, 18 p., 1991. 
Bertoletti, E. e Ferrari, L.R. Metodologia para avaliação da toxicidade crônica com o peixe Brachydanio rerio. São Paulo. CETESB. Relatório Técnico. 19p, 1994.

Bertoletti, E.; Goldstein, E.G. e Nipper, M.G. Toxicidade de águas superficiais na região da Grande São Paulo. Rev.Soc.Bras.Toxicol. 2 (2): 01-20, 1989.

Birge, W.J.; Black, J.A. e Westerman, A.G.. Short-term fish and amphibian embryolarval tests for determining the effects of toxicant stress on early life stages and estimating chronic values for single compounds and complex effluents. Environ.Toxicol.Chem. 4 : 807-821, 1985.

Birge, W.J.; Black, J.A.; Short, T.M. e Westerman, A.G. A comparative ecological and toxicological investigation of a secundary wastewater treatment plant effluent and its receiving stream. Environ.Toxicol.Chem. 8 : 437-450, 1989.

Brasil. Ministério do Desenvolvimento Urbano e Meio Ambiente. Resolução CONAMA n ${ }^{\circ} 20$ de 18/06/1986. Diário Oficial da União. Brasília. p. 11356, $30 / 07 / 1986$.

Brasil. Ministério do Meio Ambiente dos Recursos Hídricos e da Amazônia Legal. IBAMA. Portaria Normativa $n^{\circ} 84$ de 15/10/1996. Diário Oficial da União $n^{\circ}$ 206. Brasília, 23/10/1996.

Bresch, H. Investigation of the long-term action of xenobiotics on fish with special regard to reporduction. Ecotox.Envir.Saf.(6): 102-112, 1982.

Bresch, H. Early life-stage test in zebrafish versus a growth test in rainbow trout to evaluate toxic effects. Bull. Environ. Contam. Toxicol. 46 : 641-648, 1991. 
Bruce, R.D. e Versteeg, D.. A statistical procedure for modeling continuous toxicity data. Environ.Toxicol.Chem. 11 : 1485-1494, 1992.

Buikema, A.L. Jr., Niederlehner, B.R. e Cairns, J. JR. Biological monitoring - Part IV Toxicity testing. Water Res. 16: 239-262, 1982.

Burton, G.A. et al. Effluent toxicity test variability. In: Grothe,D.R.; Dickson, K.L; Reed-Judkins, D.K.(eds). Whole effluent toxicity testing: An evaluation of methods and prediction of receiving system impacts. Pensacola (FL). SETAC Press. p. 131-156, 1996.

Call, D. J.; Brooke L.T.; Ahmad N. e Richter J.E. Toxicity and metabolism studies with EPA priority pollutants and related chemicals in freshwater organisms. USEPA-Duluth(MN). EPA-600/3-83-095, 120 p., 1983. (PB83263655).

Call, D.J.; Poirier, S.H.; Knuth, M.L.; Harting, S.L. e Lindberg, C.A. Toxicity fo 3,4dichloroaniline in acute and early life-stage exposures. Bull. Environ. Contam. Toxicol. 38: 352-358, 1987.

CETESB (Cia. Tecnol. Saneamento Ambiental). Desenvolvimento de métodos para - estabelecimento de critérios ecotoxicológicos. São Paulo, CETESB. Relatório Final - 1983. Vol. I, 174 p., 1986.

CETESB (Cia. Tecnol. Saneamento Ambiental). Programa Bioensaios - Relatório final anual. São Paulo, CETESB. Relatório técnico. Vol. I, 275 p., 1979.

CETESB (Cia. Tecnol. Saneamento Ambiental). Programa Bioensaios - Relatório de atividades. São Paulo, CETESB. Relatório técnico. 55 p. + anexos, 1980. 
Chapman, G. A. Do organisms in laboratory tests respond like organisms in nature? In: Bishop, W.E.; Cardwell, R.D.; Heidolph, B.B. (Eds). Aquatic Toxicology and Hazard Assessment: Sixth Symposium. STP 802. Philadelphia, ASTM., p. $315-327,1983$.

Chapman, G. A. et al. Methods and appropriate endpoints. In: Grothe,D.R.; Dickson, K.L; Reed-Judkins, D.K.(eds). Whole effluent toxicity testing: An evaluation of methods and prediction of receiving system impacts. Pensacola (FL). SETAC Press. p. 51-82, 1996.

Chapman, P.M.; Caldwell, R.S. e Chapman, P.F.. A warning: NOEC are inapropriate for regulatory use. Environ.Toxicol.Chem. 15 (2): 77 - 79, 1996.

Dave, $\mathrm{G}$. The influence of $\mathrm{pH}$ on the toxicity of aluminum, cadmium, and iron to eggs and larvae of the zebrafish, Brachydanio rerio. Ecotox.Envir.Safety, 10 : $253-267,1985$.

Dave, G. e Xiu, R. Toxicity of mercury, copper, nickel, lead, and cobalt to embryos and larvae of zebrafish Brachydanio rerio. Arch.Environ.Contam.Toxicol. 21: 126-134, 1991.

Dave, G.; Andersson, K.; Berglind, R. e Hasselrot, B.. Toxicity of eight solvent extration chemicals and of cadmium to water fleas, Daphnia magna, rainbow trout, Salmo gairdneri, and zebrafish, Brachydanio rerio. Comp.Biochem.Physiol. 69 C : 83-98, 1981

Dave, G.; Damgaard, B.; Grande, M.; Martelin, J.E.; Rosander, B. e Viktor, T.. Ring test of an embryo-larval toxicity test with zebrafish (Brachydanio rerio) using chromium and zinc as toxicants. Environ.Toxicol.Chem. $6: 61-71,1987$. 
Degraeve, G.M.; Geiger, D.L.; Meyer, J.S. e Bergman, H.L. Acute and embryo-larval toxicity of phenolic compounds to aquatic biota. Arch. Environm. Contam. Toxicol. 9. p. 557-568, 1980.

Denton, D.L. e Norberg-King, T.J. Whole effluent toxicity statistics: a regulatory perspective In: Grothe, D.R.; Dickson, K.L; Reed-Judkins, D.K.(eds). Whole effluent toxicity testing: An evaluation of methods and prediction of receiving system impacts. Pensacola (FL). SETAC Press. p. 83-102, 1996.

Doherty, F.G. Interspecies correlations of acute aquatic median lethal concentration for four standard testing species. Environ.Sci.Tech. 17 (11): 661-665, 1983.

Draper, N.R. e Smith, H. Applied regression analysis. New York. John Wiley \& Sons, Inc. Second edition, 709 p., 1981.

Elonen, G.E. et al. Comparative toxicity of 2,37,8-tetrachlorodibenzo-p-dioxin to seven freshwater fish species during early life-stage development. Environ.Toxicol.Chem. 17 (3): 472-483, 1998.

Emerson, K; Russo, R.C.; Lund, R.E. e Thurston, R.V. Aqueous ammonia equilibrium calculations: effect of $\mathrm{pH}$ and temperature. J.Fish.Res.Board Can. 32 : 2379-2383, 1975.

Environment Canada. Guidance Document on control of toxicity test precision using reference toxicants. Ottawa (ON). Report EPS 1/RM/12, 85 p., 1990

Erickson, W.P. e McDonald, L.L. Tests for bioequivalence of control media and test media in studies of toxicity. Environ.Toxicol.Chem. 14 (7): 1247-1256, 1995. 
Gelber. R.D.; Lavin, C.R.; Mehta, C.R. e Schoenfeld, D.A.. Statistical Analysis. In: Rand, G.M. e Petrocelli, S.R. Fundamentals of aquatic toxicology. Washington. Hemisphere Publ. p. $110-123,1985$.

Gendusa, T.C.; Beitinger, T.L. e Rodgers, J.H. Toxicity of hexavalent chromium from aqueous and sediment sources to Pimephales promelas and Ictalurus punctatus. Bull.Environ.Contam.Toxicol. 50: 144-151, 1993.

Gherardi-Goldstein, E.; Bertoletti, E.; Zagatto, P.A.; Araújo, R.P.A.A. e Ramos, M.L.L.C.. Procedimentos para utilização de testes de toxicidade no controle de efluentes líquidos. São Paulo. CETESB/PROCOP. Série Manuais/SMA, 17 p., 1990 .

Görge G. e Nagel R. Toxicity of lindane, atrazine, and deltamethrin to early life stages of zebrafish (Brachydanio rerio). Ecotox.Environm.Safety. 20: 246-255, 1990.

Gulley, D.D; Boelter, A.M. e Bergman, H.L. Toxstat version 3.3 (programa de computador). Univ. Wyoming (Laramie/WY), 1991.

Hamilton, M.A.; Russo, R.C. e Thurston, R.V. Trimmed Spearman-Karber method for estimating median lethal concentration in toxicity bioassays. Environ.Sci.Tech. 11 (11):714-719, 1977. Correction: 12 (4): 417p., 1978. (programa de computador).

Hoekstra, J.A. e vanEwijk, P.H. Alternatives for the no-observed-effect level. Environ.Toxicol.Chem. 12 : 187-194, 1993. 
Holcombe, G.W.; Phipps, G.L. e Fiandt, J.T.. Effects of phenol, 2,4-dimethylphenol, 2,4-dichlorophenol, and pentachlorophenol on embryo, larval, and early-juvenile fathead minnow (Pimephales promelas). Arch.Environm.Contam.Toxicol. 11: $73-78,1982$.

Holcombe, G.W.; Phipps, G.L. e Fiandt, J.T. Toxicity of selected priority pollutants to various aquatic organisms. Ecotox.Environ.Safety, 7: 400-409, 1983.

Hughes, M.M.; Herber, M.A.; Morrison, G.E.; Schimmel, S.C. e Berry, W.J. An evaluation of a short-term chronic effluent toxicity test using sheepshead minnow (Cyprinodon variegatus) larvae. Environ.Pollut. 60 : 1-14, 1989.

Jarvinen, A. W. e Tanner, D.K. Toxicity of selected controlled release and corresponding unformulated technical grade pesticides to the fathead minnows. Envir. Pollut. (Series A). 27 : 179-195, 1982.

Kenaga, E.E. Test organisms and methods useful for early assessment of acute toxicity of chemicals. Envir.Sci.Tech. 12 (12) : 1322-1329, 1978.

Leblanc, G.A. Interspecies relationships in acute toxicity of chemicals to aquatic organisms. Environ.Toxicol.Chem. 3 : 47-60, 1984.

Leblanc, G.A; Mastone, J.D.; Paradice, A.P.; Wilson, B.F.; Lockhart, H.B. e Robillard, K.A. The influence of speciation on the toxicity of silver to fathead minnow (Pimephales promelas). Environ.Contam.Chem. 3: 37-46, 1984.

Leland, H.V. e Kuwabara, J.S. Trace metals. In: Rand, G.M. e Petrocelli, S.R. (Eds). Fundamentals of aquatic toxicology. Washington. Hemisphere Publ. p. $374-$ $415,1985$. 
Markle, P.J.; Gully, R.J.; Baird, R.B.; Nakada, K.M. e Bottomley, J.P.. Effects of several variables on whole effluent toxicity test performance and interpretation. Environ.Toxicol.Chem. 19 (1): 123-132, 2000.

Mayer, F.L. e Ellersieck, M.R. Manual of acute toxicity: interpretation and data base for 410 chemicals and 66 species of freshwater animal. Washington, U.S.Fish and Wildlife Service. Resource Publication 160, 579p., 1986.

Mayer, F.L.; Krause, G.F.; Ellersieck, M.R. e Lee, G.. Statistical approach to predicting chronic toxicity of chemicals to fishes from acute toxicity test data., USEPA - Gulf Breeze(FL). EPA/600/R-92/091. 94 p, 1992. (PB92169655).

Mayer, F.L.; Krause, G.F.; Buckler, D.R.; Ellersieck, M.R. e Lee, G.. Predicting chronic lethality of chemichal to fishes from acute toxicity test data: concepts and linear regression analysis. Envir.Toxicol.Chem. 13 (4) : 671-678, 1994.

Mayer, F.L.; Mayer, K.S. e Ellersieck, M.R. Relation of survival to other endpoints in chronic toxicity tests with fish. Environ.Toxicol.Chem. 5 : 737-748, 1986.

Mayer, F.L.; Sun, K.; Lee, G.; Ellersieck, M. e Krause, G. Acute to chronic estimation (ACE) [programa de computador]. US.EPA/ Univ. Missouri Columbia, 1996.

Mayes, M.A.; Alexander, H.C.; Hopkins, D.L. e Latvaitis, P.B. Acute and chronic toxicity of ammonia to freshwater fish: a site-specific study. Environ.Toxicol.Chem. 5: 437 - $442,1986$.

Mckim, J.M. Evaluation of tests with early life stages of fish for predicting long-term toxicity. J. Fish. Res. Board Can. 34: 1148-1154, 1977. 
Mckim, J.M. Early life stage toxicity tests. In: Rand, G.M. e Petrocelli, S.R.(eds.) Fundamentals of aquatic toxicology. Washington. Hemisphere Publ. p. 58 $95,1985$.

Meinelt, T. e Staaks, G. The embryo-larval test with zebrafish (Brachydanio rerio): validity, limits and perspectives. In: Muller, R. e Lloyd, R. (eds). Sublethal and chronic effects of pollutants on freshwater fish. Oxford, FAO/FIsh. News Books. p: 167-174, 1994.

Meyer, A.; Biermann, C.H. e Orti, G. The phylogenetic position of the zebrafish (Danio rerio), a model system in developmental biology: an invitation to the comparative method. Proc. R. Soc. London. Series B. 252 (1335): 231-236, 1993.

Moore, D.R.J. e Caux, P. Estimating low toxic effects. Environ.Toxicol.Chem. 16 (4): 794-801, 1997.

Moore, D.R.J. et al. Intra and intertreatment variability in reference toxicant test: implication for whole effluent toxicity testing programs. Environ.Toxicol.Chem. 19 (1): $105-112,2000$.

Morrison, G. et al.. Intralaboratory precision of saltwater short-term chronic toxicity tests. Journal W.P.C.Fed. 61 (11/12), 1989.

Mount, D.I. e Stephan, C.E. Chronic toxicity of copper to the fathead minnow (Pimephales promelas) in soft water. J.Fish.Res.Bd.Canada 26: 2449-2457, 1969. 
Mount, D.R.; Gulley, D.D.; Hockett, J.R; Garrison, T.D. e Evans, J.M. Statistical models to predict the toxicity of major ions to Ceriodaphnia dubia, Daphnia magna and Pimephales promelas (fathead minnows). Envir.Toxicol.Chem. 16 (10): 2009-2019, 1997.

Nagel, R. et al. Effect of 3,4-dichloroaniline on the early life stages of the zebrafish (Brachydanio rerio): results of a comparative laboratory study Ecotox.Envir.Safety, 21 : 157-164, 1991.

NAS/NAE. National Academy of Sciences/ National Acadeny of Engeneering. WATER QUALITY CRITERIA - 1972. Washington, USEPA (EPA.R3.73.033), 1973.

Norberg, T.J. e Mount, D.I. A new fathead minnow (Pimephales promelas) subchronic toxicity test. Envir.Toxicol.Chem. 4 : 711-718, 1985.

Norberg-King, T.J. An evaluation of the fathead minnow seven-day subchronic test for estimating chronic toxicity. Envir.Toxicol.Chem. 8 : 1075-1089, 1989.

Norberg-King, T.J. A linear interpolation method for sublethal toxicity: the inhibition concentration (ICp) approach. Version 2.0. (software). US.EPADuluth (MN), 1993

Norberg-King, T.J.; Mount, D.I.; Amato, J.R.; Jensen, D.A. e Thompson, J.A. Toxicity identification evaluation: characterization of chronically toxic effluents. Phase I. National Effluent Toxicity Asses. Center, USEPA/ Duluth. Technical Report 05-91, EPA/600/6-91/005. p.i, 1991.

Oris, J.T. e Bailer, J.. Statistical analysis of the Ceriodaphnia toxicity test: sample size determination for reproductive effects. Environ.Toxicol.Chem. 12:85-90, 1993. 
Parkhurst, B.R.; Warren-Hicks, W. e Noel, L.E. Performance characteristics of effluent toxicity tests: summarization and evaluation of data. Envir.Toxicol.Chem. $11: 771$ - 791, 1992.

Phipps, G.L. e Holcombe, G.W. A method for aquatic multiple species toxicant testing: acute toxicity of 10 chemicals to 5 vertebrates and 2 invertebrates. Environ.Pollut. (series A) 38: 141-157, 1985.

Phipps, G.L.; Holcombe, G.W e Fiandt, J.T. Acute toxicity of phenol and substituted phenols to the fathead minnow. Bull.Envir.Contam.Toxicol. $26: 585-593$, 1981.

Pickering, Q.H. Chronic toxicity of hexavalent chromium to the fathead minnow (Pimephales promelas). Arch.Environ.Contam.Toxicol. 9: 405-413, 1980.

Pickering, Q.H. Evaluation and comparison of two short-term fathead minnow tests for estimating chronic toxicity. Water Research. $7: 883-893,1988$.

Pickering, Q.H. e Henderson, C. The acute toxicity of some heavy metals to different species of warmwater fishes. Air Wat.Pollut.Int.J. 10 : 453-463, 1966.

Rand, G.M. e Petrocelli, S.R. Fundamentals of aquatic toxicology. Washington. Hemisphere Publ. p. $666,1985$.

Rue, W.J.; Fava, J.A. e Grothe, D.R.. A review of inter and intralaboratory effluent toxicity test method variability. In: Adams, W.J.; Chapman, G.A. e Landis, W.G. (Eds), Aquatic Toxicology and Hazard Assessment: 10th volume - STP 971. Philadelphia. ASTM. p. 190-203, 1988. 
Russo, R.C. Ammonia, nitrite, and nitrate. In: Rand, G.M. e Petrocelli, S.R.(eds) Fundamentals of aquatic toxicology. Washington. Hemisphere Publ. p. 455$471,1985$.

São Paulo (Estado). Secretaria do Meio Ambiente. Resolução SMA-3, de 22/02/2000. Diário Oficial do Estado de São Paulo, São Paulo. p. 24. 25/02/2000,

SEMA. Manual de testes para avaliação da ecotoxicidade de agentes químicos. Brasília. STC/CTA. 351 p., 1988.

Slooff, W.; vanOers, A.M. e Zwart, D. Margins of uncertainty in ecotoxicological hazard assessment. Environ.Toxicol.Chem. 5 : 841-852, 1986.

Slooff, W.; Canton, J.H. e Hermens, J.L.M. Comparison of the susceptibility of 22 freshwater species to 15 chemicals compounds. I (sub)acute toxicity tests. Aquatic.Toxicol. $4:$ 113-128, 1983.

Snarski, V.M. e Olson, G.F. Chronic toxicity and bioaccumulation of mercuric chloride in the fathead minnow (Pimephales promelas). Aquatic Toxicol. 2 $143-156,1982$

Spehar, R.L. e Fiandt, J.T. Acute and chronic effects of water quality criteria-based metal mixtures on three aquatic species. Environ.Toxicol.Chem. 5 : 917-931, 1986.

Spehar, R.L.; Nelson, H.P.; Swanson, M.J. e Renoos, J.W. Pentachlorophenol toxicity to amphipods and fathead minnows at different test $\mathrm{pH}$ values. Environ.Toxicol.Chem. 4 : 389-397, 1985. 
Sprague, J.B. Measurement of pollutant toxicity to fish. I. Bioassay methods for acute toxicity. Water Res. 3: 793-821, 1969.

Sprague, J.B. Factors that modify toxicity. In: Rand., G.M. e Petrocelli, S.R. (eds). Fundamentals of aquatic toxicology. Washington. Hemisphere Publ, p. 124 $163,1985$.

Stephan, C.E.; Mount, D.I.; Hansen, D.J.; Gentile, J.H.; Chapman, G.A. e Brungs, W.A. Guidelines for deriving numerical national water quality criteria for protection of aquatic life and its uses. Draft (July, 5) U.S.EPA. 83 p., 1983.

Stephan, C.E. e Rogers, J.W. Advantages of using regression analysis to calculate results of chronic toxicity tests. In: Bahner, R.C. e Hansen, D.J. (Eds). Aquatic Toxicology and Hazard Assessment: Eighth Symposium - STP 891. Philadelphia: ASTM. p. 328-338, 1985.

Suter, G.W.; Barnthouse, L.W.; Breck, J.E.; Gardner, R.H. e O'Neill, R.V. Extrapolating from the laboratory to the field: how uncertain are you? In: Cardwell. R.D.; Purdy, R. e Bahner, R.C. (eds). Aquatic Toxicology and Hazard Assessment: Seventh Symposium - STP 854. Philadelphia. ASTM. p. 400-413. 1985.

Suter, G.W.; Rosen, A.E.; Linder, E. e Parkhurst, D. F. Endpoints for responses of fish to chronic toxic exposures. Envir.Toxicol.Chem. 6 : 793-809, 1987.

Suter, G.W. Seven-day tests and chronic tests. Envir.Toxicol.Chem. 9 : 1435-1436, 1990.

Thursby, G.B.; Heltshe, J. e Scott, K.J. Revised approach to toxicity test acceptability criteria using a statistical performance assessment. Environ.Toxicol.Chem. 16(6): 1233-1329, 1997. 
USEPA (U.S. Environmental Protection Agency). Ambient water quality criteria for nickel. EPA 440/5-86-004. 93 p, 1986.

USEPA (U.S. Environmental Protection Agency). Technical support document for water quality-based toxic control. Washington, USEPA-Office of Water. (EPA/505/2-90-001), 145 p., 1991.

vanLeewen, C.J.; Griffioen, P.S.; Vergouw, W.H.A. e Maas-Diepeveen, J.L.. Differences in susceptibility of early life stages of rainbow trout (Salmo gairdneri) to environmental pollutants. Aquatic Toxicology, $7: 59-78,1985$.

vanLeewen, C.J.; Adema, D.M.M. e Hermens, J. Quantitative structure-activicy relationship for fish early life stage toxicity. Aquatic Toxicology, 16:321-334. 1990

Vittozzi, L. e DeAngelis, G. A critical review of comparative acute toxicity data on freshwater fish. Aquatic Toxicol. 19: 167-204, 1991.

Waller, W.T. et al. Predicting instream effects from wet tests. In: Grothe, D.R.; Dickson, K.L; Reed-Judkins, D.K.(eds). Whole effluent toxicity testing: An evaluation of methods and prediction of receiving system impacts. Pensacola (FL). SETAC Press. p. 271-286, 1996.

Ward, G.S. e Parrish, P.R. Evaluation of early life-stage toxicity tests with embryos and juveniles of sheepshead minnows (Cyprinodon variegatus). In: Eaton, J.G.; Parrish, P.R. e Hendricks, A.C.(Eds) Aquatic Toxicology - STP 707. Philadelphia, ASTM. p: 243-247, 1980. 
Weber, C.I.; Horning, W.B.; Klemm, D.J.; Neiheisel, T.W.; Lewis, P.A. e Robinson, E.L..Short-term methods for estimating the chronic toxicity of effluents and receiving waters to marine and estuarine organisms. Cincinnati (USA), U.S.EPA/ Environ. Monit. Support Lab. EPA/600/4-87/028. 417 p., 1988.

Weber, C.I. Methods for measuring the acute toxicity of effluents and receiving waters to freshwater and marine organisms. (Fourth edition). Cincinnati (USA), U.S.EPA/ Environ. Monit. Support Lab. EPA/600/4-90/027F. 293 p., 1993.

Wood, C.M. et al. Environmental toxicology of metals. In: Bergman, H.L. e Dorward-King, E. $J$ (eds). Reassessment of metals criteria for aquatic life protection. Pensacola (FL). SETAC Press. p. 31-56, 1997.

Zagatto, P.A. e Gherardi-Goldstein, E. Toxicidade em águas do Estado de São Paulo. Ambiente. 5 (1) : 13-20, 1991.

Zagatto, P.A.; Gherardi-Goldstein, E.; Bertoletti, E.; Lombardi, C.C.; Martins, M.H.R.B. e Ramos, M.L.L.C.. Bioassays with aquatic organisms: toxicity of water and sediment from Cubatão river basin. Wat.Sci.Tech. 19 (11) : 95-106, 1987.

Zagatto, P.A.; Lorenzetti, M.L.; Lamparelli, M.C.; Salvador, M.E.P.; Menegon $\mathrm{Jr}, \mathrm{N}$. e Bertoletti, E. Aperfeiçoamento de um índice de qualidade de águas. Acta Limnol.Bras. 11(2) : 111-126, 1999. 
TABELAS 
Tabela 01 - Resultados dos testes ecotoxicológicos, com várias substâncias e fases distintas do ciclo de vida de Danio rerio , expressos como a média das CL(1) 50 (onde apropriado) em dois períodos de exposiçao

\begin{tabular}{|c|c|c|c|c|c|c|}
\hline \multirow{2}{*}{ SUBSTÂNCIA } & \multicolumn{3}{|c|}{ Média das CL(I) $50 ; 96 \mathrm{~h}$} & \multicolumn{3}{|c|}{ Média das CL(I) $50 ; 168 \mathrm{~h}$} \\
\hline & Embriðes & Larvas & Jovens & Embriðes & Larvas & Jovens \\
\hline \multirow[t]{2}{*}{ Cádmio (em mg/L) } & $>\mathbf{2 , 0}$ & 0,345 & 4,6 & 1,437 & 0,190 & 4,0 \\
\hline & - & $(\mathrm{CV}=4 \%, 2)$ & - & - & $(\mathrm{CV} \approx 42 \%, 2)$ & - \\
\hline \multirow[t]{2}{*}{ Cobre (em mg/L) } & $>0,509$ & 0,113 & 0,234 & 0,177 & 0,071 & 0,204 \\
\hline & (3) & $(\mathrm{CV}=54 \%, 4)$ & - & $(\mathrm{CV}=52 \%, 3)$ & $(\mathrm{CV}=45 \%, 4)$ & - \\
\hline \multirow[t]{2}{*}{ Cromo (em mg/L) } & $>84,8$ & $\mathbf{3 1 , 0}$ & 19,0 & 47,6 & 31,0 & 19,0 \\
\hline & (9) & $(\mathrm{CV}=13 \%, 3)$ & - & $(\mathrm{CV}=35 \%, 9)$ & $(\mathrm{CV}=13 \%, 3)$ & - \\
\hline \multirow[t]{2}{*}{ Niquel (em mg/L) } & 78,9 & 38,6 & 17,7 & 30,5 & 10,8 & 7,0 \\
\hline & 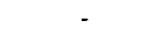 & $(\mathrm{CV}=50 \%, 3)$ & - & - & $(\mathrm{CV}=7 \%, 3)$ & $\cdot$ \\
\hline \multirow[t]{2}{*}{ Mercúrio (em mg/L) } & 0,036 & $\mathbf{0 , 0 3 3}$ & 0,259 & 0,028 & 0,026 & 0,244 \\
\hline & $(\mathrm{CV}=33 \%, 4)$ & $(\mathrm{CV}=47 \%, 2)$ & - & $(\mathrm{CV}=26 \%, 4)$ & $(\mathrm{CV}=22 \%, 2)$ & - \\
\hline \multirow[t]{2}{*}{ Prata (em mg/L) } & 0,040 & 0,029 & 0,026 & 0,029 & 0,028 & 0,026 \\
\hline & $(\mathrm{CV}=9 \%, 3)$ & $(\mathrm{CV}=36 \%, 4)$ & - & $(\mathrm{CV}=26 \%, 3)$ & $(\mathrm{CV}=40 \%, 4)$ & - \\
\hline \multirow[t]{2}{*}{ Zinco (em mg/L) } & 8,6 & 5,2 & 9,1 & 5,8 & 4,9 & 9,1 \\
\hline & $(\mathrm{CV}=16 \% .2)$ & $(\mathrm{CV}=39 \%, 3)$ & - & $(\mathrm{CV}=29 \%, 2)$ & $(\mathrm{CV}=38 \% .3)$ & - \\
\hline \multirow[t]{2}{*}{ Fenol (em mg/L) } & 177,9 & 102,6 & 46,6 & 98.9 & 26,8 & 40,6 \\
\hline & $\left(C V=11^{\circ} \%, 3\right)$ & $(\mathrm{CV}=40 \%, 3)$ & - & $(\mathrm{CV}=29 \%, 3)$ & $(\mathrm{CV}=26 \%, 3)$ & - \\
\hline \multirow[t]{2}{*}{ Cloreto de sódio (em g/L) } & $>10$ & 7,0 & 7,0 & 3,6 & 3,3 & $\mathbf{7 , 0}$ \\
\hline & (4) & $(\mathrm{CV}=16 \%, 4)$ & - & $(\mathrm{CV}=27 \%, 4)$ & $(\mathrm{CV}=26 \%, 4)$ & - \\
\hline \multirow{2}{*}{$\begin{array}{l}\text { Amônia não ionizada } \\
\text { (em mg/L) }\end{array}$} & 1,36 & 1,10 & não calculável & 0,95 & 1,0 & não calculável \\
\hline & $(\mathrm{CV}=9 \%, 2)$ & $(\mathrm{CV}=23 \%, 3)$ & - & $(\mathrm{CV}=0 \%, 2)$ & $(\mathrm{CV}=25 \%, 3)$ & - \\
\hline \multirow[t]{2}{*}{ DSS (em mg/L) } & 11,2 & 35,6 & não efetuado & 9,3 & 16,1 & não efetuado \\
\hline & $\left(C V=17^{\circ} .0 .5\right)$ & $(\mathrm{CV}=12 \%, 5)$ & - & $(\mathrm{CV}=14 \%, 5)$ & $(C V=17 \%, 5)$ & - \\
\hline
\end{tabular}

- No corpo da tabela. entre parênteses, o coeficiente de variação (CV, em porcentagem),e $\mathbf{n}^{\circ}$ de testes utilizados.

a) Valores indicados com > representam a média da maior concentração experimental em testes onde, por ausência de mortalidade. não foi possivel calcular a $\mathrm{CL}(\mathrm{I}) 50$. 
Tabela 02 - Resultados dos testes ecotoxicológicos crônicos, de curta duração, para a sobrevivência das fases embriolarval e larval de Danio rerio frente a diversas substâncias, em 168 horas de exposição, calculados pelo teste de hipóteses.

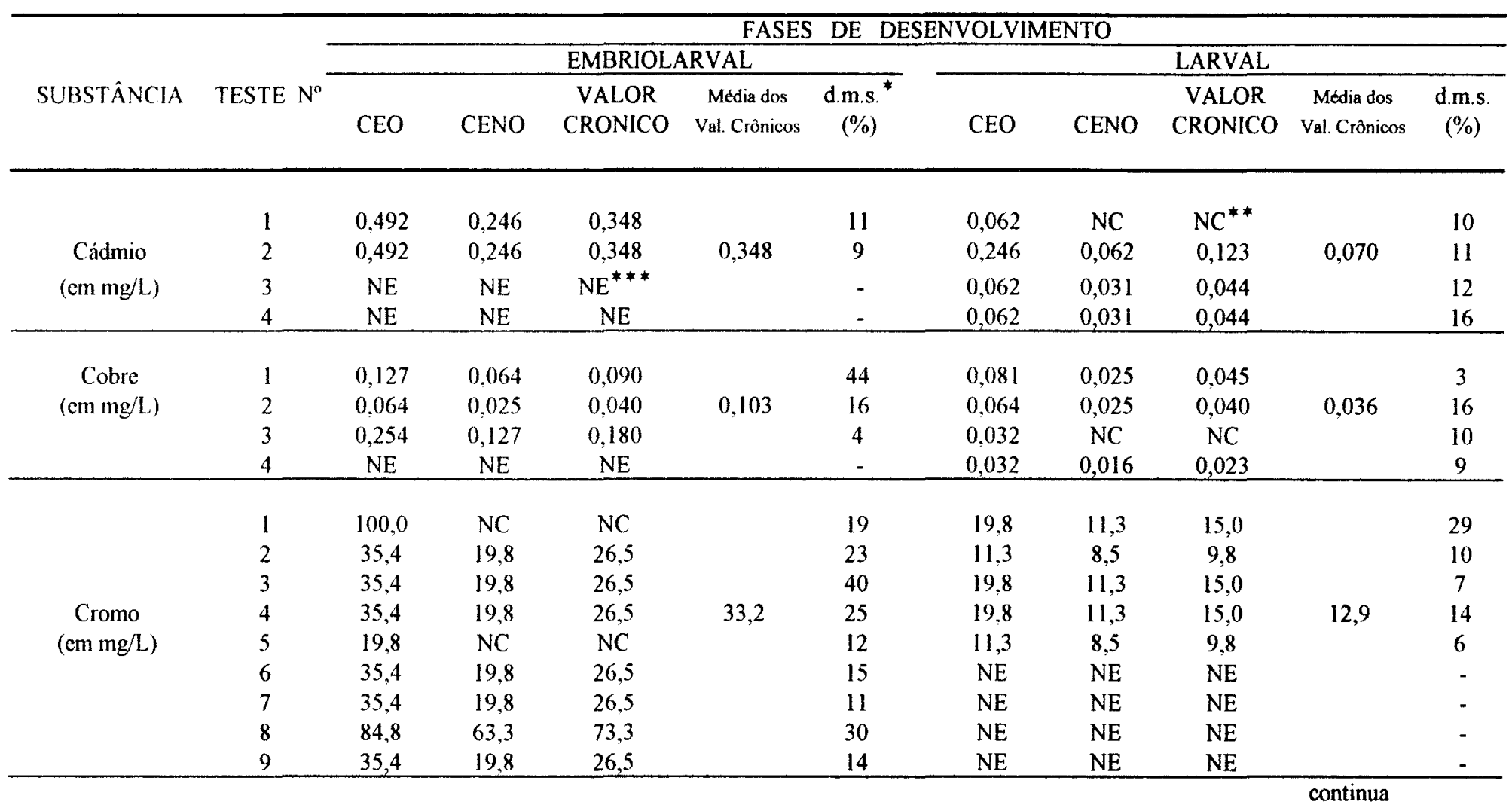


continuação

Tabela 02 - Resultados dos testes ecotoxicológicos crônicos, de curta duração, para a sobrevivência das fases embriolarval e larval de Danio rerio frente a diversas substâncias, em 168 horas de exposição, calculados pelo teste de hipóteses.

\begin{tabular}{|c|c|c|c|c|c|c|c|c|c|c|c|}
\hline \multirow{2}{*}{ SUBSTÂNCIA } & \multirow{2}{*}{ TESTE $\mathrm{N}^{\circ}$} & \multicolumn{10}{|c|}{ FASES DE DESENVOLVIMENTO } \\
\hline & & \multicolumn{5}{|c|}{ EMBRIOLARVAL } & \multicolumn{5}{|c|}{ LARVAL } \\
\hline $\begin{array}{c}\text { Niquel } \\
(\mathrm{cm} \mathrm{mg/L})\end{array}$ & $\begin{array}{l}1 \\
2 \\
3 \\
4 \\
\end{array}$ & $\begin{array}{l}27,9 \\
27,9 \\
\mathrm{NE} \\
\mathrm{NE} \\
\end{array}$ & $\begin{array}{l}14.0 \\
14,0 \\
\mathrm{NE} \\
\mathrm{NE}\end{array}$ & $\begin{array}{l}19,8 \\
19,8 \\
\mathrm{NE} \\
\mathrm{NE}\end{array}$ & 19,8 & $\begin{array}{c}9 \\
17 \\
- \\
- \\
\end{array}$ & $\begin{array}{c}14,0 \\
14,0 \\
7,0 \\
7,0 \\
\end{array}$ & $\begin{array}{l}7.0 \\
7.0 \\
\text { NC } \\
3,5 \\
\end{array}$ & $\begin{array}{l}9,9 \\
9,9 \\
\mathrm{NC} \\
4,9 \\
\end{array}$ & 8,2 & $\begin{array}{c}8 \\
5 \\
27 \\
11 \\
\end{array}$ \\
\hline $\begin{array}{c}\text { Mercúrio } \\
\text { (em mg/L) }\end{array}$ & $\begin{array}{l}1 \\
2 \\
3 \\
4 \\
5 \\
\end{array}$ & $\begin{array}{c}0,037 \\
0,037 \\
0,018 \\
0,018 \\
\mathrm{NE} \\
\end{array}$ & $\begin{array}{c}0,018 \\
0,018 \\
\mathrm{NC} \\
0,009 \\
\mathrm{NE} \\
\end{array}$ & $\begin{array}{c}0,026 \\
0,026 \\
\mathrm{NC} \\
0,013 \\
\mathrm{NE} \\
\end{array}$ & 0,022 & $\begin{array}{c}7 \\
3 \\
3 \\
12 \\
- \\
\end{array}$ & $\begin{array}{l}0,037 \\
0,074 \\
0,018 \\
0,074 \\
0,074 \\
\end{array}$ & $\begin{array}{l}0,018 \\
0,037 \\
0,009 \\
0,037 \\
0,037 \\
\end{array}$ & $\begin{array}{l}0,026 \\
0,052 \\
0,013 \\
0,052 \\
0,052 \\
\end{array}$ & 0,039 & $\begin{array}{c}26 \\
25 \\
28 \\
9 \\
6 \\
\end{array}$ \\
\hline $\begin{array}{c}\text { Zinco } \\
(\mathrm{em} \mathrm{mg} / \mathrm{L})\end{array}$ & $\begin{array}{l}1 \\
2 \\
3\end{array}$ & $\begin{array}{l}5,7 \\
4,5 \\
9,1\end{array}$ & $\begin{array}{l}2,3 \\
2,3 \\
4,5\end{array}$ & $\begin{array}{l}3,6 \\
3,2 \\
6,4\end{array}$ & 4,4 & $\begin{array}{c}8 \\
16 \\
13\end{array}$ & $\begin{array}{l}4,5 \\
9,1 \\
4,5\end{array}$ & $\begin{array}{l}2,3 \\
4,5 \\
2,3\end{array}$ & $\begin{array}{l}3,2 \\
6,4 \\
3,2\end{array}$ & 4,3 & $\begin{array}{c}5 \\
13 \\
12\end{array}$ \\
\hline
\end{tabular}

continua 
continuação

Tabela 02 - Resultados dos testes ecotoxicológicos crônicos, de curta duração, para a sobrevivência das fases embriolarval e larval de I anio rerio frente a diversas substâncias, em 168 horas de exposição, calculados pelo teste de hipóteses.

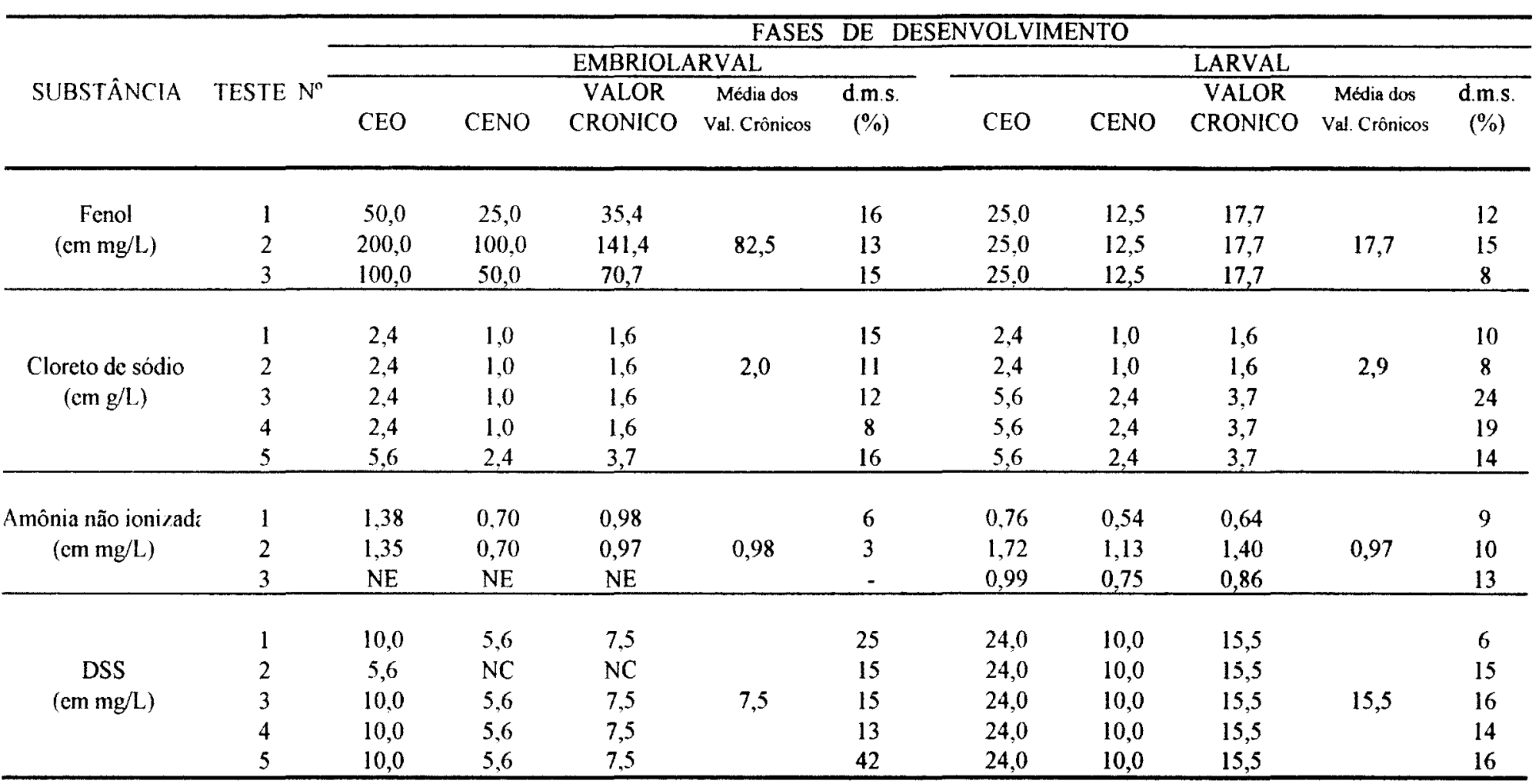

* d.m.s. = diferença minima significativa, em porcentagem relativa ao controle

* $* \mathrm{NC}=$ não calculável

* *NE = não cfetuado 
Tabela 03 - Resultados dos testes ecotoxicológicos crônicos, de curta duração, com a fase embriolarval de Danio rerio e diversas substâncias, em 168 horas de exposição, calculados pelo método LRA.

\begin{tabular}{|c|c|c|c|c|c|}
\hline Substância & Teste $n^{0}$ & $\begin{array}{l}\text { Estimativa } \\
\text { da PCENO }\end{array}$ & Intervalo de confiança & $\begin{array}{l}\text { Média das } \\
\text { PCENO }\end{array}$ & $\begin{array}{c}\text { Coeficiente } \\
\text { de variação } \\
(\%)\end{array}$ \\
\hline $\begin{array}{c}\text { Cádmio } \\
\text { (em mg/L) }\end{array}$ & $\begin{array}{l}1 \\
2 \\
\end{array}$ & $\begin{array}{c}0.256 \\
0.015 \mathbf{0} \\
\end{array}$ & $\begin{array}{c}0.010 \text { a } 6,20 \\
\text { não calculável }\end{array}$ & 0.136 & 125 \\
\hline $\begin{array}{c}\text { Cobre } \\
(\mathrm{em} \mathrm{mg/L})\end{array}$ & $\begin{array}{l}1 \\
2 \\
3 \\
\end{array}$ & $\begin{array}{c}\text { não calculável } \\
0.015 \\
0.0740 \\
\end{array}$ & $\begin{array}{c}- \\
0,000002 \text { a } 124,7 \\
0.061 \text { a } 0.091 \\
\end{array}$ & 0,045 & 93 \\
\hline $\begin{array}{c}\text { Cromo } \\
(\mathrm{cm} \mathrm{mg/L})\end{array}$ & $\begin{array}{l}1 \\
2 \\
3 \\
4 \\
5 \\
6 \\
7 \\
8 \\
9 \\
\end{array}$ & $\begin{array}{c}36,8 \\
6,0 \\
4.6 \\
3.0 \\
0.8 \\
4.90 \\
4.3 \\
12.7 \\
5.80 \\
\end{array}$ & $\begin{array}{c}1.3 \text { a } 1045,8 \\
1.4 \text { a } 27.1 \\
0.2 \text { a } 105,4 \\
0.01 \text { a } 939,4 \\
0.03 \text { a } 22,5 \\
0.2 \text { a } 132.6 \\
2.9 \text { a } 6.4 \\
5.6 \text { a } 28.8 \\
0.2 \text { a } 191.0 \\
\end{array}$ & 8.8 & 137 \\
\hline $\begin{array}{c}\text { Niquel } \\
\text { (em mg/L) }\end{array}$ & $\begin{array}{l}1 \\
2 \\
\end{array}$ & $\begin{array}{c}19.10 \\
9.4 \\
\end{array}$ & $\begin{array}{c}1.8 \text { a } 199.1 \\
2.4 \text { a } 36.7 \\
\end{array}$ & 14.3 & 48 \\
\hline $\begin{array}{l}\text { Metcúrio } \\
\text { (em mg/L) }\end{array}$ & $\begin{array}{l}1 \\
2 \\
3 \\
4 \\
\end{array}$ & $\begin{array}{l}0.089 \\
0.070 \\
0.119 \\
0.009 \\
\end{array}$ & $\begin{array}{c}0.007 \text { a } 0.011 \\
0.0005 \text { a } 9,46 \\
0.001 \text { a } 7.91 \\
0.007 \text { a } 0.010 \\
\end{array}$ & 0.072 & 64 \\
\hline $\begin{array}{c}\text { Prata } \\
\text { (em mg/L) }\end{array}$ & $\begin{array}{l}1 \\
2 \\
3 \\
\end{array}$ & $\begin{array}{l}0.010 \\
0.011 \\
0.015 \\
\end{array}$ & $\begin{array}{l}0.008 \text { a } 0.012 \\
0.007 \text { a } 0.016 \\
0.008 \text { a } 0.026 \\
\end{array}$ & 0.018 & 22 \\
\hline
\end{tabular}


continuação

Tabela 03 - Resultados dos testes ecotoxicológicos crônicos, de curta duração, com a fase embriolarval de Danio rerio e diversas substâncias, em 168 horas de exposição, calculados pelo método LRA.

\begin{tabular}{|c|c|c|c|c|c|}
\hline Substância & Teste $\mathbf{n}^{\mathfrak{0}}$ & $\begin{array}{l}\text { Estimativa } \\
\text { da PCENO }\end{array}$ & Intervalo de confiança & $\begin{array}{l}\text { Média das } \\
\text { PCENO }\end{array}$ & $\begin{array}{c}\text { Coeficiente } \\
\text { de variação } \\
(\%)\end{array}$ \\
\hline $\begin{array}{c}\text { Zinco } \\
\text { (em mg/L) }\end{array}$ & $\begin{array}{l}1 \\
2 \\
3 \\
\end{array}$ & $\begin{array}{l}1,6 \\
0,5 \\
3.6 \\
\end{array}$ & $\begin{array}{l}1,3 \text { a } 2,1 \\
0,1 \text { a } 3,8 \\
3.2 \text { a } 4.0 \\
\end{array}$ & 1,9 & 84 \\
\hline $\begin{array}{c}\text { Fenol } \\
\text { (em mg/L) }\end{array}$ & $\begin{array}{l}1 \\
2 \\
3 \\
\end{array}$ & $\begin{array}{l}27,7 \\
16,4 \\
50,0\end{array}$ & $\begin{array}{c}7,7 \text { a } 100,4 \\
15,2 \text { a } 17,7 \\
10.1 \text { a } 247,6\end{array}$ & 31,4 & 54 \\
\hline $\begin{array}{l}\text { Cloreto de sódio } \\
\quad(\mathrm{em} \mathrm{g} / \mathrm{L})\end{array}$ & $\begin{array}{l}1 \\
2 \\
3 \\
4 \\
5\end{array}$ & $\begin{array}{l}0,81 \\
0.27 \\
2,08 \\
0.23 \\
0.07 \\
\end{array}$ & $\begin{array}{c}0.74 \text { a } 0.91 \\
0.69 \text { a } 1.10 \\
0.28 \text { a } 15.6 \\
0.02 \text { a } 2.40 \\
0.00005 \text { a } 98.7\end{array}$ & 0,69 & 119 \\
\hline $\begin{array}{l}\text { Amônia não ionizada } \\
\text { (em mg/L) }\end{array}$ & $\begin{array}{l}1 \\
2\end{array}$ & $\begin{array}{l}0.68 \\
0.63 \\
\end{array}$ & $\begin{array}{c}0,02 \text { a } 29.40 \\
0.21 \text { a } 1.77 \\
\end{array}$ & 0,66 & 6 \\
\hline $\begin{array}{c}\text { DSS } \\
\text { (em mg/L) }\end{array}$ & $\begin{array}{l}1 \\
2 \\
3 \\
4 \\
5\end{array}$ & $\begin{array}{l}5.0 \\
1.8 \\
1.9 \\
3.6 \\
3.2\end{array}$ & $\begin{array}{l}4.6 \text { a } 5.6 \\
1.3 \text { a } 2.5 \\
0.9 \text { a } 3.8 \\
3.5 \text { a } 3.6 \\
2.7 \text { a } 4.0\end{array}$ & 3.1 & 42 \\
\hline
\end{tabular}

- Calculado pela análise de probitos para cada periodo de observação. 
Tabela 04 - Resultados dos testes ecotoxicológicos crônicos, de curta duração, com a fase larval de Damio rerio e diversas substâncias, em diferentes períodos de exposição, calculados pelo método LRA

\begin{tabular}{|c|c|c|c|c|c|c|c|c|c|}
\hline \multirow{3}{*}{ SUBSTÂNCIA } & \multirow[b]{3}{*}{ TESTE $N^{\circ}$} & \multicolumn{8}{|c|}{ PERIODOS DE EXPOSIÇẢO } \\
\hline & & \multicolumn{4}{|c|}{96 horas } & \multicolumn{4}{|c|}{168 horas } \\
\hline & & $\begin{array}{l}\text { Estimativa } \\
\text { da PCENO }\end{array}$ & Intervalo de confiança & $\begin{array}{l}\text { Média das } \\
\text { PCENO }\end{array}$ & $\begin{array}{c}\text { Coeficiente } \\
\text { de variação } \\
(\%) \\
\end{array}$ & $\begin{array}{l}\text { Estimativa } \\
\text { da PCENO }\end{array}$ & Intervalo de confiança & $\begin{array}{l}\text { Média das } \\
\text { PCENO }\end{array}$ & $\begin{array}{c}\text { Coeficiente } \\
\text { de variação } \\
(\%) \\
\end{array}$ \\
\hline $\begin{array}{c}\text { Cádmio } \\
(\mathrm{em} \mathrm{mg} / \mathrm{L})\end{array}$ & $\begin{array}{r}1 \\
2 \\
3 \\
40 \\
\end{array}$ & $\begin{array}{c}0,081 \\
0.015 \\
0,005 \\
0,0004 \\
\end{array}$ & $\begin{array}{c}0,001 \text { a } 5.22 \\
0,00001 \text { a } 21.58 \\
0.00002 \text { a } 1.32 \\
\propto 0,0 \text { a } 8.22 \\
\end{array}$ & 0.034 & 121 & $\begin{array}{c}0,003 \\
0,011 \\
0,004 \\
0,0001 \\
\end{array}$ & $\begin{array}{c}0,00001 \text { a } 7,78 \\
0,0004 \text { a } 0,37 \\
0,0003 \text { a } 0,06 \\
\propto 0,0 \text { a } 0,03 \\
\end{array}$ & 0,006 & 73 \\
\hline $\begin{array}{c}\text { Cobre } \\
(\mathrm{cm} \mathrm{mg/L})\end{array}$ & $\begin{array}{l}1 \\
2 \\
3 \\
4 \\
\end{array}$ & $\begin{array}{l}0,028 \\
0,028 \\
0,038 \\
0,056 \\
\end{array}$ & $\begin{array}{l}0,012 \text { a } 0.056 \\
0,023 \text { a } 0,030 \\
0,015 \text { a } 0,097 \\
0,053 \text { a } 0,061 \\
\end{array}$ & 0,038 & 34 & $\begin{array}{l}0,028 \\
0,025 \\
0,015 \\
0,013 \\
\end{array}$ & $\begin{array}{r}0,020 \text { a } 0,038 \\
0,023 \text { a } 0,028 \\
0,001 \text { a } 0,132 \\
0,0005 \text { a } 0,341 \\
\end{array}$ & 0,020 & 35 \\
\hline $\begin{array}{c}\text { Cromo } \\
\text { (cm mg/L) }\end{array}$ & $\begin{array}{l}1 \\
2 \\
3 \\
4 \\
5 \\
\end{array}$ & $\begin{array}{c}4.70 \\
0.80 \\
2.98 \\
10.5 \\
10.12 \\
\end{array}$ & $\begin{array}{c}0,6 \text { a } 34,0 \\
0,1 \text { a } 6,4 \\
0.3 \text { a } 23.9 \\
5,2 \text { a } 21,1 \\
0,9 \text { a } 117,6 \\
\end{array}$ & 5.8 & 74 & $\begin{array}{l}1.50 \\
1,00 \\
2.98 \\
2,50 \\
6,30 \\
\end{array}$ & $\begin{array}{c}0,1 \text { a } 24,1 \\
0,4 \text { a } 2,9 \\
1,1 \text { a } 7,9 \\
0,61 \text { a } 82,3 \\
1,3 \text { a } 30,6 \\
\end{array}$ & 2,8 & 75 \\
\hline $\begin{array}{c}\text { Níquel } \\
(\mathrm{em} \mathrm{mg} / \mathrm{L})\end{array}$ & $\begin{array}{l}1 \\
2 \\
3 \\
4\end{array}$ & $\begin{array}{c}12.3 \\
9.38 \\
11,80 \\
15,4\end{array}$ & $\begin{array}{c}3,3 \text { a } 46,2 \\
3.2 \text { a } 27,3 \\
0,3 \text { a } 408,4 \\
1,5 \text { a } 156,7\end{array}$ & 12,2 & 20 & $\begin{array}{c}5,9 \\
5.12 \\
1,42 \\
6,5\end{array}$ & $\begin{array}{c}1.0 \text { a } 35,2 \\
1,2 \text { a } 22,2 \\
0,007 \text { a } 246,4 \\
0,7 \text { a } 61,9\end{array}$ & 4.7 & 49 \\
\hline
\end{tabular}


Tabela 04 - Resultados dos testes ecotoxicológicos crônicos, de curta duração, com a fase larval de Danio rerio e diversas substâncias, em diferentes períodos de exposiçăo, calculados pelo método LRA

\begin{tabular}{|c|c|c|c|c|c|c|c|c|c|}
\hline \multirow{3}{*}{ SUBSTÂNCIA } & \multirow[b]{3}{*}{ TESTE $N^{\circ}$} & \multicolumn{8}{|c|}{ PERIODOS DE EXPOSIÇÃO } \\
\hline & & \multicolumn{4}{|c|}{96 horas } & \multicolumn{4}{|c|}{168 horas } \\
\hline & & $\begin{array}{l}\text { Estimativa } \\
\text { da PCENO }\end{array}$ & Intervalo de confiança & $\begin{array}{l}\text { Média das } \\
\text { PCENO }\end{array}$ & $\begin{array}{c}\text { Coeficiente } \\
\text { de variação } \\
(\%)\end{array}$ & $\begin{array}{l}\text { Estimativa } \\
\text { da PCENO }\end{array}$ & Intervalo de confiança & $\begin{array}{l}\text { Média das } \\
\text { PCENO }\end{array}$ & $\begin{array}{c}\text { Coeficiente } \\
\text { de variação } \\
(\%)\end{array}$ \\
\hline $\begin{array}{c}\text { Mercúrio } \\
(\mathrm{cm} \mathrm{mg} / \mathrm{L})\end{array}$ & $\begin{array}{l}1 \\
2 \\
3 \\
4 \\
5 \\
\end{array}$ & $\begin{array}{c}0.012 \\
0.1483 \\
0.010 \\
0,093 \\
0,128 \\
\end{array}$ & $\begin{array}{c}0,0007 \text { a } 0.214 \\
\text { não calculável } \\
0,009 \text { a } 0.010 \\
0,018 \text { a } 0,451 \\
0,034 \text { a } 0,485 \\
\end{array}$ & 0,078 & 82 & $\begin{array}{l}0.008 \\
0.066 \\
0.007 \\
0.053 \\
0.057 \\
\end{array}$ & $\begin{array}{l}0,002 \text { a } 0,041 \\
0,010 \text { a } 0,409 \\
0,004 \text { a } 0,013 \\
0,012 \text { a } 0,231 \\
0,008 \text { a } 0,404 \\
\end{array}$ & 0,038 & 74 \\
\hline $\begin{array}{c}\text { Prata } \\
\text { (em mg/L) }\end{array}$ & $\begin{array}{l}1 \\
2 \\
3 \\
4 \\
\end{array}$ & $\begin{array}{c}0,008 \\
0,015 \\
0,0323 \\
0,010 \\
\end{array}$ & $\begin{array}{l}0,002 \text { a } 0,027 \\
0,012 \text { a } 0,017 \\
\text { não calculável } \\
0,008 \text { a } 0,015 \\
\end{array}$ & 0,016 & 69 & $\begin{array}{l}0.008 \\
0.015 \\
0,032 \\
0.012 \\
\end{array}$ & $\begin{array}{r}0,004 \text { a } 0,135 \\
0,013 \text { a } 0,017 \\
\text { não calculável } \\
0,008 \text { a } 0,017 \\
\end{array}$ & 0,017 & 65 \\
\hline $\begin{array}{c}\text { Zinco } \\
(\mathrm{em} \mathrm{mg} / \mathrm{L} \text { ) }\end{array}$ & $\begin{array}{l}1 \\
2 \\
3 \\
\end{array}$ & $\begin{array}{l}0.43 \\
0,64 \\
0.32 \\
\end{array}$ & $\begin{array}{c}0,10 \text { a } 1,86 \\
0,03 \text { a } 15.12 \\
0,02 \text { a } 4,62 \\
\end{array}$ & 0,46 & 35 & $\begin{array}{l}0.51 \\
0.71 \\
0.57 \\
\end{array}$ & $\begin{array}{l}0,23 \text { a } 1,14 \\
0,16 \text { a } 3,16 \\
0,10 \text { a } 3,40 \\
\end{array}$ & 0,60 & 17 \\
\hline $\begin{array}{c}\text { Fenol } \\
(\mathrm{em} \mathrm{mg} / \mathrm{L})\end{array}$ & $\begin{array}{l}1 \\
2 \\
3 \\
\end{array}$ & $\begin{array}{l}11,0 \\
17,7 \\
55,4 \\
\end{array}$ & $\begin{array}{c}0.11 \text { a } 1.123,6 \\
0,14 \text { a } 2.173,2 \\
5,85 \text { a } 524,7 \\
\end{array}$ & 28,0 & 85 & $\begin{array}{r}8,4 \\
9,7 \\
20,6 \\
\end{array}$ & $\begin{array}{r}0,88 \text { a } 80,8 \\
0,69 \text { a } 136,9 \\
1,72 \text { a } 248,3 \\
\end{array}$ & 12,9 & 52 \\
\hline
\end{tabular}


Continuação

Tabela 04 - Resultados dos testes ecotoxicológicos crônicos, de curta duração, com a fase larval de Damio rerio e diversas substâncias, em diferentes períodos de exposição, calculados pelo método LRA

\begin{tabular}{|c|c|c|c|c|c|c|c|c|c|}
\hline \multirow{3}{*}{ SUBSTÂNCIA } & \multirow[b]{3}{*}{ TESTE $N^{\circ}$} & \multicolumn{8}{|c|}{ PERIODOS DE EXPOSICACO } \\
\hline & & \multicolumn{4}{|c|}{96 horas } & \multicolumn{4}{|c|}{168 horas } \\
\hline & & $\begin{array}{l}\text { Estimativa } \\
\text { da PCENO }\end{array}$ & Intervalo de confiança & $\begin{array}{l}\text { Média das } \\
\text { PCENO }\end{array}$ & $\begin{array}{c}\text { Coeficiente } \\
\text { de variação } \\
(\%)\end{array}$ & $\begin{array}{l}\text { Estimativa } \\
\text { da PCENO }\end{array}$ & Intervalo de confiança & $\begin{array}{l}\text { Média das } \\
\text { PCENO }\end{array}$ & $\begin{array}{c}\text { Coeficiente } \\
\text { de variação } \\
(\%)\end{array}$ \\
\hline \multirow{4}{*}{$\begin{array}{l}\text { Cloreto de sódio } \\
\quad(\mathrm{em} \mathrm{g} / \mathrm{L})\end{array}$} & 1 & 1,0 & 1,0 a 1,0 & \multirow{4}{*}{2,0} & \multirow{4}{*}{50,0} & 1,0 & não calculável & \multirow{4}{*}{1,1} & \multirow{4}{*}{36} \\
\hline & 2 & 2,1 & 0,49 a 9,67 & & & 1,3 & 0,3 a 5,3 & & \\
\hline & 3 & 3,3 & 0.55 a 20.0 & & & 1,8 & 0,3 a 9,3 & & \\
\hline & 4 & 2.5 & 0,65 a 10,3 & & & 0,7 & 0,04 a 13,8 & & \\
\hline \multirow{3}{*}{$\begin{array}{c}\text { Amonia } \\
\text { não ionizada } \\
\text { (em } \mathrm{mg} / \mathrm{L} \text { ) }\end{array}$} & 1 & 0.39 & 0,21 a 0,72 & \multirow{3}{*}{0,55} & \multirow{3}{*}{25} & 0.39 & 0,29 a 0,52 & \multirow{3}{*}{0,56} & \multirow{3}{*}{25} \\
\hline & 2 & 0,64 & 0,62 a 0,67 & & & 0,64 & 0,63 a 0,65 & & \\
\hline & 3 & 0,61 & 0,45 a 0,83 & & & 0.64 & 0,54 a 0,76 & & \\
\hline \multirow{4}{*}{$\begin{array}{c}\text { DSS } \\
(\mathrm{em} \mathrm{mg} / \mathrm{L})\end{array}$} & 1 & 12.3 & 2,7 a 56,1 & \multirow{4}{*}{13,5} & \multirow{4}{*}{35} & 6,6 & 1,3 a 32,7 & & \multirow{4}{*}{51} \\
\hline & 2 & 15.8 & 2,9 a 86,1 & & & 11,8 & 4,2 a 33,4 & & \\
\hline & 3 & 19,9 & 12,0 a 33,0 & & & 10.4 & 2,3 a 46,8 & 7,3 & \\
\hline & 4 & 7,2 & 0,6 a 83,3 & & & 4,2 & 0,75 a 23,0 & & \\
\hline
\end{tabular}

- Teste não considerado nos cálculos devido a ausência de monotonicidade dos dados experimentais

2 Cálculado pela análise de próbilos para cada período de observação

(3) Calculado manualmente 
Tabela 05 - Resultados dos testes ecotoxicológicos com jovens de Danio rerio e diversas substâncias, em diferentes periodos de exposição, calculados pelo método LRA.

\begin{tabular}{|c|c|c|c|c|}
\hline \multirow[b]{3}{*}{ SUBSTÂNCIA } & \multicolumn{4}{|c|}{ PERIODOS DE EXPOSIÇÁO } \\
\hline & \multicolumn{2}{|r|}{96 horas } & \multicolumn{2}{|r|}{168 horas } \\
\hline & $\begin{array}{l}\text { Estimativa } \\
\text { da PCENO }\end{array}$ & Intervalo de confiança & $\begin{array}{l}\text { Estimativa } \\
\text { da PCENO }\end{array}$ & Intervalo de confiança \\
\hline Cádmio (em mg/L) & 2.4 & 2,3 a 2,5 & 2,4 & 2,3 a 2,5 \\
\hline Cobre (em mg/L) & 0,084 & 0.074 a 0,094 & 0,092 & 0,076 a 0,109 \\
\hline Cromo (em $\mathrm{mg} / \mathrm{L})$ & 1,3 & 0,6 a 3,0 & 1,6 & 0,9 a 2,9 \\
\hline Niquel (em $\mathrm{mg} / \mathrm{L}$ ) & 8,2 & 1,0 a 69,1 & 2.60 & 0,4 a 18,7 \\
\hline Mercírio (em mg/L) & 0.096 & 0,089 a 0,103 & 0,096 & 0,089 a 0,103 \\
\hline Prata (em mg/L) & 0.016 & 0,013 a 0,019 & 0,015 & 0.014 a 0,017 \\
\hline Zinco (em mg/L) & 1,7 & 1,0 a 3,0 & 1,9 & 1,4 a 2,7 \\
\hline Fenol (em $\mathrm{mg} / \mathrm{L}$ ) & 24.7 & 23.9 a 25.6 & 24,2 & 23.0 a 25.5 \\
\hline Cloreto de sódio (em g/L) & 4.5 & 3.7 a 5,7 & 4.7 & 4.1 a 5.4 \\
\hline mônia não ionizada ( $\mathrm{cm} \mathrm{mg} /$ ) & 1,4 & 1,2 a 1,6 & 1,4 & 1,3 a 1,5 \\
\hline DSS (em mg/L) & 12.5 & 2,5 a 61,7 & não efetuado & - \\
\hline
\end{tabular}

- Calculado pela análise de probitos para cada periodo de observação 
Tabela 06 - Resultados dos testes ecotoxicológicos crônicos, de curta duração, com a fase embriolarval de Danio rerio e diversas substâncias, em 168 horas de exposição, calculados pelo método ICp para a sobrevivência dos organismos.

\begin{tabular}{|c|c|c|c|c|c|}
\hline Substâncias & Teste $\mathbf{n}^{\circ}$ & $\begin{array}{l}\text { Estimativa } \\
\text { da CL(I) } 5\end{array}$ & Intervalo de confiança & $\begin{array}{l}\text { Média das } \\
\text { CL(I) } 5\end{array}$ & $\begin{array}{l}\text { Coeficiente } \\
\text { de variação } \\
(\%) \\
\end{array}$ \\
\hline $\begin{array}{c}\text { Cádmio } \\
(\mathrm{em} \mathrm{mg} / \mathrm{L})\end{array}$ & $\begin{array}{l}1 \\
2 \\
\end{array}$ & $\begin{array}{l}0,123 \\
0,184 \\
\end{array}$ & $\begin{array}{l}0,092 \text { a } 0,262 \\
0,128 \text { a } 0,328 \\
\end{array}$ & 0,154 & 29 \\
\hline $\begin{array}{c}\text { Cobre } \\
(\mathrm{em} \mathrm{mg/L})\end{array}$ & $\begin{array}{l}1 \\
2 \\
3 \\
\end{array}$ & $\begin{array}{l}0,035 \\
0,025 \\
0,127 \\
\end{array}$ & $\begin{array}{l}0,017 \text { a } 0,065 \\
0,013 \text { a } 0,032 \\
0,091 \text { a } 0,139 \\
\end{array}$ & 0,062 & 90 \\
\hline $\begin{array}{c}\text { Cromo } \\
(\mathrm{em} \mathrm{mg/L})\end{array}$ & $\begin{array}{l}1 \\
2 \\
3 \\
4 \\
5 \\
6 \\
7 \\
8 \\
9 \\
\end{array}$ & $\begin{array}{c}4,4 \\
20,7 \\
2,8 \\
4,6 \\
2,7 \\
5,9 \\
20,9 \\
23,3 \\
17,0 \\
\end{array}$ & $\begin{array}{c}3,1 \text { a } 17,7 \\
20,6 \text { a } 20,9 \\
1,7 \text { a } 12,9 \\
3,0 \text { a } 8,9 \\
2,5 \text { a } 3,3 \\
3,7 \text { a } 14,8 \\
17,0 \text { a } 23,7 \\
21,8 \text { a } 29,6 \\
12,7 \text { a } 21,7 \\
\end{array}$ & 11,4 & 77 \\
\hline $\begin{array}{c}\text { Niquel } \\
(\mathrm{em} \mathrm{mg} / \mathrm{L})\end{array}$ & $\begin{array}{l}1 \\
2 \\
\end{array}$ & $\begin{array}{l}18,0 \\
16.5 \\
\end{array}$ & $\begin{array}{l}16.3 \text { a } 28.7 \\
15.4 \text { a } 28.6 \\
\end{array}$ & 17,3 & 6 \\
\hline $\begin{array}{l}\text { Mercúrio } \\
(\mathrm{em} \mathrm{mg} / \mathrm{L})\end{array}$ & $\begin{array}{l}1 \\
2 \\
3 \\
4 \\
\end{array}$ & $\begin{array}{l}0,019 \\
0,019 \\
0,012 \\
0,011 \\
\end{array}$ & $\begin{array}{l}0,015 \text { a } 0,020 \\
0,012 \text { a } 0,019 \\
0,009 \text { a } 0,019 \\
0,010 \text { a } 0,012\end{array}$ & 0.015 & 27 \\
\hline $\begin{array}{c}\text { Prata } \\
\text { (em mg/L) }\end{array}$ & $\begin{array}{l}1 \\
2 \\
3\end{array}$ & $\begin{array}{l}0,016 \\
0,016 \\
0,019\end{array}$ & $\begin{array}{l}0.016 \text { a } 0.017 \\
0.011 \text { a } 0.018 \\
0.015 \text { a } 0.028\end{array}$ & 0,017 & 12 \\
\hline
\end{tabular}


continuação

Tabela 06 - Resultados dos testes ecotoxicológicos crônicos, de curta duração, com a fase embriolarval de Danio rerio e diversas substâncias, em 168 horas de exposição, calculados pelo método ICp para a sobrevivência dos organismos.

\begin{tabular}{|c|c|c|c|c|c|}
\hline Substâncias & Teste $\mathrm{n}^{\circ}$ & $\begin{array}{l}\text { Estimativa } \\
\text { da CL(I) } 5\end{array}$ & Intervalo de confiança & $\begin{array}{l}\text { Média das } \\
\text { CL(I) } 5\end{array}$ & $\begin{array}{c}\text { Coeficiente } \\
\text { de variação } \\
(\%)\end{array}$ \\
\hline $\begin{array}{c}\text { Zinco } \\
(\mathrm{em} \mathrm{mg} / \mathrm{L})\end{array}$ & $\begin{array}{l}1 \\
2 \\
3 \\
\end{array}$ & $\begin{array}{l}2,5 \\
2,6 \\
4,8 \\
\end{array}$ & $\begin{array}{l}2,5 \text { a } 2,6 \\
1,6 \text { a } 3,2 \\
4,7 \text { a } 4,8 \\
\end{array}$ & 3,3 & 39 \\
\hline $\begin{array}{c}\text { Fenol } \\
(\mathrm{em} \mathrm{mg/L})\end{array}$ & $\begin{array}{l}1 \\
2 \\
3 \\
\end{array}$ & $\begin{array}{l}26,2 \\
33,3 \\
44,8 \\
\end{array}$ & $\begin{array}{l}20,8 \text { a } 27,6 \\
25,0 \text { a } 80,0 \\
37,5 \text { a } 61,9 \\
\end{array}$ & 34,8 & 27 \\
\hline $\begin{array}{l}\text { Cloreto de sódio } \\
\quad(\mathrm{em} \mathrm{g} / \mathrm{L})\end{array}$ & $\begin{array}{l}1 \\
2 \\
3 \\
4 \\
5 \\
\end{array}$ & $\begin{array}{l}1,2 \\
1,0 \\
1,0 \\
1,3 \\
1,4 \\
\end{array}$ & $\begin{array}{l}0,8 \text { a } 1,3 \\
0,5 \text { a } 1,1 \\
0,8 \text { a } 1,4 \\
0,9 \text { a } 1,4 \\
1,3 \text { a } 1,9 \\
\end{array}$ & 1,2 & 17 \\
\hline $\begin{array}{l}\text { Amônia não ionizada } \\
\text { (em mg/L) }\end{array}$ & $\begin{array}{l}1 \\
2\end{array}$ & $\begin{array}{l}0,47 \\
0,70\end{array}$ & $\begin{array}{l}0.23 \text { a } 0,73 \\
0.47 \text { a } 0,73\end{array}$ & 0,59 & 27 \\
\hline $\begin{array}{c}\text { DSS } \\
\text { (em } \mathrm{mg} / \mathrm{L})\end{array}$ & $\begin{array}{l}1 \\
2 \\
3 \\
4 \\
5\end{array}$ & $\begin{array}{l}5,9 \\
1,4 \\
5,9 \\
6,1 \\
4,2\end{array}$ & $\begin{array}{l}5,9 \text { a } 6,0 \\
0,9 \text { a } 2,6 \\
4,2 \text { a } 5,9 \\
5,7 \text { a } 6,2 \\
2.8 \text { a } 6,0\end{array}$ & 4,7 & 42 \\
\hline
\end{tabular}


Tabela 07 - Resultados dos testes ecotoxicológicos crônicos, de curta duração, com a fase larval de Danio rerio e diversas substâncias, em 168 horas de exposição, calculados pelo método ICp para diferentes níveis de efeito na sobrevivência.

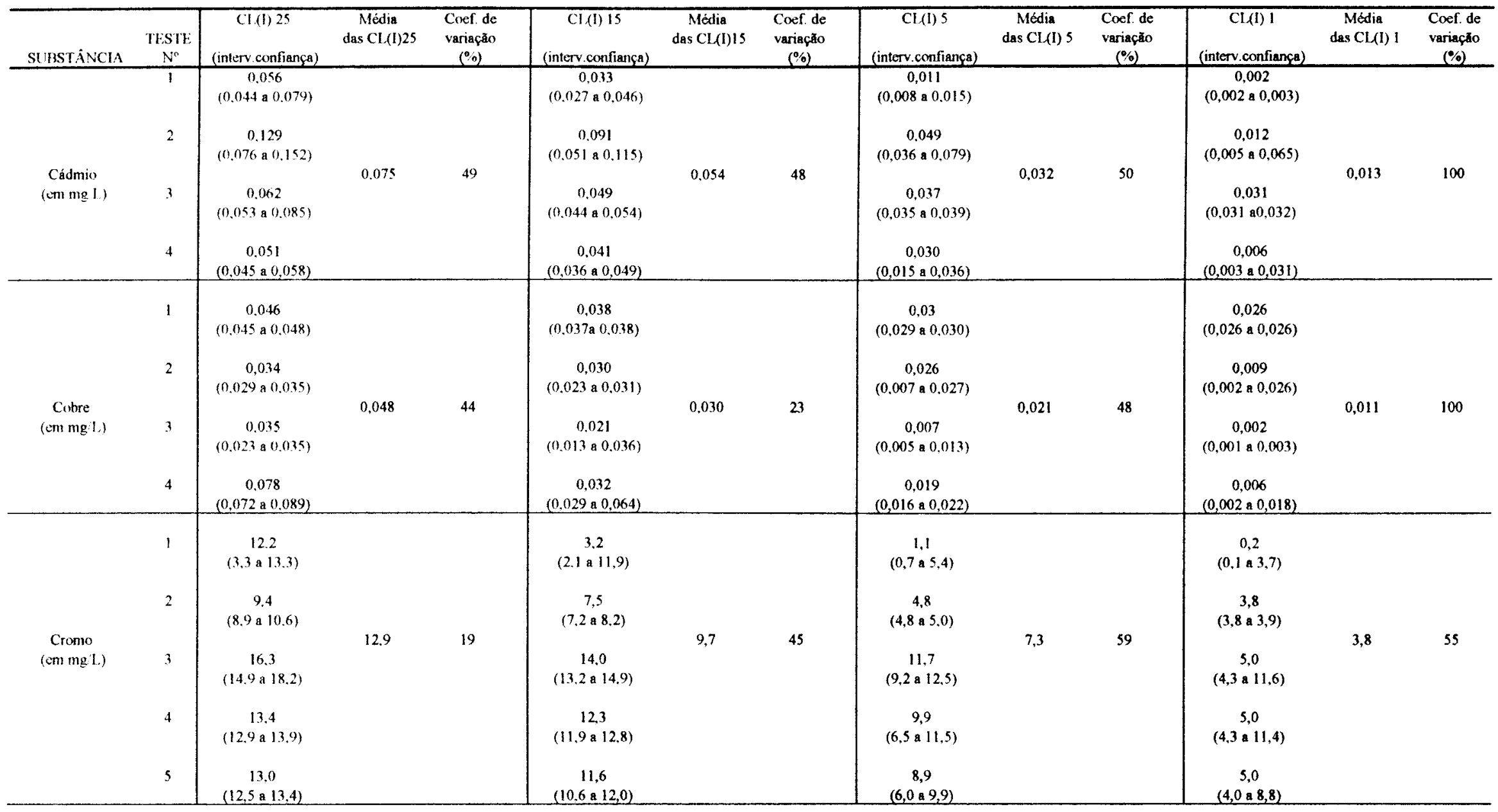


Tabela 07 - Resultados dos testes ecotoxicológicos crônicos, de curta duração, com a fase larval de Danio rerio e diversas substâncias, em 168 horas de exposição, calculados pelo método $\mathrm{ICp}$ para diferentes níveis de efeito na sobrevivência.

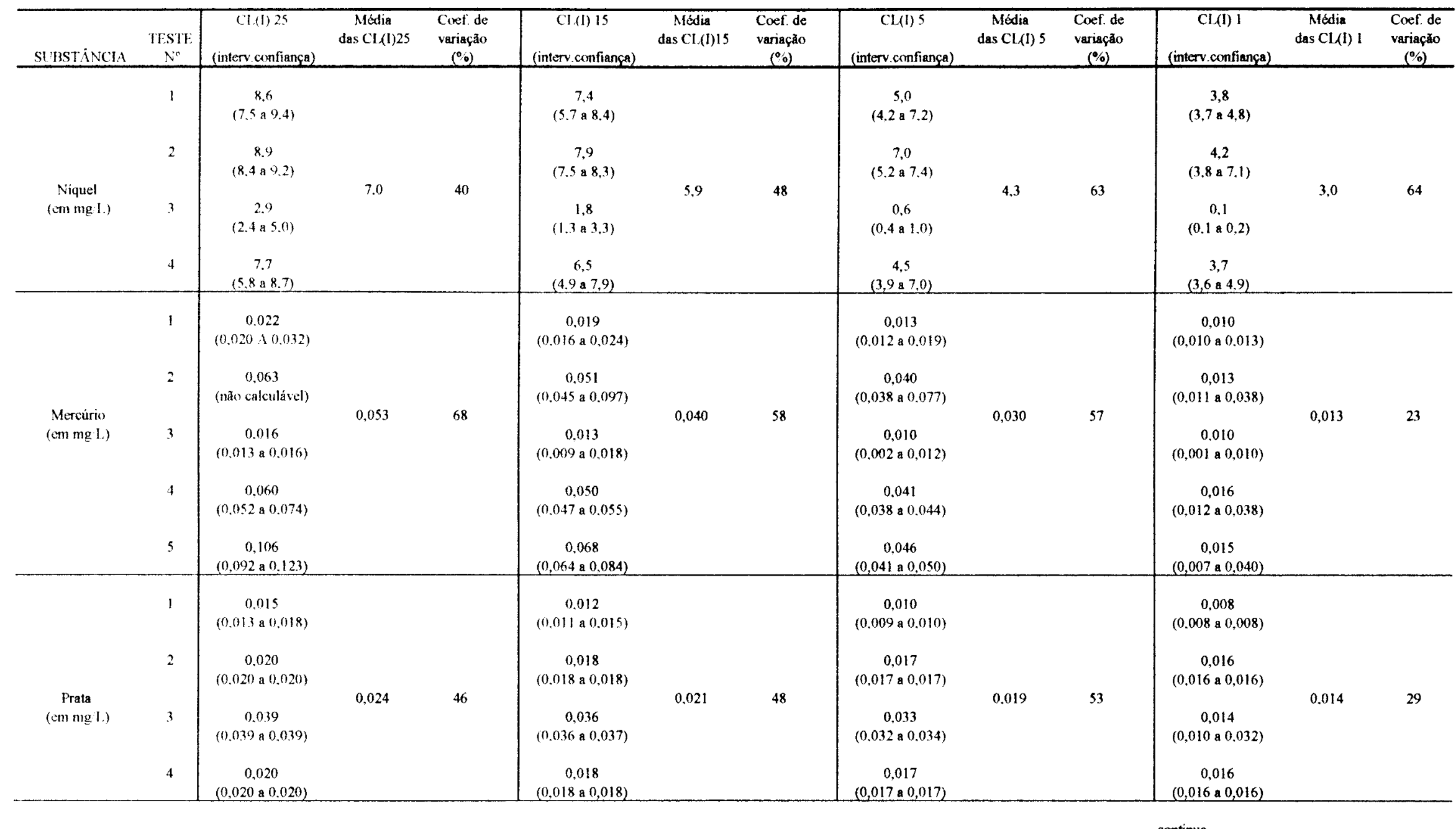


Tabela 07 - Resultados dos testes ecotoxicológicos crônicos, de curta duração, com a fase larval de Danio rerio e diversas substâncias, em 168 horas de exposição, calculados pelo método ICp para diferentes níveis de efeito na sobrevivência.

\begin{tabular}{|c|c|c|c|c|c|c|c|c|c|c|c|c|c|}
\hline SUEBSTANCLA & $\begin{array}{c}\text { TESTE } \\
\mathrm{N}^{\circ} \\
\end{array}$ & $\begin{array}{c}\mathrm{CL}(\mathrm{I}) 25 \\
\text { (interv.comfianca) } \\
\end{array}$ & $\begin{array}{c}\text { Média } \\
\text { das CL(I)25 }\end{array}$ & $\begin{array}{c}\text { Coef. de } \\
\text { variação } \\
(\%) \\
\end{array}$ & $\begin{array}{c}\text { CI.(I) } 15 \\
\text { (interv.confianca) }\end{array}$ & $\begin{array}{c}\text { Módia } \\
\text { das } \mathrm{Cl}(\mathrm{l}) 15\end{array}$ & $\begin{array}{c}\text { Coef. de } \\
\text { variaçito } \\
(\%)\end{array}$ & $\begin{array}{c}\mathrm{CL}(\mathrm{I}) \mathrm{S} \\
\text { (interv.confianca) }\end{array}$ & $\begin{array}{c}\text { Média } \\
\text { das CL(I) } 5\end{array}$ & $\begin{array}{c}\text { Coef. de } \\
\text { variaçàto } \\
(\%) \\
\end{array}$ & $\begin{array}{c}\text { CL(I) } 1 \\
\text { (interv.confianga) }\end{array}$ & $\begin{array}{c}\text { Média } \\
\text { das CL(I) } 1\end{array}$ & $\begin{array}{c}\text { Coef. de } \\
\text { variaçdo } \\
(\%) \\
\end{array}$ \\
\hline $\begin{array}{c}\text { 7inco } \\
\text { (am mg L) }\end{array}$ & $\begin{array}{l}2 \\
3\end{array}$ & $\begin{array}{c}2.8 \\
(2.7 \mathrm{a} 3.0) \\
5.8 \\
(4.8 \mathrm{a} 6.2) \\
3.1 \\
(2.8 \mathrm{a} 3.4) \\
\end{array}$ & 3.9 & 44 & $\begin{array}{c}2,5 \\
(2,4 \text { a } 2,7) \\
5,1 \\
(3.8 \text { a } 5.5) \\
2,7 \\
(2,6 \text { a } 2,8)\end{array}$ & 3,6 & 43 & $\begin{array}{c}1,7 \\
(0,8 \times 2.4) \\
4,0 \\
(2,0 \therefore 4.8) \\
2,4 \\
(1,5 \text { a } 2,5)\end{array}$ & 2,7 & 44 & $\begin{array}{c}0,5 \\
(0,2 \otimes 1,3) \\
\\
2,0 \\
(1,4 \& 4,6) \\
0,9 \\
(0,3 \approx 2,3)\end{array}$ & 1,1 & 73 \\
\hline $\begin{array}{c}\text { Fenol } \\
\text { (em mg L.) }\end{array}$ & $\begin{array}{l}2 \\
3\end{array}$ & $\begin{array}{c}18.0 \\
(16.7 \text { a } 19.7) \\
17.0 \\
(15.7 \text { a } 20.0) \\
27.5 \\
(22,1 \times 29.7)\end{array}$ & 20,8 & 28 & $\begin{array}{c}15.8 \\
(15.0 \text { a } 16,7) \\
14.8 \\
(13.8 \text { a } 16.7) \\
23.2 \\
(18,3 \times 26,7)\end{array}$ & 17,9 & 26 & $\begin{array}{c}13.6 \\
(13,3 \text { a } 14.0) \\
12.5 \\
(6,3 \text { a } 13.6) \\
16,1 \\
(15,0 \text { a } 18,8)\end{array}$ & 14,1 & 13 & $\begin{array}{c}12,7 \\
(12,6 \text { a } 12,8) \\
2,5 \\
(1,2 \text { a } 12,8) \\
13,2 \\
(12,9 \times 13,8) \\
\end{array}$ & 9,5 & 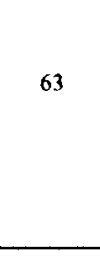 \\
\hline $\begin{array}{l}\text { Cloreto de sídio }) \\
(\mathrm{em} \mathrm{QL})\end{array}$ & $\begin{array}{l}3 \\
4 \\
5\end{array}$ & $\begin{array}{c}1.6 \\
(1.6 \mathrm{a} 1.6) \\
1.5 \\
(1.4 \times 1.7) \\
3,0 \\
(1.7 \mathrm{a} 3.7) \\
3,1 \\
(2.8 \mathrm{a} .3 .3) \\
2,8 \\
(2,2 \mathrm{a} 3.2)\end{array}$ & 2,4 & 33 & $\begin{array}{c}1,4 \\
(1,4 \text { a } 1.4) \\
1,3 \\
(1,3 \text { a } 1,4) \\
2,4 \\
(1,6 \text { a } 3,2) \\
2,7 \\
(2.1 \text { a } 3,0) \\
\\
2,4 \\
(1,8 \text { a } 2,8)\end{array}$ & 2,0 & 30 & $\begin{array}{c}1,1 \\
(1,1 \text { a } 1,1) \\
1,1 \\
(1,1 \text { a } 1,1) \\
1,4 \\
(1,2 \text { a } 2,7) \\
1,6 \\
(0.3 \text { a } 2.6) \\
1,4 \\
(1,3 \text { a } 2.6)\end{array}$ & 1,3 & 15 & $\begin{array}{c}1,0 \\
(1,0 \mathrm{a} 1,0) \\
1,0 \\
(1,0 \mathrm{a} 1,0) \\
1,1 \\
(1,0 \mathrm{a} 2.4) \\
0.2 \\
(0,04 \mathrm{a} 2.4) \\
1,1 \\
(1,0 \mathrm{a} 2.4)\end{array}$ & 0,9 & 44 \\
\hline
\end{tabular}


contimuą̧ằ

Tabela 07 - Resultados dos testes ecotoxicológicos crônicos, de curta duração, com a fase larval de Danio rerio e diversas substâncias, em 168 horas de exposição, calculados pelo método ICp para diferentes níveis de efeito na sobrevivência.

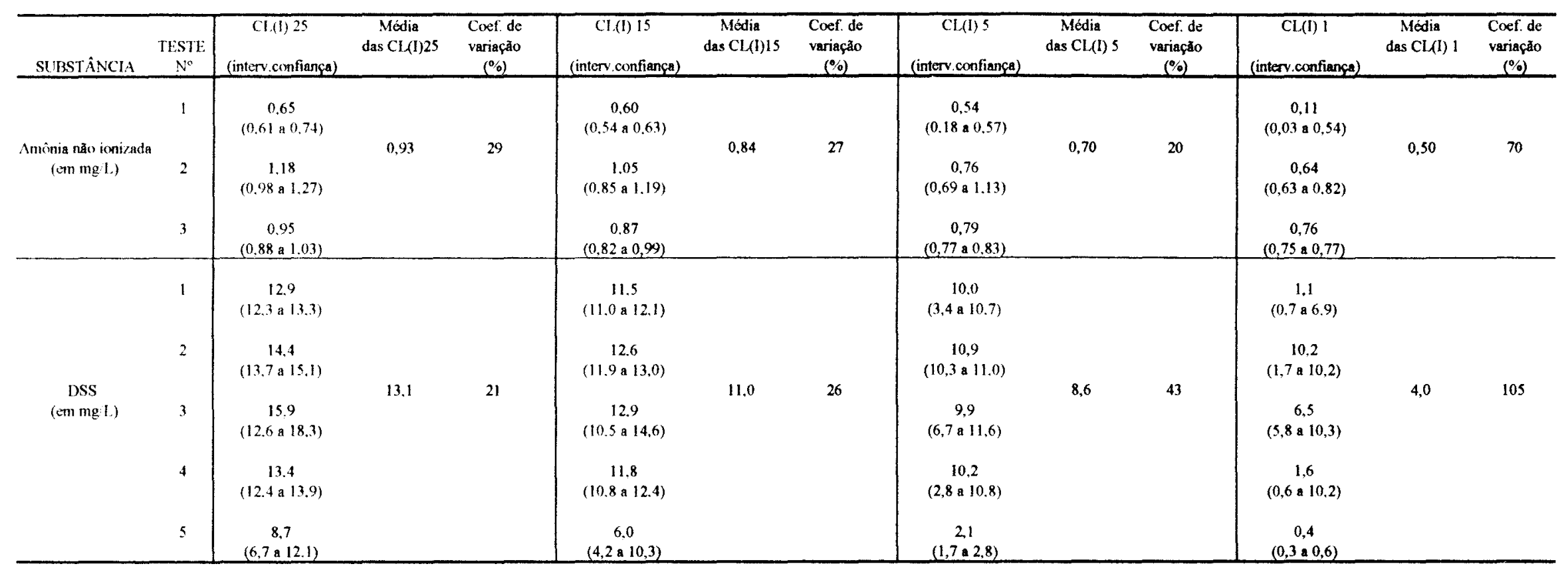


Tabela 08 - Resultados dos testes ecotoxicológicos crônicos, de curta duração, com a fase larval de Danio rerio e diversas substâncias, em 168 horas de exposição, calculados pelo método dos Probitos para diferentes níveis de efeito na sobrevivência.

\begin{tabular}{|c|c|c|c|c|c|c|c|c|c|c|}
\hline SUBSTAANCIA & $\begin{array}{c}\text { TESTE } \\
N^{\circ} \\
\end{array}$ & $\begin{array}{c}\text { (I/1) } 15 \\
\text { (interv.confianca) }\end{array}$ & $\begin{array}{c}\text { Média } \\
\text { das Cl(I) } 15\end{array}$ & $\begin{array}{l}\text { Coef. de } \\
\text { variaça } \\
\text { (0.0) }\end{array}$ & $\begin{array}{c}\text { CI(I) } 5 \\
\text { (interviconfianca) }\end{array}$ & $\begin{array}{c}\text { Media } \\
\text { das Cu(I) } 5\end{array}$ & $\begin{array}{l}\text { Coef. de } \\
\text { variação } \\
(\%)\end{array}$ & $\begin{array}{c}\text { CL(I) 1 } \\
\text { (imterv.confianca) }\end{array}$ & $\begin{array}{c}\text { Módia } \\
\text { das Cl(1) } 1\end{array}$ & $\begin{array}{c}\text { Coef de } \\
\text { variaçalo } \\
(\%)\end{array}$ \\
\hline \multirow{4}{*}{$\begin{array}{l}\text { Cádmio } \\
\text { (em mg l.) }\end{array}$} & 1 & $\begin{array}{c}0.024 \\
(0,006 \text { a } 0.049)\end{array}$ & \multirow{4}{*}{0.050} & \multirow{4}{*}{64} & $\begin{array}{c}0.007 \\
(0.001 \text { a } 0.020)\end{array}$ & \multirow{4}{*}{0,026} & \multirow{4}{*}{84} & $\begin{array}{c}0,002 \\
(0,001 \text { a } 0,007)\end{array}$ & \multirow{4}{*}{0,013} & \multirow{4}{*}{100} \\
\hline & 2 & $\begin{array}{c}0.093 \\
(0.063 \text { a } 0.122)\end{array}$ & & & $\begin{array}{c}0,054 \\
(0,033 \text { a } 0,076)\end{array}$ & & & $\begin{array}{c}0,030 \\
(0,015 \mathrm{a} 0,046)\end{array}$ & & \\
\hline & 3 & $\begin{array}{c}0,055 \\
(0.038 \text { a } 0,073)\end{array}$ & & & $\begin{array}{c}0,032 \\
(0,019 \mathrm{a} 0,045)\end{array}$ & & & $\begin{array}{c}0,017 \\
(0,009 \times 0,027)\end{array}$ & & \\
\hline & 4 & $\begin{array}{c}0,027 \\
\text { (nåo calculável) }\end{array}$ & & & $\begin{array}{c}0,011 \\
\text { (nto calculável) }\end{array}$ & & & $\begin{array}{c}0,004 \\
\text { (nảo calculável) }\end{array}$ & & \\
\hline \multirow{4}{*}{$\begin{array}{l}\text { Cobre } \\
\text { (emm mgl.) }\end{array}$} & 1 & $\begin{array}{c}0,041 \\
(0,029 \mathrm{a} 0,050)\end{array}$ & \multirow{4}{*}{0.037} & \multirow{4}{*}{22} & $\begin{array}{c}0,032 \\
(0,021: 0,041)\end{array}$ & \multirow{4}{*}{0,024} & \multirow{4}{*}{33} & $\begin{array}{c}0,024 \\
(0,014 \text { a } 0,033)\end{array}$ & \multirow{4}{*}{0,015} & \multirow{4}{*}{53} \\
\hline & 2 & não calculável & & & nao calculável & & & não calculável & & \\
\hline & 3 & $\begin{array}{c}0.027 \\
(0.018 \mathbf{a} 0.036)\end{array}$ & & & $\begin{array}{c}0,016 \\
(0,009 \text { a } 0,024)\end{array}$ & & & $\begin{array}{c}0,009 \\
(0,004 \text { a } 0,015)\end{array}$ & & \\
\hline & 4 & $\begin{array}{c}0,042 \\
(0,030 \mathrm{a} 0,054)\end{array}$ & & & $\begin{array}{c}0,024 \\
(0,015 \mathrm{a} 0,033)\end{array}$ & & & $\begin{array}{c}0,013 \\
(0,007 \times 0,020) \\
\end{array}$ & & \\
\hline \multirow{5}{*}{$\begin{array}{l}\text { Cromo } \\
(\mathrm{em} \mathrm{mgL} \text { ) }\end{array}$} & 1 & $\begin{array}{c}4.5 \\
\text { (næo calculável) }\end{array}$ & \multirow{5}{*}{9,0} & \multirow{5}{*}{47} & $\begin{array}{c}2,7 \\
\text { (nåo calculável) }\end{array}$ & \multirow{5}{*}{6,9} & \multirow{5}{*}{92} & $\begin{array}{c}1,5 \\
\text { (nđa calculável) }\end{array}$ & \multirow{5}{*}{5,2} & \multirow{5}{*}{56} \\
\hline & 2 & $\begin{array}{c}4,7 \\
\text { (ñ̃o calculável) }\end{array}$ & & & $\begin{array}{c}3,7 \\
\text { (nåo calculável) }\end{array}$ & & & $\begin{array}{c}2,8 \\
\text { (næa calculável) }\end{array}$ & & \\
\hline & 3 & $\begin{array}{c}14,1 \\
(11,4 \text { a 16,3) }\end{array}$ & & & $\begin{array}{c}10,8 \\
(8,0 \times 12,9)\end{array}$ & & & $\begin{array}{c}8,0 \\
(5,4 \text { a } 10,2)\end{array}$ & & \\
\hline & 4 & $\begin{array}{c}10,3 \\
\text { (nåo calculível) }\end{array}$ & & & $\begin{array}{c}8,1 \\
\text { (não calculável) }\end{array}$ & & & $\begin{array}{c}6,1 \\
\text { (n̊̃o calculável) }\end{array}$ & & \\
\hline & $s$ & $\begin{array}{c}11,5 \\
(9,7 \text { a } 12,9)\end{array}$ & & & $\begin{array}{c}9,4 \\
(7,5 \cdot 10,9)\end{array}$ & & & $\begin{array}{c}7,6 \\
(5,6: 9,1)\end{array}$ & & \\
\hline
\end{tabular}


Tabela 08 - Resultados dos testes ecotoxicológicos crônicos, de curta duração, com a fase larval de Danio rerio e diversas substâncias, em 168 horas de exposição, calculados pelo método dos Probitos para diferentes niveis de efeito na sobrevivência.

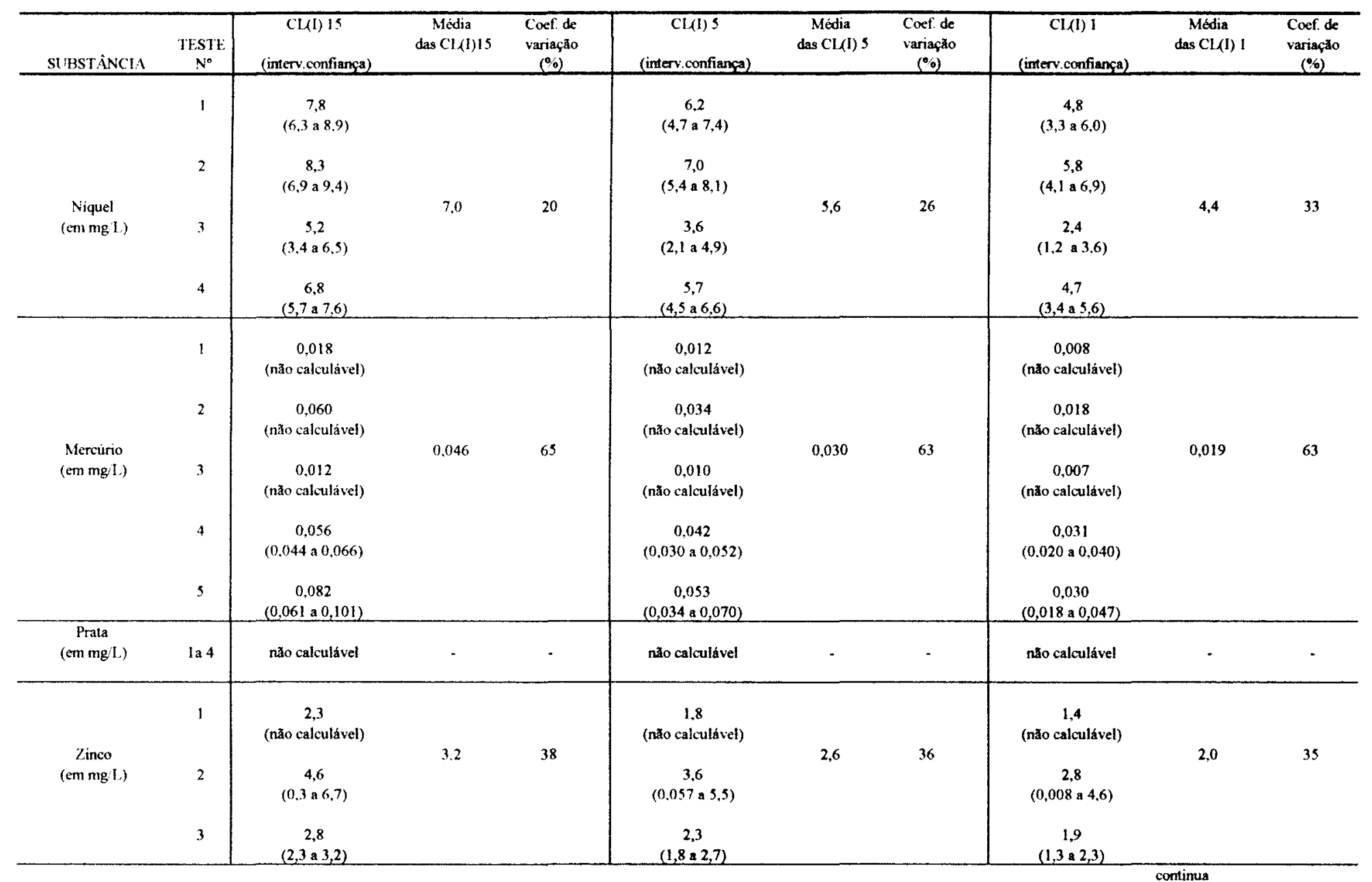


comtinuą̧a

Tabela 08 - Resultados dos testes ecotoxicológicos crônicos, de curta duração, com a fase larval de Danio rerio e diversas substâncias, em 168 horas de exposição, calculados pelo método dos Probitos para diferentes níveis de efeito na sobrevivência.

\begin{tabular}{|c|c|c|c|c|c|c|c|c|c|c|}
\hline SUBSTANCLI & $\begin{array}{c}\text { TESTE } \\
\mathrm{N}^{\circ} \\
\end{array}$ & $\begin{array}{c}\text { CL(1) } 15 \\
\text { (interv.confiança) } \\
\end{array}$ & $\begin{array}{c}\text { Média } \\
\text { das Cl(I) } 15\end{array}$ & $\begin{array}{c}\text { Coef. de } \\
\text { variaçăo } \\
(\%) \\
\end{array}$ & $\begin{array}{c}\text { CL(1) } 5 \\
\text { (imterv,confianca) }\end{array}$ & $\begin{array}{c}\text { Media } \\
\text { das Cu(l) } 5\end{array}$ & $\begin{array}{c}\text { Coef. de } \\
\text { variaçăo } \\
(\%) \\
\end{array}$ & $\begin{array}{c}\text { CL(I) } 1 \\
\text { (interv.confianca) } \\
\end{array}$ & $\begin{array}{c}\text { Média } \\
\text { das CL(1) I }\end{array}$ & $\begin{array}{c}\text { Coef. de } \\
\text { variaça } \\
(\%) \\
\end{array}$ \\
\hline $\begin{array}{c}\text { Fenol } \\
\text { (cm mg I.) }\end{array}$ & 3 & $\begin{array}{c}17.3 \\
(13.9 \times 19.6) \\
15.6 \\
(12.7 \text { a } 17.7) \\
21.3 \\
\text { (naxo calculável) }\end{array}$ & 18.1 & 16 & $\begin{array}{c}14.3 \\
(10.6 \mathrm{a} 16.8) \\
12.8 \\
(9,7 \mathrm{a} 15,0) \\
15,7 \\
\text { (não calculável) }\end{array}$ & 14,2 & 10 & $\begin{array}{c}11,5 \\
(7,7 \mathrm{a} 14,2) \\
10,3 \\
(7,1 \text { a } 12,6) \\
11,2 \\
\text { (nào calculável) } \\
\end{array}$ & 11,0 & 6 \\
\hline $\begin{array}{l}\text { (loreto de sódio } \\
\text { (ern g I.) }\end{array}$ & $\begin{array}{l}3 \\
4 \\
5\end{array}$ & $\begin{array}{c}\text { nao calculável } \\
1,4 \\
(1.0 \text { a } 1.7) \\
2,5 \\
(1.8 \text { a } 3.1) \\
1,5 \\
\text { (não calculável) } \\
2,3 \\
(1,8 \mathrm{a} 2,7)\end{array}$ & 1.9 & 29 & $\begin{array}{c}\text { não calculável } \\
1,1 \\
(0.7 \times 1,4) \\
1,9 \\
(1,2 \text { a } 2.4) \\
1,0 \\
(\text { năo calculável) } \\
1,9 \\
(1,4 \mathrm{a} 2,3)\end{array}$ & 1,5 & 33 & $\begin{array}{c}\text { não cakculável } \\
0,9 \\
(05 \text { a } 1,1) \\
1,3 \\
(0,8 \text { a } 1,8) \\
0.6 \\
\text { (nảo calculável) } \\
1,5 \\
(1,0 \mathrm{a} 1,9)\end{array}$ & 1,1 & 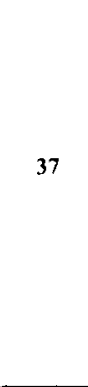 \\
\hline $\begin{array}{l}\text { Amònia não ionizada } \\
\text { (em mg } \mathrm{L} \text { ) }\end{array}$ & $\begin{array}{c}1 \\
2 \mathrm{e} 3 \\
\end{array}$ & $\begin{array}{c}0.63 \\
(0.57 \text { a } 0.68) \\
\text { não calculável }\end{array}$ & - & - & $\begin{array}{c}0.57 \\
(0.50 \mathrm{a} 0.62) \\
\text { nåo calculảvel }\end{array}$ & - & - & $\begin{array}{c}0.51 \\
(0,43 \text { a } 0.57) \\
\text { não calculável } \\
\end{array}$ & - & - \\
\hline $\begin{array}{c}\text { DSS } \\
\text { (em mgI.) }\end{array}$ & $\begin{array}{l}3 \\
4 \\
5\end{array}$ & $\begin{array}{c}\text { nác calculável } \\
15,4 \\
(9,2 \text { a } 18,5) \\
13,4 \\
(10,1 \text { a } 15,9) \\
8.4 \\
\text { (não calculável) } \\
6,6 \\
(4,8 \text { a } 8,1)\end{array}$ & 11.0 & 38 & $\begin{array}{c}\text { nđo calculável } \\
13,3 \\
(6,8 \text { a } 16,7) \\
10.6 \\
(7,2 \text { a } 13,1) \\
6,4 \\
\text { (não calculável) } \\
4,6 \\
(3,0 \text { a } 6,0)\end{array}$ & 8,7 & 46 & $\begin{array}{c}\text { nåo calculável } \\
11,3 \\
(4,9 \text { a } 14,9) \\
8,1 \\
(5,0 \text { a } 10,6) \\
4,7 \\
\text { (ña calculà vel) } \\
3,0 \\
(1,8 \text { a } 4,2)\end{array}$ & 6,8 & 54 \\
\hline
\end{tabular}


Tabela 09 - Resultados dos testes ecotoxicológicos crônicos, de curta duração, com a fase larval de Danio rerio e diversas substâncias, em 168 horas de exposição, calculados pelo método ICp, para a sobrevivência dos organismos em experimentos com tratamentos em duplicata.

\begin{tabular}{|c|c|c|c|c|c|}
\hline Substâncias & Teste $\mathrm{n}^{\circ}$ & $\begin{array}{l}\text { Estimativa } \\
\text { da } C E(I) 15\end{array}$ & Intervalo de confiança & $\begin{array}{c}\text { Média das } \\
C E(I) 15\end{array}$ & $\begin{array}{c}\text { Coeficiente } \\
\text { de variação } \\
(\%)\end{array}$ \\
\hline $\begin{array}{c}\text { Cádmio } \\
(\mathrm{em} \mathrm{mg/L})\end{array}$ & $\begin{array}{l}1 \\
2 \\
3 \\
4\end{array}$ & $\begin{array}{l}0,027 \\
0,062 \\
0,031 \\
0,043 \\
\end{array}$ & $\begin{array}{l}0,022 \text { a } 0,031 \\
0,043 \text { a } 0,112 \\
0,004 \text { a } 0,058 \\
0,036 \text { a } 0,054\end{array}$ & 0,041 & 38 \\
\hline $\begin{array}{c}\text { Cobre } \\
\text { (em mg/L) }\end{array}$ & $\begin{array}{l}1 \\
2 \\
3 \\
4 \\
\end{array}$ & $\begin{array}{l}0,037 \\
0,031 \\
0,016 \\
0,064 \\
\end{array}$ & $\begin{array}{l}0,037 \text { a } 0,037 \\
0,027 \text { a } 0,031 \\
0,012 \text { a } 0,024 \\
0,026 \text { a } 0,073\end{array}$ & 0,037 & 54 \\
\hline $\begin{array}{c}\text { Cromo } \\
(\mathrm{em} \mathrm{mg} / \mathrm{L})\end{array}$ & $\begin{array}{l}1 \\
2 \\
3 \\
4 \\
5\end{array}$ & $\begin{array}{c}3,2 \\
7,7 \\
13,8 \\
12,4 \\
11,3 \\
\end{array}$ & $\begin{array}{c}2,1 \text { a } 12,5 \\
7,2 \text { a } 8,2 \\
12,7 \text { a } 15,2 \\
11,8 \text { a } 12,9 \\
10,6 \text { a } 12,0 \\
\end{array}$ & 9,7 & 44 \\
\hline $\begin{array}{c}\text { Niquel } \\
\text { (em mg/L) }\end{array}$ & $\begin{array}{l}1 \\
2 \\
3 \\
4\end{array}$ & $\begin{array}{c}8,0 \\
7,8 \\
1,8 \\
5,20 \\
\end{array}$ & $\begin{array}{l}7.5 \text { a } 8,7 \\
7,4 \text { a } 8,2 \\
1,2 \text { a } 7,5 \\
4.5 \text { a } 7,4 \\
\end{array}$ & 5,7 & 51 \\
\hline $\begin{array}{l}\text { Mercúrio } \\
\text { (em mg/L) }\end{array}$ & $\begin{array}{l}1 \\
2 \\
3 \\
4 \\
5\end{array}$ & $\begin{array}{l}0,018 \\
0,052 \\
0,013 \\
0,052 \\
0.064 \\
\end{array}$ & $\begin{array}{c}0,016 \text { a } 0.020 \\
\text { não calculável } \\
0.005 \text { a } 0,018 \\
0,048 \text { a } 0,065 \\
0.061 \text { a } 0.065\end{array}$ & 0,04 & 57 \\
\hline
\end{tabular}

continua 
continuação

Tabela 09 - Resultados dos testes ecotoxicológicos crônicos, de curta duração, com a fase larval de Danio rerio e diversas substâncias, em 168 horas de exposição, calculados pelo método ICp, para a sobrevivência dos organismos em experimentos com tratamentos em duplicata.

\begin{tabular}{|c|c|c|c|c|c|}
\hline Substâncias & Teste $\mathrm{n}^{\circ}$ & $\begin{array}{r}\text { Estimativa } \\
\text { da CE(I) } 15\end{array}$ & Intervalo de confiança & $\begin{array}{l}\text { Média das } \\
\text { CE(I) } 15\end{array}$ & $\begin{array}{c}\text { Coeficiente } \\
\text { de variação } \\
(\%)\end{array}$ \\
\hline $\begin{array}{c}\text { Prata } \\
\text { (em mg/L) }\end{array}$ & $\begin{array}{l}1 \\
2 \\
3 \\
4 \\
\end{array}$ & $\begin{array}{l}0,011 \\
0,018 \\
0,037 \\
0,018 \\
\end{array}$ & $\begin{array}{l}0,011 \text { a } 0,011 \\
0,018 \text { a } 0,018 \\
0,037 \text { a } 0,037 \\
0,018 \text { a } 0,018 \\
\end{array}$ & 0,021 & 53 \\
\hline $\begin{array}{c}\text { Zinco } \\
\text { (em } \mathrm{mg} / \mathrm{L} \text { ) }\end{array}$ & $\begin{array}{l}1 \\
2 \\
3 \\
\end{array}$ & $\begin{array}{l}2,5 \\
4,6 \\
2.7 \\
\end{array}$ & $\begin{array}{l}2,4 \text { a } 2,5 \\
3,4 \text { a } 5,5 \\
2,4 \text { a } 2,8 \\
\end{array}$ & 3,3 & 35 \\
\hline $\begin{array}{c}\text { Fenol } \\
(\mathrm{em} \mathrm{mg/L})\end{array}$ & $\begin{array}{l}1 \\
2 \\
3 \\
\end{array}$ & $\begin{array}{l}16,3 \\
14,2 \\
26,6 \\
\end{array}$ & $\begin{array}{l}15,7 \text { a } 17,6 \\
13,3 \text { a } 15,2 \\
26,5 \text { a } 26,8 \\
\end{array}$ & 19,0 & 35 \\
\hline $\begin{array}{l}\text { Cloreto de sódio } \\
\quad(\mathrm{em} \mathrm{g} / \mathrm{L})\end{array}$ & $\begin{array}{l}1 \\
2 \\
3 \\
4 \\
5 \\
\end{array}$ & $\begin{array}{l}1,4 \\
1,3 \\
1,9 \\
2,6 \\
2,5 \\
\end{array}$ & $\begin{array}{l}1,4 \text { a } 1,4 \\
1,3 \text { a } 1,3 \\
1,4 \text { a } 3,2 \\
0,9 \text { a } 2,8 \\
1,7 \text { a } 2,9 \\
\end{array}$ & 1,9 & 32 \\
\hline $\begin{array}{l}\text { Amônia não ionizada } \\
\text { (em } \mathrm{mg} / \mathrm{L})\end{array}$ & $\begin{array}{l}1 \\
2 \\
3 \\
\end{array}$ & $\begin{array}{l}0,60 \\
0,87 \\
0.99 \\
\end{array}$ & $\begin{array}{c}0,60 \text { a } 0,61 \\
0,81 \text { a } 1,0 \\
0,93 \text { a } 1,1 \\
\end{array}$ & 0.82 & 24 \\
\hline $\begin{array}{c}\text { DSS } \\
(\mathrm{em} \mathrm{mg/L})\end{array}$ & $\begin{array}{l}1 \\
2 \\
3 \\
4 \\
5\end{array}$ & $\begin{array}{l}11,1 \\
12,8 \\
13,8 \\
10,9 \\
10,0\end{array}$ & $\begin{array}{c}10,8 \text { a } 11,5 \\
12,0 \text { a } 13,6 \\
13,0 \text { a } 15,3 \\
10,9 \text { a } 10,9 \\
4,2 \text { a } 10,9\end{array}$ & 11,7 & 13 \\
\hline
\end{tabular}


Tabela 10 - Resultados dos testes de toxicidade aguda, expressos como CL(1)50, com várias substâncias e fases distintas do ciclo vital de Pimephales promelas. (Expoentes indicam a fonte bibliográfica e a dureza da água em $\mathrm{mg} \mathrm{CaCO}_{3} / \mathrm{L}$ )

\begin{tabular}{|c|c|c|c|}
\hline \multirow{2}{*}{ SUBSTÂNCIA } & \multicolumn{2}{|c|}{ CL(1)50;96h } & \multirow{2}{*}{$\begin{array}{c}\text { CL(I) } 50 ; 168 \mathrm{~h} \\
\text { Larvas }\end{array}$} \\
\hline & Adultos & Larvas & \\
\hline Cádmio (mg/L) & $1,5^{\mathrm{a}, 44}$ & $0,15^{b, 40-48}$ & $0,041^{c, 101}$ \\
\hline Cobre $(\mathrm{mg} / \mathrm{L})$ & $0,096^{\text {d. } 44}$ & $0,2^{\mathrm{t}, 80-100}$ & $0,070^{\text {e. } 48}$ \\
\hline Cromo (mg/L) & $43,3^{\mathrm{d}, 44}$ & $23,9^{f .88-108}$ & $22,4^{\text {g. } 202}$ \\
\hline Niquel (mg/L) & - & $5,2^{h, 44}$ & - \\
\hline Mercúrio (mg/L) & $0,168^{i, 46}$ & $0,150^{j .46}$ & - \\
\hline Prata $(\mathrm{mg} / \mathrm{L})$ & $0,0067^{k, 44}$ & $0,0082^{L_{4} 44-49}$ & $0,0082^{L 44-49}$ \\
\hline Zinco $(\mathrm{mg} / \mathrm{L})$ & $0,60^{\mathrm{m}, 48}$ & $0,24^{\text {e. } 48}$ & $0,24^{\mathrm{e}, 48}$ \\
\hline Fenol $(\mathrm{mg} / \mathrm{L})$ & $29,0^{\text {n., } 43-48}$ & $28,8^{\circ, 46}$ & - \\
\hline Cloreto de sódio $(\mathrm{g} / \mathrm{L})$ & $7.65^{\text {p. } 210}$ & $6,39^{5.80-106 i}$ & - \\
\hline Amônia não ionizada (mg/L) & $1,5^{9 \cdot 190-230}$ & $1,0^{r .80-100}$ & - \\
\hline $\mathrm{DSS}(\mathrm{mg} / \mathrm{L})$ & - & $8,6^{\text {b. } 40-48}$ & $6,1^{\text {g. } 220}$ \\
\hline
\end{tabular}

Fonte: a) PHIPPS e HOLCOMBE (1985): b) WEBER (1993): c) estimado de BIRGE et al. (1985) d) SPEHAR e FIANDT (1986): e) NORBERG e MOUNT (1985): I GENDUSA el al.(1993) g) estimada de PICKERING (1988); h) LIND et al.. apud USEPA (1986); i) SNARSKI e OLSON (1982); j) CALL et al.(1983); k) HOLCOMBE et al.(1983): L) NORBERG-KING (1989): m) BENOIT e HOLCOMBE (1978): n) PHIPPS et al (1981): o) HOLCOMBE et al. (1982); p) ADELMAN e SMITH (1976); q) MAYES et al. (1986): r) MARKLE et al. (2000): s) MOUNT et al. (1997) 
Tabela 11 - Resultados de testes ecotoxicológicos crônicos, de curta e longa duração, com várias substâncias e Pimephales promelas em águas com dureza semelhante $\mathrm{O}$, calculados pela análise de variância (expoentes indicam a fonte bibiliográfica e o critério para avaliaçăo do efeito tóxico)

\begin{tabular}{|c|c|c|c|c|c|c|}
\hline \multirow{2}{*}{ SUBSTÃNCIA } & \multicolumn{3}{|c|}{ Larvas (168 horas) } & \multicolumn{3}{|c|}{ Ciclo de vida ( 228 dias) } \\
\hline & CEO & CENO & VC & $\mathrm{CEO}$ & CENO & VC \\
\hline Cádmio (mg/L) & 0.022 & 0,011 & $0,016^{1, \text { crescimento }}$ & 0,018 & 0,009 & $0,013^{1, \text { wobrevivencis }}$ \\
\hline Cobre $(\mathrm{mg} / \mathrm{L})$ & 0,026 & 0,010 & $0,016^{2 . \text { creacimento }}$ & 0,018 & 0,011 & $0,014^{12, \text { sobrevivencis }}$ \\
\hline Cromo (mg/l) & 5,56 & 2,94 & $4,04^{1, \text { crescimento }}$ & 3,95 & 1,00 & $1,99^{3, \text { sobrevivencin }}$ \\
\hline Niquel $(\mathrm{mg} / \mathrm{l}$.) & - & - & - & 0,43 & 0,11 & $0,22^{4, \text { indeterminado }}$ \\
\hline Mercúrio $(\mu \mathrm{g} / \mathrm{L})$ & - & - & - & 1,0 & 0,5 & $0,71^{5, \text { resecimento }}$ \\
\hline Prata $(\mu g /)$. & 1,4 & 0,7 & $1,0^{1, \text { crescimento }}$ & 0,65 & 0,37 & $0,49^{6 . \text { «obrevivencia }}$ \\
\hline 7 inco $(\mathrm{mg} / \mathrm{l})$ & 0,184 & 0,085 & $0,125^{2, \text { sobrevivència }}$ & 0,295 & 0,145 & $0,207^{7 \text { sobrevivencia }}$ \\
\hline Fenol (mg/l) & - & - & - & 3,57 & 1,83 & $2,56^{8, \text { crescimento }}$ \\
\hline Cloreto de sódio $(\mathrm{g} / \mathrm{L})$ & 1,0 & 0,5 & $0,71^{9, \text { erescimento }}$ & - & - & - \\
\hline Amônia não ionizada (mg/L) & - & - & - & 0,26 & 0,17 & $0,21^{10, \text { sotrerivencis }}$ \\
\hline $\operatorname{DSS}(\mathrm{mg} / \mathrm{L})$ & 8,5 & 4,2 & $6,0^{11, \text { solxevivància }}$ & - & - & - \\
\hline
\end{tabular}

- Dureza entre 40 a $48 \mathrm{mg} \mathrm{CaCO} / \mathrm{L}$, exceto nos testes de ciclo vital com cobre ( $=30 \mathrm{mg} \mathrm{L})$, cromo ( $=209 \mathrm{mg} / \mathrm{L}$ ), amônia não ionizada (- 190-230 mg l ) e DSS (- $202 \mathrm{mg} / \mathrm{L})$

Fonte: 1) NORBERG-KING (1989); 2) NORBERG e MOINT (1985); 3) PICKERING (1980); 4) LIND et al,,apud USEPA (1986); 5) SNARSKI e OLSON (1982): 6) HOLCOMBE et al. (1983); 7) BENOIT e HOLCOMBE (1978); 8) HOLCOMBE et al.(1982): 9) NORBERG-KING et al. (1991); 10) MAYES et al. (1986); 11) estimado de PICKFRING (1988); 12) MOUNT e STEPHAN (1969) 
Tabela 12 - Relação numérica entre diferentes critérios para avaliação de efeito tóxico em testes ecotoxicológicos com peixes.

\begin{tabular}{|c|c|c|c|c|c|c|}
\hline \multirow[b]{2}{*}{$\begin{array}{l}\text { Especie (1) } \\
\text { utilizada }\end{array}$} & \multirow[b]{2}{*}{ Agente quimico } & \multicolumn{3}{|c|}{ Concentracãa de efeito năo observado (CENO) } & \multirow[b]{2}{*}{ fator(D) } & \multirow[b]{2}{*}{ Fonte } \\
\hline & & $\begin{array}{l}\text { tempo de } \\
\text { exposiçào }\end{array}$ & sobrevivência & crescimento & & \\
\hline P.p. & efluente ind. fertilizantes & 7 dias & $30 \%$ & $3 \%$ & 10 & NORBERG e MOUNT (1985) \\
\hline P.p. & efluente de refinaria & 7 dias & $10 \%$ & $3 \%$ & 3,3 & NORBERG e MOUNT (1985) \\
\hline P.p. & efluente de coqueria $n^{\circ} 1$ & 7 dias & $1 \%$ & $0,50 \%$ & 2 & NORBERG e MOUNT (1985) \\
\hline P.p. & efluente de coqueria n'2 & 7 dias & $50 \%$ & $10 \%$ & 5 & NORBERG e MOUNT (1985) \\
\hline P.p. & NaPCP-teste IB & 7 dias & $256 \mu \mathrm{g} / \mathrm{L}$ & $128 \mu \mathrm{g} / \mathrm{L}$ & 2 & PICKERING (1988) \\
\hline P.p. & Linear alquil. sódio (L.AS) & 7 dias & $2,4 \mathrm{mg} / \mathrm{L}$ & $1,2 \mathrm{mg} / \mathrm{L}$ & 2 & PICKERNG (1988) \\
\hline P.p. & Efluente B & 7 dias & $22 \%$ & $<13 \%$ & $>1,70$ & PICKERING (1988) \\
\hline P.p. & Efluente C & 7 dias & $1 \%$ & $0.5 \%$ & $>2$ & PICKERING (1988) \\
\hline P.p. & Cromo & 7 dias & $12 \mathrm{mg} / \mathrm{L}$ & $3 \mathrm{mgL}$ & 4 & PICKERING (1988) \\
\hline P.p. & mercúrio & 41 semanas & $>3,7 \mu \mathrm{g} / \mathrm{L}$ & $<0,3 \mu \mathrm{g} /$. & $>12$ & SNARSKI e OLSON (1982) \\
\hline P.p. & mercúrio & 35 dias & $1,8 \mu \mathrm{g} / \mathrm{L}$ & $0,2 \mu \mathrm{g} /$ & $>9$ & CALL et. al. (1983) \\
\hline P.p. & arsênio & 30 dias & $7,4 \mathrm{mg} / \mathrm{L}$ & $2,1 \mathrm{mg} / \mathrm{L}$ & 3,5 & CALL et. al. (1983) \\
\hline P.p. & complexo Ag-tiossulfato & 30 dias & $64 \mathrm{mg} / \mathrm{L}$ & $35 \mathrm{mg} / \mathrm{L}$ & 1,8 & LEBLANC et. al. (1984) \\
\hline P.p. & fenol & 30 dias & $6,1 \mathrm{mg} / \mathrm{L}$ & $0,75 \mathrm{mg} / \mathrm{L}$ & 8,1 & DEGRAEVE et. al. (1980) \\
\hline P.p. & 2.4 dimetilfenol & 28 dias & $3,11 \mu \mathrm{g} / \mathrm{L}$ & $1.97 \mu \mathrm{g} / \mathrm{L}$ & 1.6 & HOLCOMBE et. al. (1982) \\
\hline P.p. & pentaclorofenol & 28 dias & $73,0 \mu \mathrm{g} / \mathrm{L}$ & $44,9 \mu \mathrm{g} /$ & 1,6 & HOLCOMBE et. al. (1982) \\
\hline P.p. & pentaclorofenol & 32 dias & $58,2 \mu \mathrm{g} / \mathrm{L}$ & $27.6 \mu \mathrm{g} / \mathrm{L}$ & 2,1 & SPEHAR et al. (1985) \\
\hline P.p. & 1.2- dicloropropano & 28 dias & $11,0 \mathrm{mg} / \mathrm{L}$ & $6.0 \mathrm{mg} / \mathrm{L}$ & 1,8 & BENOIT et al. (1982) \\
\hline P.p. & 1,3-dicloropropano & 28 dias & $32,0 \mathrm{mg} / \mathrm{L}$ & $8.0 \mathrm{mg} / \mathrm{L}$ & 4 & BENOIT et al. (1982) \\
\hline P.p. & 1.2 - dicloroetano & 28 dias & $59.0 \mathrm{mg} / \mathrm{L}$ & $29.0 \mathrm{mg} / \mathrm{L}$ & 2 & BENOIT et al. (1982) \\
\hline P.p. & 3.4 dicloroanilina-teste 1 & 28 dias & $26 \mu g / L$ & $15,1 \mu \mathrm{g} / \mathrm{L}$ & 1,7 & CALL et al. (1987) \\
\hline P.p. & 3.4 dicloroanilina-teste 2 & 28 dias & $14,8 \mu \mathrm{g} / \mathrm{L}$ & $5,1 \mu \mathrm{g} L$ & 2,9 & CALL et. al. (1987) \\
\hline P.p. & metil-parathion & 32 dias & $0,59 \mathrm{mg} \mathrm{L}$ & $0,31 \mathrm{mg} \mathrm{L}$ & 1.9 & JARVINEN e TANNER (1982) \\
\hline P.p. & dursban & 32 dias & $32 \mu \mathrm{g} / \mathrm{L}$ & $1.6 \mu \mathrm{g} / \mathrm{L}$ & 2.0 & JAR VINEN e TANNER (1982) \\
\hline P.p. & diazinon & 32 dias & $140,0 \mu \mathrm{g} / \mathrm{L}$ & $50,0 \mu \mathrm{g} / \mathrm{L}$ & 2,8 & JARVINEN e TANNER (1982) \\
\hline D.r. & lindano & 35 dias & $110 \mu \mathrm{g} / \mathrm{L}$ & $40 \mu \mathrm{g} / \mathrm{L}$ & 2.8 & GÖRGE e NAGEL (1990) \\
\hline D.r. & 4-clorotolueno & 28 dias & $3.4 \mathrm{mg} / \mathrm{L}$ & $1.9 \mathrm{mg} / \mathrm{L}$ & 1.8 & vanLEEUWEN et. al. (1990) \\
\hline D.r. & monoclorobenzeno & 28 dias & $8.5 \mathrm{mg} / \mathrm{L}$ & $4.8 \mathrm{mg} / \mathrm{l}$ & 1.8 & vanLEEUWEN et al. (1990) \\
\hline D.r. & 1.4-diclorobenzeno & 28 dias & $2.1 \mathrm{mg} /$ & $0.65 \mathrm{mg} /$ & 3.2 & vanLEEUWEN et. al. (1990) \\
\hline D.r. & 1.2.3-triclorobenzeno & 28 dias & $0.45 \mathrm{mgl}$ & $0.25 \mathrm{mg} /$ & 1.8 & vanl EEUWEN et. al. (1990) \\
\hline D.r. & 12,3,4-1etraclorobenzeno & 28 dias & $0.31 \mathrm{mg} /$ & $0.1 \mathrm{mg} / \mathrm{L}$ & 3,1 & vanLEEUWEN et. al. (1990) \\
\hline D.t. & pentaclorobenzeno & 28 dias & $0.11 \mathrm{mg} / \mathrm{L}$ & $0.034 \mathrm{mg} /$ & 3,2 & vanLFEUWEN et. al. (1990) \\
\hline D.r. & anilina & 28 dias & $5.6 \mathrm{mg} / \mathrm{L}$ & $1,8 \mathrm{mg} / \mathrm{L}$ & 3,1 & vanLFEUWEN et. al. (1990) \\
\hline D.r. & 3-cloroanilina & 28 dias & $5.6 \mathrm{mg} /$ & $1.0 \mathrm{mg} / \mathrm{L}$ & 5,6 & vanLEEUWEN et. al. (1990) \\
\hline D.r. & 3.5-diclorosnilina & 28 dias & $1,0 \mathrm{mgl}$ & $0.32 \mathrm{mg} / \mathrm{L}$ & 3,1 & vanLEEUWEN et. al. (1990) \\
\hline \multirow[t]{2}{*}{ D.r. } & 2.3.4.5-tetracloroanilina & 28 dias & $0.056 \mathrm{mg} / \mathrm{L}$ & $0.032 \mathrm{mg} / \mathrm{L}$ & 1.8 & vanLEEUWEN et al (1990) \\
\hline & & RECIPROO & $\begin{array}{l}\text { VALOR ME } \\
\text { O VALOR ME }\end{array}$ & $\begin{array}{l}\text { OOS FATORES }= \\
\text { DOS FATORES }=\end{array}$ & $\begin{array}{l}3,0 \\
0,3\end{array}$ & \\
\hline
\end{tabular}

(1) P.p $=$ Pimephales promelas, D.t. = Danio rerio

(2) quociente entre os valores de CENO para a sobrevivencia e crescimento

(3) valores com * não considerados para o cálculo da média dos fatores 
Tabela 13 - Estimativas de efeitos crônicos, em testes de curta duração com a fase larval de Danio rerio, calculadas pelo método ICp e associadas ao fator para previsão de efeitos a longo prazo

\begin{tabular}{lcc}
\hline \multicolumn{1}{c}{ Agente químico } & Média das CL(I) $15 ; 168 \mathrm{~h}$ 々s & $\begin{array}{c}\text { Valor crônico estimado } \\
\text { (média das CL(1)15;168h com } \\
\text { fator 0,3) }\end{array}$ \\
\hline Cádmio (em mg/L) & 0,054 & 0,016 \\
Cobre (em mg/L) & 0,030 & 0,009 \\
Cromo (em mg/L) & 9,7 & 2,9 \\
Niquel (em mg/L) & 5,9 & 1,8 \\
Mercúrio ( em mg/L) & 0,040 & 0,012 \\
Prata (em mg/L) & 0,021 & 0,006 \\
Zinco (em mg/L) & 3,6 & 1,1 \\
Fenol (em mg/L) & 17,9 & 5,4 \\
Cloreto de sódio (em mg/L) & $2,000,00$ & 600,0 \\
Amônia não ionizada (mg/L) & 0,84 & 0,25 \\
\hline
\end{tabular}

3 dados provenientes da Tabela 07 
Tabela 14 - Resultados de validação da equação estabelecida para correlacionar dados ecotoxicológicos crônicos entre larvas de Danio renio e de Pimephales promelas.

\begin{tabular}{lccc}
\hline \multirow{2}{*}{ Agente quimico } & \multicolumn{2}{c}{$\begin{array}{c}\text { CENO }>28 \text { dias determinada } \\
\text { experimentalmente }\end{array}$} & $\begin{array}{c}\text { CENO }>28 \text { dias estimada } \\
\text { para o Danio rerio } 0\end{array}$ \\
\cline { 2 - 3 } 3,4 - dicloroanilina & $5,1 \mu \mathrm{g} / \mathrm{L}^{\mathrm{g}}$ & $20,0 \mu \mathrm{g} / \mathrm{L}^{\mathrm{b}}$ & $7,8 \mu \mathrm{g} / \mathrm{L}$ \\
lindano & $>23,4 \mu \mathrm{g} / \mathrm{L}^{\mathrm{c}}$ & $40,0 \mu \mathrm{g} / \mathrm{L}^{\mathrm{d}}$ & $>28,2 \mu \mathrm{g} / \mathrm{L}$ \\
atrazina & $>213,0 \mu \mathrm{g} / \mathrm{L}^{\mathrm{e}}$ & $300,0 \mu \mathrm{g} / \mathrm{L}^{\mathrm{d}}$ & $>180,2 \mu \mathrm{g} / \mathrm{L}$ \\
diazinon & $0,05 \mathrm{mg} / \mathrm{L}^{\mathrm{f}}$ & $>0,20 \mathrm{mg} / \mathrm{L}^{\mathrm{g}}$ & $0,24 \mathrm{mg} / \mathrm{L}$ \\
\hline
\end{tabular}

- estimativa pela equação log VC.est. D.r. $=0,30+0,84 \log$ VC; P.p

Fonte: a) CAl.L et al. (1987); b) NAGEL et al. (1991), c) MACEK et al (1976a. apud GORGE e NAGEL (1990)), d) GORGE e NAGEL (1990); e) MACEK et al. (1976b, apud GORGE e NAGEL (1990)); f) JARVINEN e TANNER (1982), g) BRESCH (1991). 
ANEXO 


\section{Anexo 01 - Fases de desenvolvimento, do ciclo vital de Danio rerio,} utilizadas nos testes ecotoxicológicos.

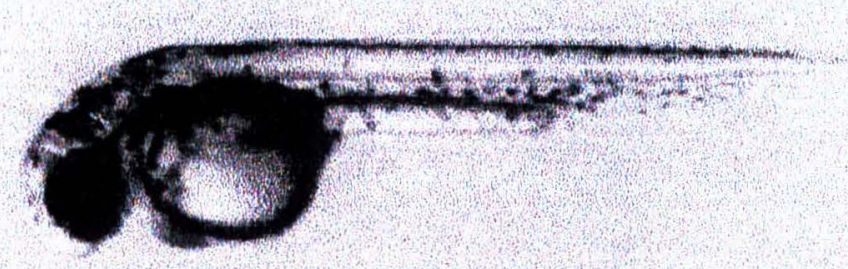

Vista lateral do embrião (sem o córion) com 36 horas de idade.
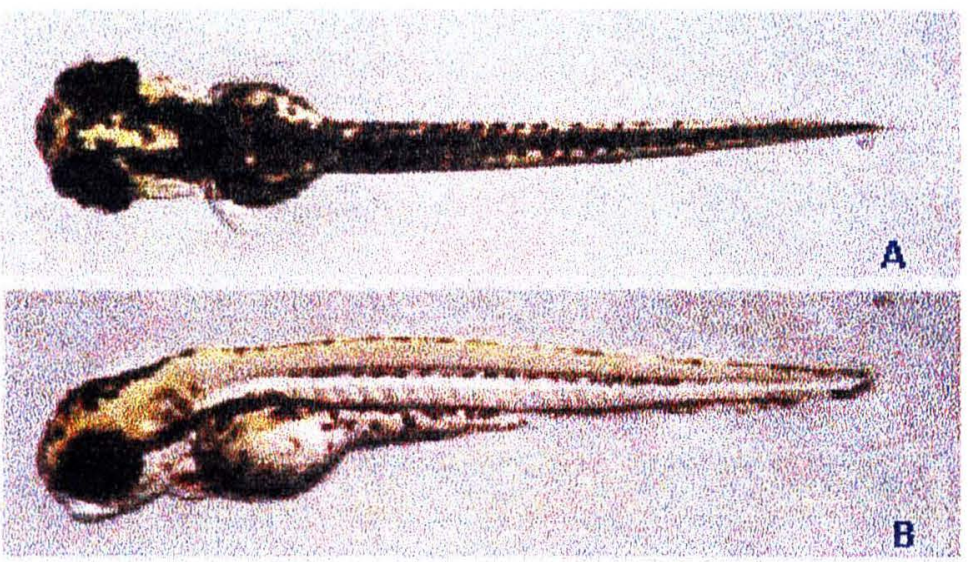

Vista dorsal (A) e lateral (B), na fase embriolarval, com 72 horas de idade.

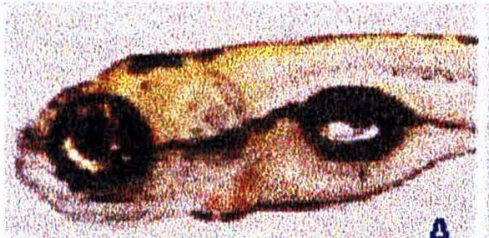

A

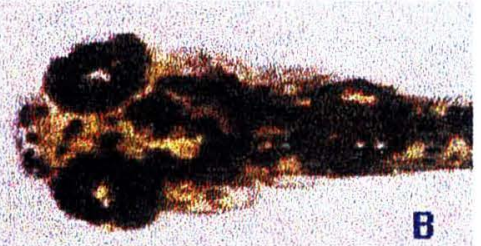

Parte da vista lateral (A) e dorsal (B) da larva, com 120 horas de idade

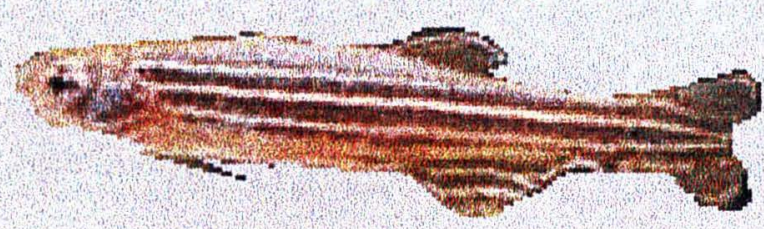

Vista lateral do jovem 